\title{
A Landscape Plan Based on Historical Fire Regimes for a Managed Forest Ecosystem: the Augusta Creek Study
}

David O. Wallin

Western Washington University, david.wallin@wwu.edu

John Cissel

Frederick J. (Frederick John) Swanson

Gordon E. (Gordon Elliot) Grant

Deanna H. Olson

See next page for additional authors

Follow this and additional works at: https://cedar.wwu.edu/esci_facpubs

Part of the Natural Resources Management and Policy Commons

\section{Recommended Citation}

Wallin, David O.; Cissel, John; Swanson, Frederick J. (Frederick John); Grant, Gordon E. (Gordon Elliot); Olson, Deanna H.; Gregory, Stanley V.; Garman, Steven L. (Steven Lee); Ashkenas, Linda R.; Hunter, Matthew G.; Kertis, Jane A.; Mayo, James H.; McSwain, Michelle D.; Swetland, Sam G.; and Swindle, Keith A., "A Landscape Plan Based on Historical Fire Regimes for a Managed Forest Ecosystem: the Augusta Creek Study" (1998). Environmental Sciences Faculty and Staff Publications. 22.

https://cedar.wwu.edu/esci_facpubs/22

This Book is brought to you for free and open access by the Environmental Sciences at Western CEDAR. It has been accepted for inclusion in Environmental Sciences Faculty and Staff Publications by an authorized administrator of Western CEDAR. For more information, please contact westerncedar@wwu.edu. 


\section{Authors}

David O. Wallin, John Cissel, Frederick J. (Frederick John) Swanson, Gordon E. (Gordon Elliot) Grant, Deanna H. Olson, Stanley V. Gregory, Steven L. (Steven Lee) Garman, Linda R. Ashkenas, Matthew G. Hunter, Jane A. Kertis, James H. Mayo, Michelle D. McSwain, Sam G. Swetland, and Keith A. Swindle 
United States

Department of

Agriculture

Forest Service

Pacific Northwest

Research Station

General Technical Report

PNW-GTR-422

May 1998

Uifs:

\section{A Landscape Plan Based on Historical Fire Regimes for a Managed Forest Ecosystem: the Augusta Creek Study}

John H. Cissel, Frederick J. Swanson, Gordon E. Grant, Deanna H. Olson, Stanley V. Gregory, Steven L. Garman, Linda R. Ashkenas, Matthew G. Hunter, Jane A. Kertis, James H. Mayo, Michelle D. McSwain, Sam G. Swetland, Keith A. Swindle, and David O. Wallin

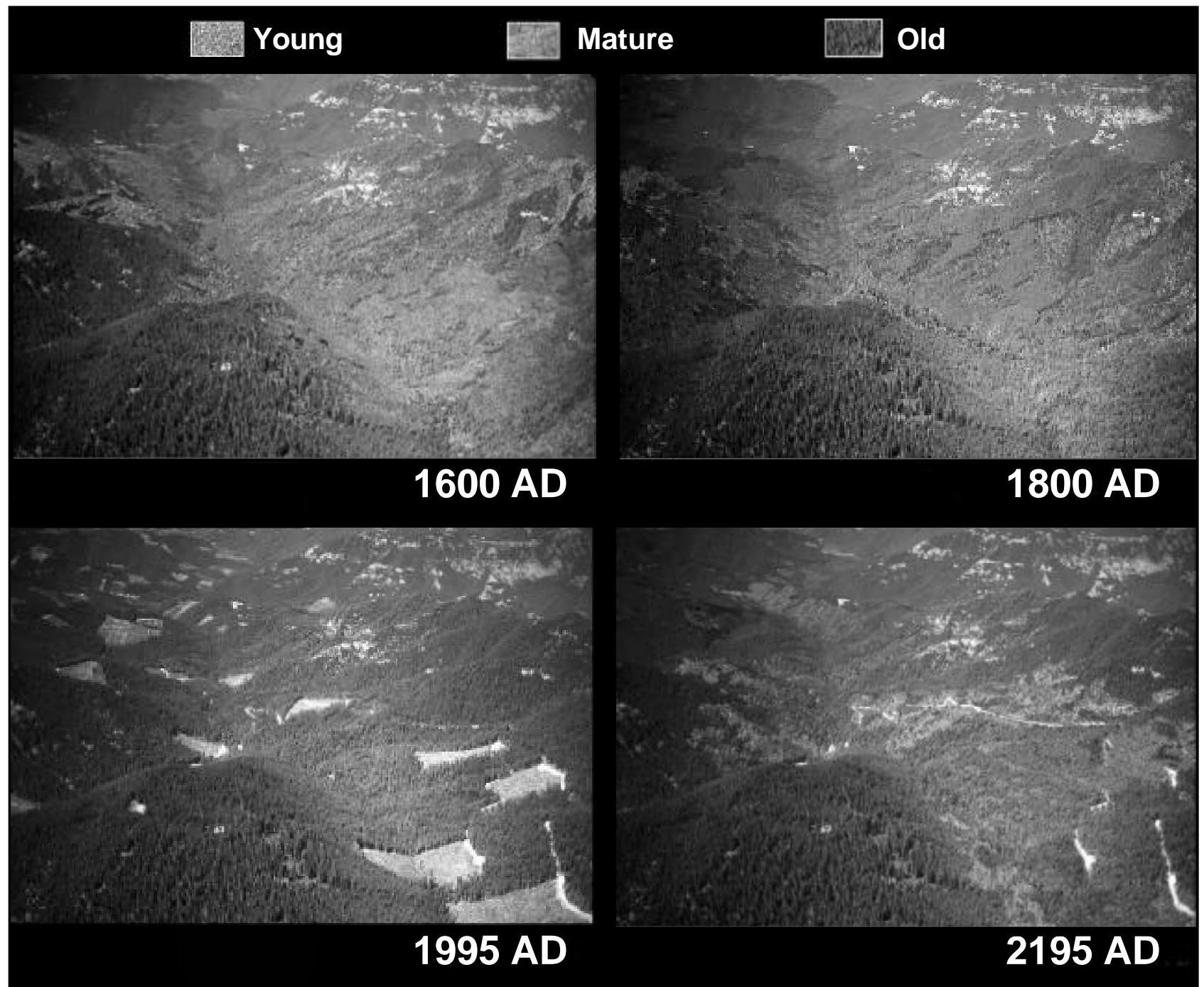




\section{Authors}

JOHN H. CISSEL is the Cascade Center research coordinator, JAMES H. MAYO is a silviculturist, MICHELLE D. McSWAIN is a hydrologist, and SAM G. SWETLAND is a fire and fuels specialist, Blue River Ranger District, P.O. Box 199, Blue River, OR 97413; FREDERICK J. SWANSON is an ecosystem team leader, GORDON E. GRANT is a research hydrologist, and DEANNA $\mathrm{H}$. OLSON is a research biologist, Forestry Sciences Laboratory, 3200 SW Jefferson Way, Corvallis, OR 97331;

STANLEY V. GREGORY is a professor, LINDA R. ASHKENAS is a research associate, and KEITH A. SWINDLE is a faculty research assistant, Oregon State University, Department of Fisheries and Wildlife, Nash Hall, Corvallis, OR 97331; STEVEN L. GARMAN is an assistant professor and MATTHEW G. HUNTER is a wildlife ecologist, Oregon State University, College of Forestry, Forest Science Department, Corvallis, OR 97331; JANE A. KERTIS is an ecologist, Siuslaw National Forest, Corvallis, OR 97339; and DAVID O. WALLIN is an assistant professor, Huxley College of Environmental Studies, Western Washington University, Bellingham, WA 98225. 


\section{Abstract}

Summary Introduction
Cissel, John H.; Swanson, Frederick J.; Grant, Gordon E.; Olson, Deanna H.; Stanley, Gregory V.; Garman, Steven L.; Ashkenas, Linda R.; Hunter, Matthew G.; Kertis, Jane A.; Mayo, James H.; McSwain, Michelle D.; Swetland, Sam G.; Swindle, Keith A.; Wallin, David O. 1998. A landscape plan based on historical fire regimes for a managed forest ecosystem: the Augusta Creek study. Gen. Tech. Rep. PNW-GTR-422. Portland, OR: U.S. Department of Agriculture, Forest Service, Pacific Northwest Research Station. $82 \mathrm{p}$.

The Augusta Creek project was initiated to establish and integrate landscape and watershed objectives into a landscape plan to guide management activities within a 7600 -hectare $(19,000$-acre) planning area in western Oregon. Primary objectives included the maintenance of native species, ecosystem processes and structures, and long-term ecosystem productivity in a federally managed landscape where substantial acreage was allocated to timber harvest. Landscape and watershed management objectives and prescriptions were based on an interpreted range of natural variability of landscape conditions and disturbance processes. A dendrochronological study characterized fire patterns and regimes over the last 500 years. Changes in landscape conditions throughout the larger surrounding watershed due to human uses (e.g., roads in riparian areas, widespread clearcutting, a major dam, and portions of a designated wilderness and an unroaded area) also were factored into the landscape plan. Landscape prescriptions include an aquatic reserve system comprised of small watersheds distributed throughout the planning area and major valley-bottom corridor reserves that connect the small-watershed reserves. Where timber harvest was allocated, prescriptions derived from interpretations of fire regimes differ in rotation ages (100 to 300 years), green-tree retention levels (15- to 50percent canopy cover), and spatial patterns of residual trees. General prescriptions for fire management also were based on interpretations of past fire regimes. All these prescriptions were linked to specific blocks of land to provide an efficient transition to site-level planning and project implementation. Landscape and watershed conditions were projected 200 years into the future and compared with conditions that would result from application of standards, guidelines, and assumptions in the Northwest Forest Plan prior to adjustments resulting from watershed analyses. The contrasting prescriptions for aquatic reserves and timber harvest (rotation lengths, green-tree retention levels, and spatial patterns) in these two approaches resulted in strikingly different potential future landscapes. These differences have significant implications for some ecosystem processes and habitats. We view this management approach as a potential postwatershed analysis implementation of the Northwest Forest Plan and offer it as an example of how ecosystem management could be applied in a particular landscape by using the results of watershed analysis.

Keywords: Landscape ecology, landscape management, landscape planning, fire history, range of historical variability, watershed analysis, fire ecology.

There is a growing awareness that to sustain human uses of an ecosystem, the ecosystem itself must be sustained. For the public forest lands considered here, we interpreted the goal of sustaining ecosystems to mean maintaining native species, ecosystem processes and structures, and long-term ecosystem productivity. In the Augusta Creek project, we developed a landscape plan to achieve these goals based on historical disturbance regimes and landscape conditions. A premise of this approach is that native species have adapted to the range of habitat patterns resulting from historical disturbance events, and the probability of survival of these species is 


\section{Phase 1-Analysis of Conditions, Processes, and Uses}

\author{
Phase 2-Landscape \\ Plan
}

reduced if their environment is maintained outside the range of historical conditions. Similarly, ecological processes, such as nutrient and hydrologic cycles, have historically functioned within a range of conditions established by disturbance and successional patterns. Management activities that move structures and processes outside the range of past conditions may adversely affect ecosystems in both predictable and unforeseen ways. Another key component of our management approach recognized that existing conditions must be integrated with this historical template to meet longterm objectives. Human uses have substantially altered conditions in the project area and in the surrounding watersheds.

A fire history study of the last 500 years revealed the fire patterns within the planning area. Plot-level data were used to map 27 of these fire events. The fire-event maps and field observations were used to describe and map characteristic fire frequencies, severities, and spatial patterns of nine general fire regimes. The fire-event maps also were used to reconstruct and analyze vegetation patterns within the same 500-year period.

Several approaches were used to analyze the aquatic ecosystem and hillslope-tostream disturbances. Landslide and debris-flow occurrences and relative potential for future occurrences were interpreted from aerial photographs, maps of existing conditions, and field surveys. Relative susceptibilities of the watershed to rain-on-snow peak flows and contributions to summer baseflows were assessed. A time-series of aerial photographs spanning the past 40 years were used to assess riparian vegetation dynamics and disturbance history.

Both prehistoric and contemporary human uses were described and mapped. Prehistoric and historical data for the general area were employed to construct a probability-of-past-use map and narrative. Current human uses include hiking (two trails), camping (three campgrounds), angling, hunting, and harvest of timber and special forest products.

In the first step, "special area reserves" allocated in the Willamette National Forest Plan, as amended by the Northwest Forest Plan, were delineated. Prescriptions for these areas generally entail a "natural" succession approach. Prescribed natural fires were encouraged where feasible.

The remainder of the planning area was then subdivided into zones with similar ecological conditions and disturbance regimes, termed "landscape areas." General prescriptions were developed for each area based on the fire regime and the condition of the vegetation. Rotation ages (100 to 300 years) were derived from fire frequency information, green-tree retention levels (15 to 50 percent) were based on fire severity interpretations, and guidelines for patch size came from historic fire and patch size analyses. Prescriptions for low-intensity fires were derived from fire regime descriptions and integrated with timber harvest patterns and schedules.

In the third step, "aquatic reserves" were established to ensure that the full range of objectives in the Northwest Forest Plan would be met, with particular attention given to the Aquatic Conservation Strategy (USDA and USDI 1994). These reserves were based, in part, on the type and intensity of upslope management in the local landscape area and were designed to reflect general patterns of disturbance processes.

Small-watershed reserves were positioned throughout the basin, such that different habitat types and topographic-disturbance regions were represented in headwater, 
Phase 3-Projection of Future Conditions

\section{Phase 4-Evaluation of Effects}

\section{Link to Project-Level Planning}

midbasin, and lower portions of the drainage, and such that species of concern (e.g., torrent salamanders [Rhyacotriton spp.]) were protected. Areas of high streamdrainage density and headwall areas were favored for reserve placement. Steep, unstable areas with simple drainage patterns and long debris flow runouts also were placed in reserves, as were two unstable hillslope areas.

Aquatic reserves also included large riparian corridors along both sides of all major streams. These areas, in which older forests survived past fire events, parallel the stream and include the stream, adjacent flood plains, and riparian vegetation. These corridors link the small-watershed reserves.

Maps of future landscape and watershed conditions were developed by simulating the growth of existing forest stands with a simple stand-age model in a Geographical Information System (GIS). Following timber cutting, blocks were reset to specific stand conditions, according to a timber harvest schedule determined by the landscape prescriptions for the area, and growth was simulated again until the next scheduled cutting. A set of maps depicting future landscape conditions show a gradual change in the landscape from the relatively fragmented existing forest to one dominated by larger blocks and containing a wider array of stand types. By year 100 , the future landscape appeared significantly different from the existing landscape and continued to gradually change before stabilizing in year 200 .

We evaluated this landscape management approach (which we termed "Landscape Plan") by comparing it to a future landscape generated by applying standards, guidelines, and assumptions from the Northwest Forest Plan before adjustments were made to it as a result of watershed analysis (termed "Interim Plan"). The Interim Plan was characterized by the extensive Riparian Reserves buffering all streams and an 80-year timber harvest rotation on most upland areas where timber harvest was allocated. Harvest areas maintained a relatively light level of green-tree retention (15 percent).

The Interim Plan leads to a high-contrast forest pattern within areas managed for timber. Old forests develop along all lower slope positions, and upper slope positions contain relatively young, structurally simple stands. Maximum protection of aquatic systems from timber harvest was provided by Riparian Reserves on all streams. Edge-using terrestrial species also were found to benefit from this design.

The Landscape Plan results in a greater range of stand structures and larger patches. In addition, higher levels of habitat features, such as green trees, snags, and downed logs, would be found in patches where timber harvest occurs. This results from the larger timber harvest blocks, longer rotations, and higher levels of green-tree retention in areas where timber harvest is allocated. These features were felt to benefit many amphibians, birds, and mammals.

Little difference between approaches was evident for many processes and species. Disturbance processes (e.g., landslides and flood events), stream flows, aquatic processes, species that use a wide range of habitats, and long-term timber yields were very similar in the two approaches.

The development of a spatially and temporally explicit landscape plan lays the groundwork for a focused and efficient project-level planning process. The type and timing of future management activities can be established by comparing existing 


\section{Relation to Northwest Forest Plan}

stand conditions with projected future landscape patterns. For example, near-term timber sale planning can begin with the blocks scheduled to be in early seral conditions at the end of the first 20-year time step. Detailed prescriptions can be developed for these blocks with confidence that management activities contribute to long-term landscape objectives. An appropriate schedule of prescribed fire, natural or introduced, also can be linked to the overall landscape block schedule and to reserve objectives.

We view this management approach as a potential postwatershed analysis implementation of the Northwest Forest Plan. Although the exact mechanisms for adjusting the Northwest Forest Plan remain unclear, changes in the plan were anticipated to follow from watershed analysis. We hope this analysis can help identify useful ways to improve implementation of the Northwest Forest Plan and better link results of watershed analysis with planning. 


\section{Contents}

1 Introduction

1 Goals

3 General Ecosystem Management Objectives and Assumptions

5 Area Description

6 General Analytical Process

7 Larger Scale Context

8 Phase 1-Analysis of Past and Present Conditions and Processes

8 Fire History

9 Landscape Structure

16 Hydrology

17 Mass Movement

20 Riparian Habitat and Fauna

26 Human Uses

27 Phase 2-Landscape Plan

29 Special Area Reserves

29 Landscape Areas

36 Aquatic Reserves

38 Phase 3-Projection of Future Conditions

38 Landscape Blocks

39 Future Landscape Conditions

42 Phase 4-Evaluation

42 Interim Plan

45 Comparison of Scenarios

46 Landscape Structure

52 Hydrology

54 Debris Slides and Flows

55 Amphibians

57 Fish and Selected Aquatic Taxa

59 Birds and Mammals

61 Northern Spotted Owls 
63 Timber Production and Operational Feasibility

64 Wildfire

65 Windthrow

66 Insects and Diseases

67 Links to Project-Scale Planning

69 Discussion

69 Key Elements of This Approach

71 Limitations of Analysis

71 Application to Other Landscapes

72 Policy Implications

74 Adaptive Management

74 Human Values

75 Future Work

75 Conclusion

76 Acknowledgments

76 Literature Cited 


\section{Introduction Goals}

A tiered approach to ecosystem management is gradually emerging in the Pacific Northwest to address biological and social issues at appropriate scales (Grumbine 1994). Each scale has distinctive biological and social issues, relevant ecological principles and concepts, and essential components of management strategies (table 1). Analyses and decisions at one scale influence those at other scales. Analyses and plans at local levels receive objectives and constraints from regional and subregional management plans. In turn, analyses and decisions from local levels provide site- or landscape-specific information for subsequent iterations of regional and subregional analyses and decisions. Such a feedback loop is essential for adaptive management across ecosystems being managed at scales of an individual hectare to habitat for a regionwide range of critical species.

The Northwest Forest Plan (USDA and USDI 1994) is based on a regional-scale analysis for forest and riverine ecosystems (Forest Ecosystem Management Assessment Team [FEMAT] 1993). The plan contains three major components:

1. A set of land allocations (Late-Successional Reserves, Key Watersheds, Adaptive Management Areas, Riparian Reserves, and Matrix lands).

2. An extensive set of standards and guidelines governing management activities.

3. Requirements for a watershed analysis process.

Through this plan, ecosystem management objectives and constraints have been established at the regional level that strongly influence the range of options available for local-level analyses and activities.

The watershed analysis process is meant to function at a scale between the Northwest Forest Plan (USDA and USDI 1994) and site-specific actions. Past, current, and potential future conditions and trends are to be assessed at the watershed scale. Watershed restoration and monitoring projects are recommended, and information from watershed analyses is to be used to develop priorities and support management decisions at all levels (USDA and USDI 1994). Watershed analysis is required before adjustments are made in Riparian Reserve locations and widths (USDA and USDI 1994). The Federal guide for watershed analysis (Regional Ecosystem Office [REO] 1995) provides general direction for watershed analyses on federally managed public lands.

This paper describes a case study integrating results from a watershed analysis into a spatially and temporally specific management plan for one watershed: Augusta Creek, which is located in the central west side of the Cascade Range of Oregon. In this critical respect, the case study differs from the watershed analysis procedures prescribed by REO (1995) and from most watershed analyses recently conducted throughout the region. Upslope management prescriptions and Riparian Reserves are recast at the watershed level based on information in a watershed-scale analysis. Elements of the landscape plan include variable-length rotations, variable levels of green-tree retention, and a modified approach to Riparian Reserves.

To prepare this case study, we first developed and demonstrated a landscape management strategy in a managed forest landscape based on historical disturbance regimes and patterns. Second, we synthesized a landscape-specific understanding of both aquatic and terrestrial ecosystems into an integrated management plan at the watershed scale. The resulting upslope management regime and aquatic reserve system 
Table 1-Examples of components of ecosystem management at regional, watershed-landscape, and stand-project scales

\begin{tabular}{|c|c|c|}
\hline Level & Component & Explanation \\
\hline \multirow[t]{4}{*}{ Regional ( $10^{7}$ hectares) } & Biological & $\begin{array}{l}\text { Sustain species with ranges } \\
\text { over the region. }\end{array}$ \\
\hline & Ecological principles-concepts & $\begin{array}{l}\text { Species are dependent on the mix of habitat } \\
\text { needed for critical components of life history; } \\
\text { e.g., forage, rearing, dispersal habitat. }\end{array}$ \\
\hline & Social & $\begin{array}{l}\text { Regional economy; Federal Government role } \\
\text { in transition related to change in wood supply. }\end{array}$ \\
\hline & Example of management strategy & $\begin{array}{l}\text { Regional conservation strategy embodying } \\
\text { reserve systems, standards and guidelines, etc. }\end{array}$ \\
\hline \multirow[t]{4}{*}{$\begin{array}{l}\text { Watershed-landscape } \\
\left(10^{4}-10^{6} \text { hectares }\right)\end{array}$} & Biological & $\begin{array}{l}\text { Sustain species through preservation or } \\
\text { management, or both, of terrestrial and } \\
\text { aquatic habitats. }\end{array}$ \\
\hline & Ecological principles-concepts & $\begin{array}{l}\text { Disturbance regimes strongly control } \\
\text { structure and function of ecosystems at } \\
\text { landscape-watershed scale. }\end{array}$ \\
\hline & Social & Stability of local communities. \\
\hline & Example of management strategy & $\begin{array}{l}\text { Landscape-watershed management plan } \\
\text { based on historical variability of disturbance } \\
\text { regimes. }\end{array}$ \\
\hline \multirow[t]{4}{*}{$\begin{array}{l}\text { Stand-project } \\
\left(10^{\circ}-10^{2} \text { hectares }\right)\end{array}$} & Biological & $\begin{array}{l}\text { Sustain productivity and habitat for species } \\
\text { with limited range. }\end{array}$ \\
\hline & Ecological principles-concepts & $\begin{array}{l}\text { Certain processes are dependent on specific } \\
\text { species or environmental conditions, and } \\
\text { certain species are dependent on specific } \\
\text { habitat elements. }\end{array}$ \\
\hline & Social & $\begin{array}{l}\text { Use of specific sites; public involvement in } \\
\text { project planning. }\end{array}$ \\
\hline & Example of management strategy & $\begin{array}{l}\text { Retention of coarse woody debris and live } \\
\text { trees at levels necessary to meet habitat and } \\
\text { ecological process objectives. }\end{array}$ \\
\hline
\end{tabular}

Source: Cissel and others 1994. 


\section{General Ecosystem Management Objectives and Assumptions}

are interdependent and meant to be jointly evaluated and implemented. Third, we placed landscape and watershed objectives in the context of a regional plan (USDA and USDI 1994) and linked those objectives to stand and site-level prescriptions.

This paper documents the concepts, methods, and potential results of a landscape management approach developed for Augusta Creek. The consequences of actually managing under such an approach are largely unknown, but the approach was developed in sufficient detail that an informed evaluation of effects was made (phase 4). A useful reference point for evaluating the potential effects of this approach is the "prewatershed analysis" landscape from the Northwest Forest Plan; i.e., the landscape that would result from literal application of the standards, guidelines, and assumptions underlying the timber harvest levels in the Northwest Forest Plan (Probable Sale Quantity [PSQ]) unmodified by watershed analysis. These two approaches are compared in the latter part of the paper.

A general goal of ecosystem management is to sustain ecosystems while providing for compatible levels of human use (Wood 1994). There is a growing awareness that to sustain human uses of the ecosystem, the ecosystem itself also must be sustained. We interpreted the goal of sustaining forest ecosystems on public lands to mean maintaining native species, ecosystem processes and structures, and long-term ecosystem productivity. In the Pacific Northwest, and elsewhere, production of wood fiber is a significant human use of forest lands. The balance among forest uses remains a contentious issue.

We currently lack the knowledge to accurately and completely state how native species and ecosystem processes and productivity can be sustained. If we knew all the relations among components of the ecosystem and human uses, a rational planning process might confidently define a range of possible management alternatives to sustain the ecosystem and provide for human uses. More realistically, partial ignorance and inevitable surprise inherently characterize our understanding of human interactions with ecosystems (Faber and others 1992). In this case study, we therefore elected to follow a relatively conservative approach to human use of ecosystems, rely on past conditions and historical patterns as guides for future management strategies, recognize the need for restoration of some ecosystems, and recommend an adaptive management approach.

We developed a landscape management strategy where past disturbance regimes and landscape conditions provided key reference points for future landscape objectives. A premise of this approach is that native species are adapted to the range of habitat patterns resulting from historical disturbance events over the last 500 years, and the probability of survival of these species is reduced if their environment lies outside the range of historical conditions for a prolonged time (Swanson and others 1993). Similarly, ecological processes, such as those involved in nutrient and hydrologic cycles, have functioned historically within a range of conditions established by disturbance and successional patterns. Operating outside the range of past conditions may affect these processes in unforeseeable and perhaps undesirable ways. The threatened or sensitive status of many species in the Northwest, including the northern spotted owl (Strix occidentalis), marbled murrelet (Brachyramphus marmoratum), certain anadromous fish stocks, and the numerous old-growth-associated species identified in the Northwest Forest Plan (USDA and USDI 1994: table C-3, p. C-49 to C-61) may be partially the result of ecosystems in conditions outside or near the extremes of past conditions. 
Our ability to use historical conditions and disturbance regimes as templates for future management plans was limited in several respects: First, in technical issues, with interpreting of past events limited by the accuracy of historical assessments; for example, fire history analyses were limited by the length of the available record. An inaccurate picture of fire frequency may be obtained if the period of record is short relative to fire frequency. Second, present and future conditions may be far outside the range of historical conditions due to factors unlikely to be affected by future management strategies (e.g., the effects of exotic species, existing engineered structures, climate change). And third, society may desire conditions that differ greatly from historical conditions. For example, large disturbance events, such as a $50000-$ hectare $(120,000$-acre) fire, have occurred historically; but the short-term effects of such an event on wildlife, watershed, and recreational values may be viewed as unacceptable by many.

Existing conditions are far different from historical conditions owing to past human uses, and the implications of these environmental alterations must be integrated with the historical template to meet our objectives. In the South Fork of the McKenzie River watershed, where Augusta Creek lies (fig. 1), Cougar Dam and Reservoir have been constructed, hundreds of miles of roads have been built, hundreds of even-aged plantations have been established in place of native forests, and nonnative species have been introduced. ${ }^{1}$ These activities have modified habitat and ecosystem processes such that some species' future existence in the area may be threatened (e.g., spotted owl and bull trout [Salvelinus confluentus]). In other portions of the South Fork watershed, wilderness and unroaded areas have been designated. A

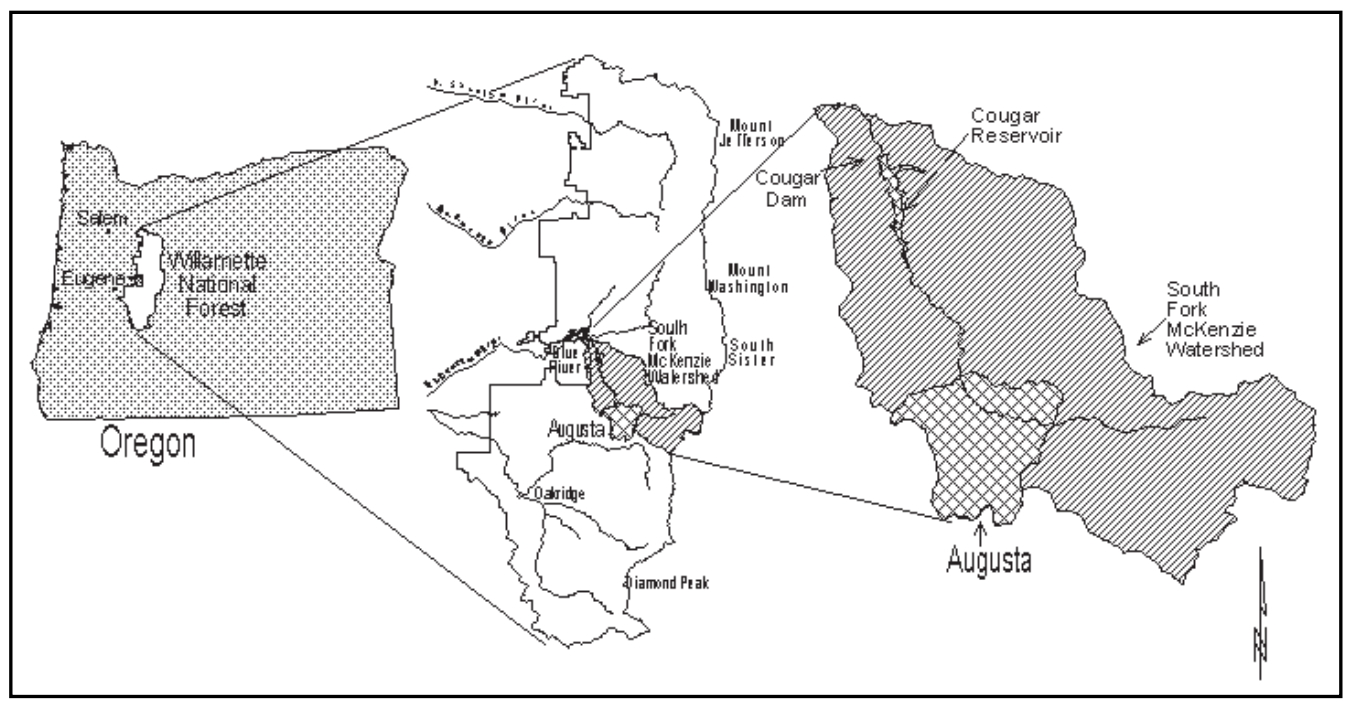

Figure 1-Location of the Augusta Creek project area.

'Willamette National Forest. 1994. South Fork watershed analysis. Eugene, OR: U.S. Department of Agriculture, Forest Service, Willamette National Forest. [unpaged]. Administrative report. On file with: Blue River Ranger District, Willamette National Forest, Blue River, OR 97413. 
relatively effective fire suppression policy has been in place for several decades throughout the watershed. Large-scale habitat modifications in combination with societal expectations (e.g., that native species be maintained, timber produced, and fire suppressed) limit the degree to which past patterns can be applied in future management.

Given our current incomplete understanding of habitat requirements and ecosystem processes, reliance on the pattern and structure of historical landscapes as key reference points nevertheless can provide a practical approach to ecosystem management in many cases. We elected to use an understanding of historical disturbance regimes, primarily fire, as a basic management template. This template was then adjusted for existing conditions, differences between active forest management and historical disturbances, and the presence of specific social objectives. The general concept of using historical disturbance regimes as a template for landscape management is being explored in various settings across the country (e.g., Baker 1992, Hardy and Arno 1996, Hunter 1993, Mladenoff and others 1993, Morgan and others 1994, Swanson and others 1993) and internationally (Stuart-Smith and Hebert 1996). Emulating patterns of historical disturbance regimes in landscape plans is one of several alternative approaches. A second approach is the intensive use of reserves, corridors, and matrix designations common in conservation biology (Noss and Cooperrider 1994). A third approach, common in intensive forestry, involves simple dispersed or aggregated cutting on a fixed rotation length. The Augusta Creek project is intended, in part, to provide a test of alternative approaches through comparison of the reserve-matrix system emphasized by the Northwest Forest Plan with the disturbance-based approach developed for the Augusta area.

\section{Area Description}

The 7600-hectare (19,000-acre) Augusta project area lies in steep, dissected mountains of the west side of the central Cascade Range of Oregon. Located in the South Fork of the McKenzie River watershed (fig. 1), the project area is typical of much of the National Forest land along the west side of the Cascade Range. Elevation ranges from 700 to 1740 meters $(2,300$ to $5,700 \mathrm{ft})$. A seasonal snowpack usually develops above 1100 meters $(3,500 \mathrm{ft})$, and a transient snowpack frequently forms and melts at lower elevations. Peak flows due to rapid snowmelt during rain-on-snow events are believed to be a primary cause of channel-altering floods in this area (Berris and Harr 1987; Coffin and Harr 1992; Harr 1981, 1986).

Douglas-fir (Pseudotsuga menziesii (Mirb.) Franco) is the dominant tree species over most of the planning area, with western hemlock (Tsuga heterophylla (Raf.) Sarg.) and western redcedar (Thuja plicata Donn ex D. Don) the most common associates. Grand fir (Abies grandis (Dougl. ex D. Don)) intermingles on drier sites, and Pacific silver fir (Abies amabalis Dougl. ex Forbes) and noble fir (Abies procera Rehd.) dominate colder sites. Mountain hemlock (Tsuga mertensiana (Bong.) Carr.) is common above 1500 meters (5,000 ft). Old forests (>200 years in age) and complex stand structures resulting from multiple wildfire events prevail over a large portion of the planning area. A series of high-elevation dry meadows occurs along the ridgetops forming the southern boundary of the planning area. Many of these meadows are currently undergoing succession to conifers. Two unroaded reserves span the northand south-bounding ridges of the planning area, while much of the lands between fall within a mix of land-use designations that prescribe timber harvest (USDA 1990, USDA and USDI 1994). Plantations regenerated after clearcutting are dispersed throughout most of the roaded area. 
General Analytical Process
Our analytical process involved four sequential phases (fig. 2). Results from any one phase, however, could trigger a return to a preceding phase. The larger context of the surrounding watersheds provided important context for each of these phases.

In the first phase (refer to fig. 2), past and current conditions, processes, disturbance regimes, and human uses were analyzed. A fire history study was conducted to describe and map past fire regimes. This analysis was similar to watershed analyses being implemented as part of the Northwest Forest Plan.

In the second phase, prescriptions guiding future management actions were developed from the results of phase one. These objectives were based on the range of variability in past habitat conditions as interpreted from studies of the histories of fire

\section{Larger Scale Context}

-Conditions in surrounding watersheds

-Direction from Northwest Forest Plan

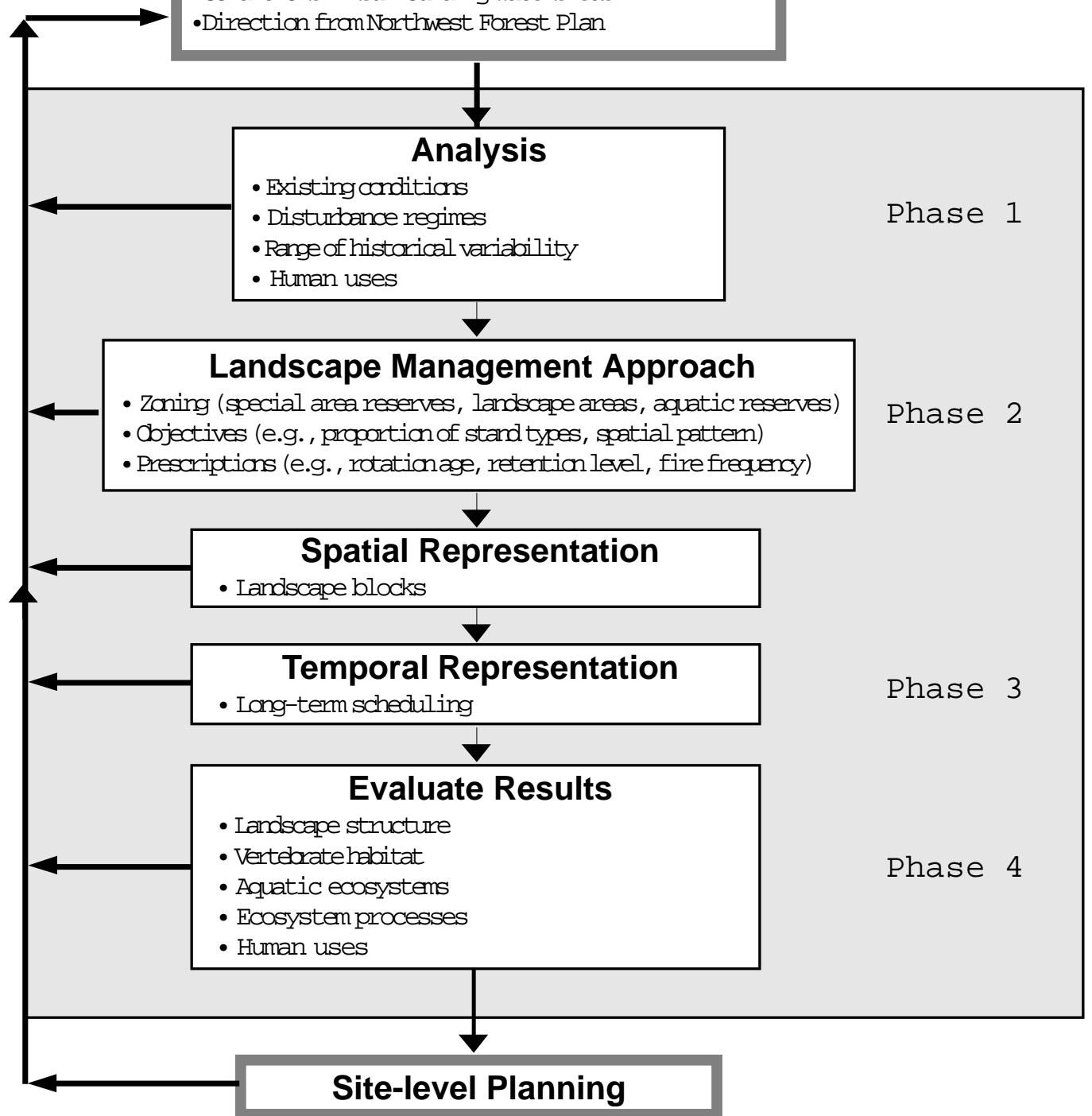

Figure 2-General analytical process used to develop the Augusta Creek Landscape Plan. 


\section{Larger Scale Context}

and other disturbances and modified where existing conditions were judged to be outside the range of past conditions. In areas where timber cutting was allocated, landscape prescriptions established cutting frequencies, intensities, and the desired spatial pattern.

In the third phase, landscape objectives and prescriptions were used to develop spatially and temporally explicit portrayals of potential future landscape and watershed conditions. Spatial pattern objectives were used to map areas, termed "landscape blocks," where timber cutting will occur. These blocks were used for long-term scheduling, each having a prescribed frequency and intensity of cutting. Maps of landscape structure were then produced for each 20-year time step.

In the fourth phase, maps of landscape structure were compared to conditions that would result from application of standards, guidelines, and assumptions in the Northwest Forest Plan, prior to any modifications that might result from watershed analysis and related plan adjustments. Landscape structure, plant and animal habitat, ecosystem processes, and human uses were evaluated, by using both quantitative and qualitative methods.

The resulting landscape management objectives and prescriptions provide a direct link to project-scale planning for timber sales, prescribed fire, silvicultural activities, and restoration or recovery projects. The type and timing of future activities can be established by comparing existing conditions to the projected trajectory of future conditions.

The South Fork of the McKenzie River watershed provides an important context for interpreting conditions and processes within the Augusta Creek area (fig. 1). Cougar Dam and Reservoir have blocked or impeded migration and movement of some aquatic and terrestrial biota, interrupted downstream movement of wood and sediment, and significantly altered stream flow below the dam since the mid-1960s. Bull trout, a threatened species in parts of its range and considered sensitive by many fish biologists, are known to use the main stem of the South Fork but are prevented from mixing with the main McKenzie River population by Cougar Dam. The bull trout population in the South Fork appears to be small and subject to local extirpation if conditions degrade and movement between the McKenzie River and the upper South Fork continues to be blocked by Cougar Dam (see footnote 1). The cold, spring-fed Roaring River provides important spawning habitat for bull trout (see footnote 1).

Vegetation conditions vary considerably within the South Fork watershed. Most lands on the east side of the South Fork above Cougar Dam are in the Three Sisters Wilderness (51 percent of the South Fork watershed). The wilderness is dominated by mature forest, with pockets of older and younger forest. The western portion of the South Fork watershed has been extensively roaded and clearcut over the last 40 years. Downstream from Augusta Creek, clearcutting has progressed to the point where even-aged plantations dominate the landscape with small fragments of older forest remaining in places. Above the confluence of Augusta Creek and the South Fork, the western slopes contain mostly mature and older forests perforated by numerous small, dispersed clearcuts and plantations. The high density of roads in the western portion of the watershed has resulted in increased sedimentation and altered hydrologic functions in some areas (see footnote 1). Plantations regenerated after clearcutting occupy many riparian areas, resulting in reduced source areas for future large wood input to streams. 


\section{Phase 1- Analysis of Past and Present Conditions and Processes}

\section{Fire History}

The regional management context set by the Northwest Forest Plan (USDA and USDI 1994) designates most of the South Fork of the McKenzie River watershed as a Tier 1 Key Watershed to provide primary habitat for bull trout. Timber harvest is expected to occur within a portion of the South Fork watershed, subject to findings from a watershed analysis indicating that harvest is compatible with objectives of the Aquatic Conservation Strategy of the Northwest Forest Plan. A Late-Successional Reserve in the northeast portion of the watershed mostly overlaps with the Three Sisters Wilderness but also contains additional lands (7 percent of the South Fork watershed) adjacent to the wilderness. This reserve and others allocated throughout the range of the northern spotted owl are intended to provide primary nesting and foraging habitat for the northern spotted owl. The Augusta area is expected to provide dispersal habitat for spotted owl movement among the large reserves.

Human use of the Augusta area is conditioned to a significant extent by the surrounding landscape. The South Fork corridor is heavily used by anglers, campers, sightseers, and others. This use occurs all along the corridor, of which the Augusta planning area occupies only a small segment. Glimpses of the Augusta area as viewed from the main road in the corridor, a National Scenic Byway, are part of a larger pattern of scenery viewed by motorists and bikers. Hiker and horserider use of ridgeline trail systems in the Augusta planning area also is linked to trailheads and other trails in nearby areas.

Mammals with large home ranges use the Augusta area as a part of a larger landscape. Cougar (Felis concolor), black bear (Ursus americanus), deer (Odocoileus spp.), and elk (Cervus elaphus) occur in the Augusta planning area but use significantly larger areas, as well. In particular, the lower slopes of Rebel Ridge and adjacent valley floor landforms are important winter range and rearing areas for elk.

Approach-Before the onset of active fire suppression and intensive timber harvest in this century, fire had been a major process controlling landscape structure along the west side of the Oregon Cascade Range for at least 500 years (Agee 1993, Morrison and Swanson 1990, Teensma 1987). An understanding of the frequency, severity, and spatial extent of past fire is critical to understanding the historical distribution of habitats. A fire history of the area was compiled from a field study using standard dendrochronological techniques (Agee 1993, Morrison and Swanson 1990).

Sample sites for the fire history study were selected from aerial photographs and clustered along stand age-class boundaries. Both stumps in clearcuts and increment cores from live trees were used to collect tree and fire-scar ages. Sites with a more complex age-class structure were sampled more intensively than those with few age classes or little evidence of fire scars. A total of 1,325 fire scar and tree age records were used from 1,101 trees sampled on 267 plots. $^{2}$

Fire episode maps for moderate- to high-severity fires were compiled from the fire evidence records by generally following procedures described in Morrison and Swanson (1990). Fire episodes were mapped when the following three conditions were present:

${ }^{2}$ Connelly, K.P.; Kertis, J.A. 1991. Report on Augusta fire history. 49 p. Administrative report. On file with: Blue River Ranger District, Willamette National Forest, Blue River, OR 97413. 
1. At least five sites had scar or tree age dates for that episode.

2. There was a high reliability rating given to the tree age or fire scar data used for that episode.

3. Sites for that episode were clustered in space as well as time.

Episode boundaries were determined from spatial patterns of fire evidence. A Geographical Information System (GIS) was used to superimpose fire evidence data over topographic and other resource maps to help discern relations. Episode boundaries were then manually drawn and digitized into the GIS (see footnote 2).

General fire regime areas were identified and mapped for nine subsections of the planning area. Each appeared to have a similar stand-age structure and fire history. Fire regime boundaries generally correlated with areas exhibiting distinctly different land surface features (i.e., predominant aspect, degree of dissection, elevation, and slope length). Mean fire return intervals were then calculated for each fire regime area. Although low-severity fires were not mapped, fire scar records were used to estimate a rough fire frequency for low-severity fires (see footnote 2).

Results-Twenty-six stand-replacing or partial stand-replacing fire episodes were dated and mapped (fig. 3). The timing and location of the fire episodes differed substantially. Most of the area burned in the 1500 s (55 percent), but very little burned in the 1600 s (9 percent). Four episodes burned 38 percent of the area in the 1700 s, and the 1800 s witnessed an increase in the amount of area burned (57 percent), possibly due to the influx of Euro-American settlement. Some areas burned multiple times in the same century, especially in the central part of the planning area in the 1800 s. Over the 500 years covered by the analysis, fire episodes ranged from 55 to 3410 hectares (mean, 657 ha [136 to 8,421 acres; mean 1,624 acres]) and differed greatly in the spatial pattern of the fires. The central portion of the planning area tended to burn more frequently than the southern portion (fig. 3).

Despite substantial variability, specific disturbance regimes appear to typify certain parts of the planning area. Through presumed effects on microclimate, fuel loads, and fire spread processes, topography significantly influenced fire regime. The fireepisode level data were compiled into general descriptions of nine fire regimes based on the frequency, severity, and patch size distribution of wildfire (fig. 4, tables 2 and 3) (see footnote 2). For example, fire regime area $\mathrm{H}$ (Upper Basins) occurs in upperelevation, north-facing, cirque basins. This area experienced fire infrequently, but the recorded fires were large and severe. The North Chucksney fire regime (area C) experienced smaller, less severe, but more frequent fires.

Approach-Fire episode maps were used to create generalized maps of historical landscape structure. Starting with the earliest fire episode, the sequence of fire polygons were overlaid in a GIS, and time since the previous fire was tracked for each grid cell ( 50 by 50 meters [ 164 by $164 \mathrm{ft}$ ]). Each fire polygon was assumed to represent a fire of moderate to high severity sufficient to create open-canopy conditions. At 20-year steps, and at the midpoint of each fire episode, maps of open- and closed-canopy forest were produced. For the purpose of this analysis, open-canopy conditions were defined to exist for 40 years after a fire. Since 1955, timber harvest has been the primary mechanism initiating open-canopy forests. Harvest records from the U.S. Department of Agriculture, Forest Service, were complied to create maps of open- and closed-canopy forests from 1955 through 1990 (Wallin and others 1996). 


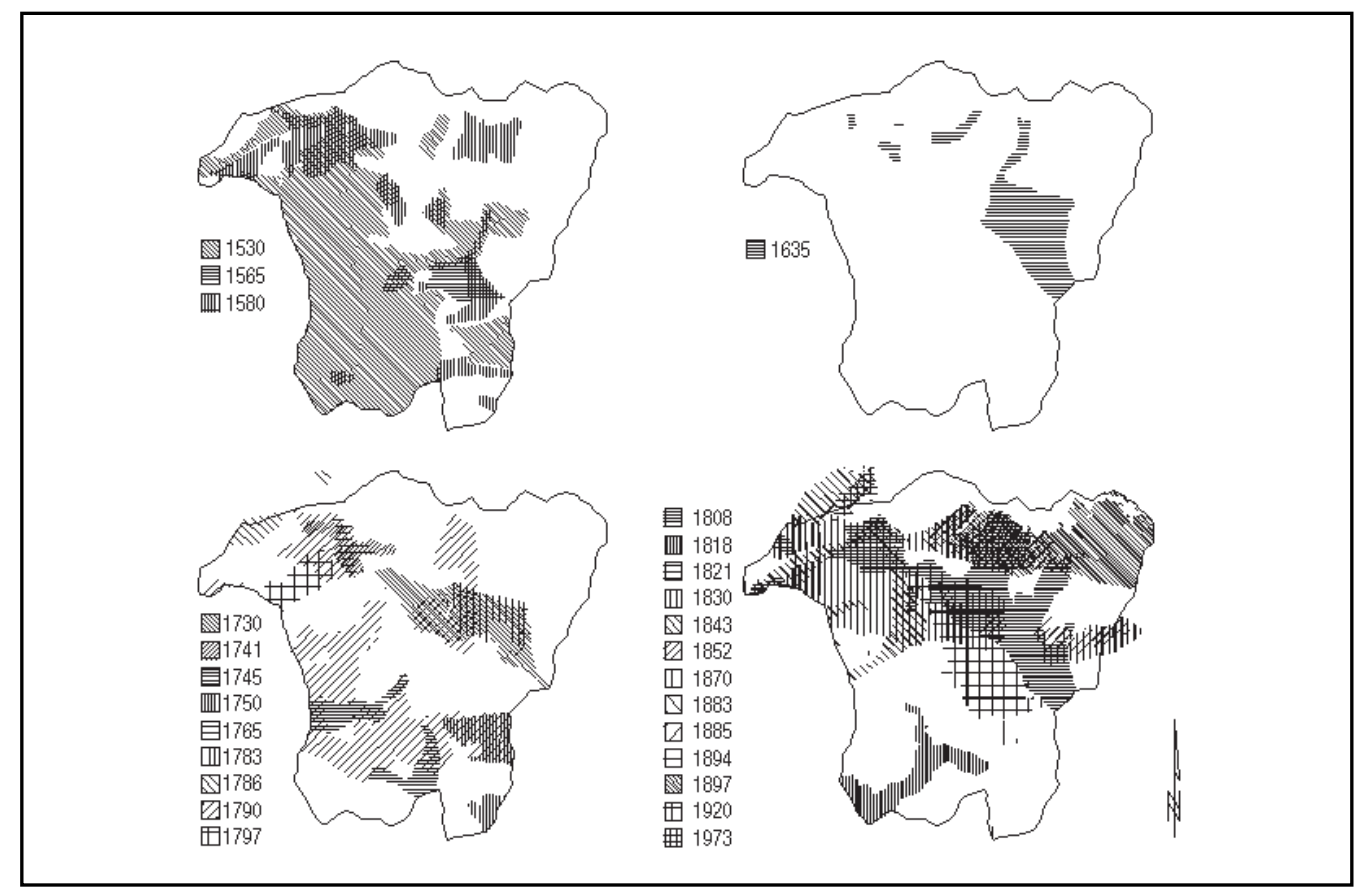

Figure 3-Fire episodes in Augusta Creek, 1530-1973.

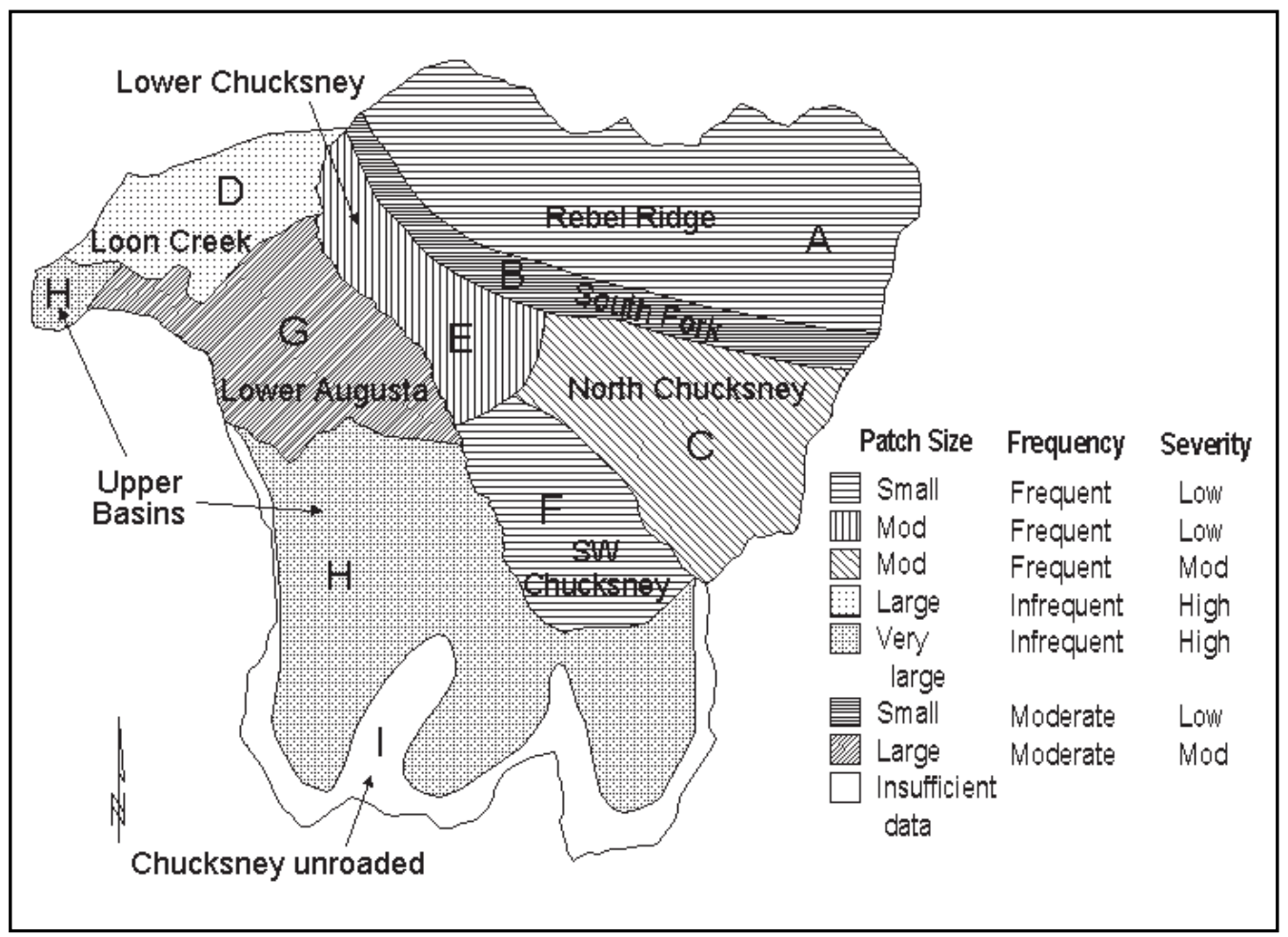

Figure 4-Augusta Creek fire regimes. 
Table 2-Augusta Creek fire regimes

\begin{tabular}{llll}
\hline Fire regime area (code) & Frequency $^{a}$ & Intensity $^{b}$ & Size $^{c}$ \\
\hline Rebel Ridge (A) & Frequent & Low-moderate & Medium-large \\
South Fork (B) & Infrequent & Low & Small \\
North Chucksney (C) & Frequent & Low-moderate & Small \\
Loon Creek (D) & Intermediate & Moderate-high & Large \\
Lower Chucksney (E) & Frequent & Moderate & Small \\
Southwest Chucksney (F) & Frequent & Low-moderate & Medium \\
Lower Augusta (G) & Intermediate & Moderate & Medium-large \\
Upper Basins (H) & Infrequent & Moderate-high & Large \\
Chucksney unroaded (I) & Insufficient data & & \\
\hline
\end{tabular}

a Infrequent=area characterized by 1 dominant period of burning over the last 500 years.

Intermediate=area characterized by 2 dominant periods of burning over the last 500 years. Frequent=area characterized by repeated burning throughout much of the last 500 years.

$b$ Low=fires generally caused 0 - to 35 -percent overstory mortality.

Moderate=fires generally caused 35 - to 60-percent overstory mortality.

High=fires generally caused $>60$-percent overstory mortality.

c Size refers to the size of the vegetation patches created by fire.

Small=mean patch size $<140$ hectares.

Medium=mean patch size 140 to 280 hectares.

Large $=$ mean patch size $>280$ hectares.

Existing forest stands were assigned to a set of stand structure classes. Classes were defined by the successional stage of the most recent cohort and the level of overstory retained through the originating disturbance event (table 4). Aerial photographs, ground data from Forest Service stand exams, and a Willamette National Forest forest-type map were integrated and validated with field checks and local knowledge.

Although significant portions of the area have been fragmented by clearcutting over the last 40 years, several large blocks of mature and old forest remain. In other places, large blocks of young forest have been initiated through forest cutting and reforestation. We mapped existing large, unfragmented blocks of either young or old forest from the current stand structure map based on the spatial pattern of existing stands.

For each map of open- and closed-canopy forest, and for the existing stand structure map, landscape metrics were generated from FRAGSTATS, software for analysis of spatial pattern (McGarigal and Marks 1995). We selected edge density (meters per hectare) and the percentage of closed-canopy forest greater than 100 meters (328 ft) from an edge with open-canopy forest as ecologically meaningful indicators of landscape structure (Wallin and others 1996).

Results-Historical landscape patterns over the last 500 years consisted of a complex, diverse mix of stand structures and patch sizes differing widely over space and time. For example, the Upper Basins area contained large patches and a high proportion of older forests. Because of the high fire severity in this area, when younger forests occurred, they were assumed to generally contain a single cohort. In contrast, 
Table 3-Hectares of each fire event within each fire regime area, Augusta Creek, 1530 to 1973

\begin{tabular}{|c|c|c|c|c|c|c|c|c|c|}
\hline \multirow[b]{2}{*}{ Fire date } & \multicolumn{9}{|c|}{ Fire regime area ${ }^{a}$} \\
\hline & $A$ & B & C & D & $E$ & $\mathrm{~F}$ & $\mathrm{G}$ & $\mathrm{H}$ & I \\
\hline Year & \multicolumn{9}{|c|}{ Hectares } \\
\hline 1530 & 51 & 6 & 235 & 140 & 204 & 131 & 656 & 1530 & 448 \\
\hline 1565 & 0 & 0 & 5 & 0 & 0 & 172 & 0 & 39 & 0 \\
\hline 1580 & 203 & 34 & 68 & 153 & 200 & 142 & 159 & 81 & 45 \\
\hline 1635 & 84 & 15 & 557 & 7 & 26 & 0 & 0 & 0 & 0 \\
\hline 1730 & 0 & 6 & 427 & 0 & 136 & 2 & 0 & 0 & 0 \\
\hline 1741 & 2 & 21 & 0 & 29 & 90 & 0 & 0 & 0 & 0 \\
\hline 1745 & 0 & 0 & 0 & 0 & 0 & 0 & 0 & 291 & 40 \\
\hline 1750 & 0 & 0 & 0 & 0 & 0 & 55 & 0 & 135 & 66 \\
\hline 1765 & 0 & 2 & 0 & 0 & 80 & 0 & 0 & 0 & 0 \\
\hline 1783 & 0 & 20 & 243 & 0 & 0 & 0 & 0 & 0 & 0 \\
\hline 1786 & 0 & 0 & 0 & 69 & 0 & 0 & 0 & 0 & 0 \\
\hline 1790 & 153 & 19 & 209 & 117 & 135 & 97 & 221 & 859 & 179 \\
\hline 1797 & 0 & 0 & 0 & 0 & 0 & 0 & 132 & 0 & 0 \\
\hline 1808 & 249 & 105 & 552 & 103 & 284 & 3 & 78 & 12 & 0 \\
\hline 1818 & 0 & 0 & 0 & 0 & 0 & 0 & 0 & 145 & 194 \\
\hline 1821 & 0 & 0 & 0 & 13 & 0 & 0 & 0 & 0 & 0 \\
\hline 1830 & 267 & 36 & 254 & 303 & 253 & 61 & 659 & 21 & 0 \\
\hline 1843 & 69 & 4 & 0 & 106 & 89 & 0 & 208 & 73 & 6 \\
\hline 1852 & 441 & 1 & 173 & 0 & 31 & 0 & 0 & 0 & 0 \\
\hline 1870 & 0 & 0 & 1 & 165 & 15 & 153 & 72 & 41 & 9 \\
\hline 1883 & 173 & 0 & 0 & 0 & 0 & 0 & 0 & 0 & 0 \\
\hline 1885 & 0 & 0 & 0 & 15 & 0 & 0 & 0 & 0 & 0 \\
\hline 1894 & 0 & 0 & 0 & 0 & 0 & 181 & 0 & 7 & 0 \\
\hline 1897 & 843 & 0 & 0 & 0 & 0 & 0 & 0 & 0 & 0 \\
\hline 1920 & 0 & 2 & 120 & 0 & 259 & 428 & 0 & 0 & 0 \\
\hline 1973 & 0 & 0 & 0 & 7 & 0 & 0 & 0 & 0 & 0 \\
\hline Total & 2533 & 271 & 2844 & 1227 & 1801 & 1424 & 2185 & 3234 & 986 \\
\hline
\end{tabular}

a Total hectares of each fire regime area: $A=1631, B=397, C=900, D=443, E=463, F=569, G=756, H=1822, I=650$. 
Table 4-Stand structure classes used for Augusta Creek analysis

\begin{tabular}{lcc}
\hline $\begin{array}{l}\text { Successional stage of } \\
\text { most recent cohort }\end{array}$ & $\begin{array}{c}\text { Age of most recent } \\
\text { cohort }\end{array}$ & $\begin{array}{c}\text { Overstory retention level } \\
\text { when most recent cohort } \\
\text { was established }\end{array}$ \\
\hline Shrub-sapling $^{b}$ & Years & Percent \\
Closed pole $^{b}$ & $1-20$ & $0,15,30$, or 50 \\
Young & $21-40$ & $0,15,30$, or 50 \\
Mature & $41-80$ & $0,15,30$, or 50 \\
Old & $81-200$ & $0,15,30$, or 50 \\
Meadows & $>200$ & na \\
Rocks & na & na \\
\hline
\end{tabular}

na=not applicable.

a The 0 - and 15-percent retention level classes and the 30- and 50-percent retention level classes were combined to simplify some analyses and displays.

$b$ Shrub-sapling and closed pole classes were combined to simplify some analyses and displays.

the North Chucksney area consisted of complex, multicohort stands generally much smaller in areal extent due to the smaller, less severe, and more frequent fires in this area.

Existing landscape structure is primarily the result of stand development patterns from past fires, with a relatively new overlay of 40 years of dispersed, small clearcuts (fig. 5 , table 5). The overall proportions of young and old forests are well within the range of historical conditions (Wallin and others 1996). However, younger forests in the existing landscape resulted from clearcutting, not fire, and generally lack the surviving green trees, snags, and down logs typical of fire-regenerated stands.

Even though the total amount of interior closed-canopy forest has varied by only about 20 percent over the last 400 years (Wallin and others 1996), patch sizes have differed greatly. Mean patch size of interior closed-canopy forest has ranged from a low of about 50 hectares (120 acres) to a high of 320 hectares (790 acres) (fig. 6A). Relatively small patches of interior closed-canopy forest occurred in the 1500 s and early 1800 s in response to extensive fires, and in the last half of the 1900 s in response to extensive dispersed-patch clearcutting. A peak in patch size was reached in the first half of the 1900s, before the onset of timber harvest, owing to a period of fire absence.

The amount of edge between closed- and open-canopied forests in the landscape varied over time in response to variation in fire size and frequency (fig. 6B). Edge densities reached a low point around 1700 due to an extended fire-free period and then increased in the 1800 s in response to a series of fires in the area. Edge densities have steadily increased over the last 40 years to relatively high levels as dispersed patch clearcutting has been implemented (fig. 6B). 


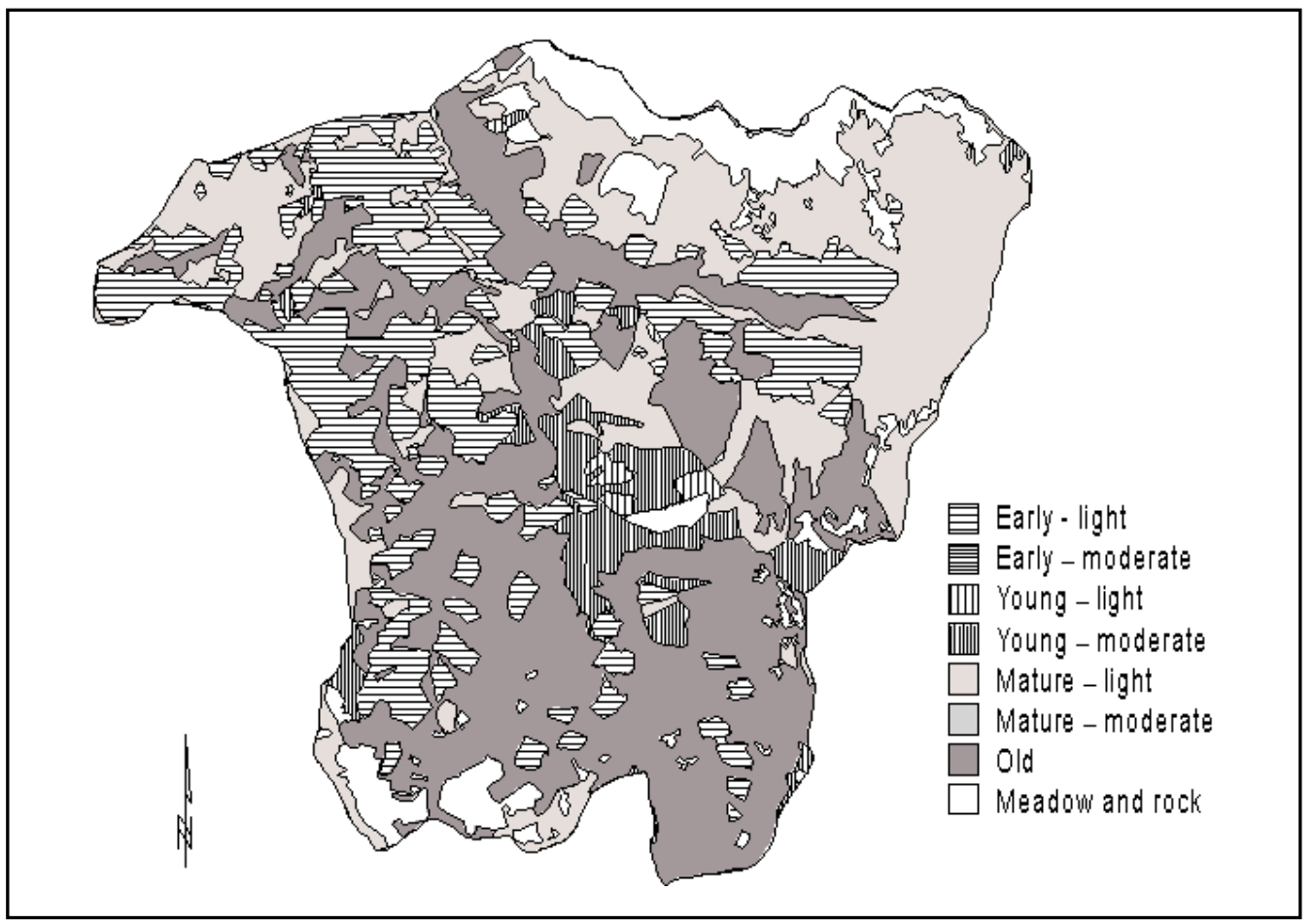

Figure 5-Existing vegetation conditions in Augusta Creek.

Table 5-Area of existing stand structure classes within the Augusta Creek study area

Stand structure classes Area

Hectares

Early: ${ }^{a}$

Light retention ${ }^{b}$

1550

Moderate to heavy retention ${ }^{c}$

Young:

Light retention ${ }^{b}$

Moderate to heavy retention ${ }^{c}$

Mature:

Light retention ${ }^{b}$

2100

Moderate to heavy retention ${ }^{c}$

0

Old

2780

Meadows and rocks

688

${ }^{a}$ Early $=a$ combination of the shrub-sapling and closed pole classes.

${ }^{b}$ Light retention $=a$ combination of the 0 - and 15 -percent retention levels. cModerate to heavy retention $=\mathrm{a}$ combination of the 30 - and 50 -percent retention levels. 

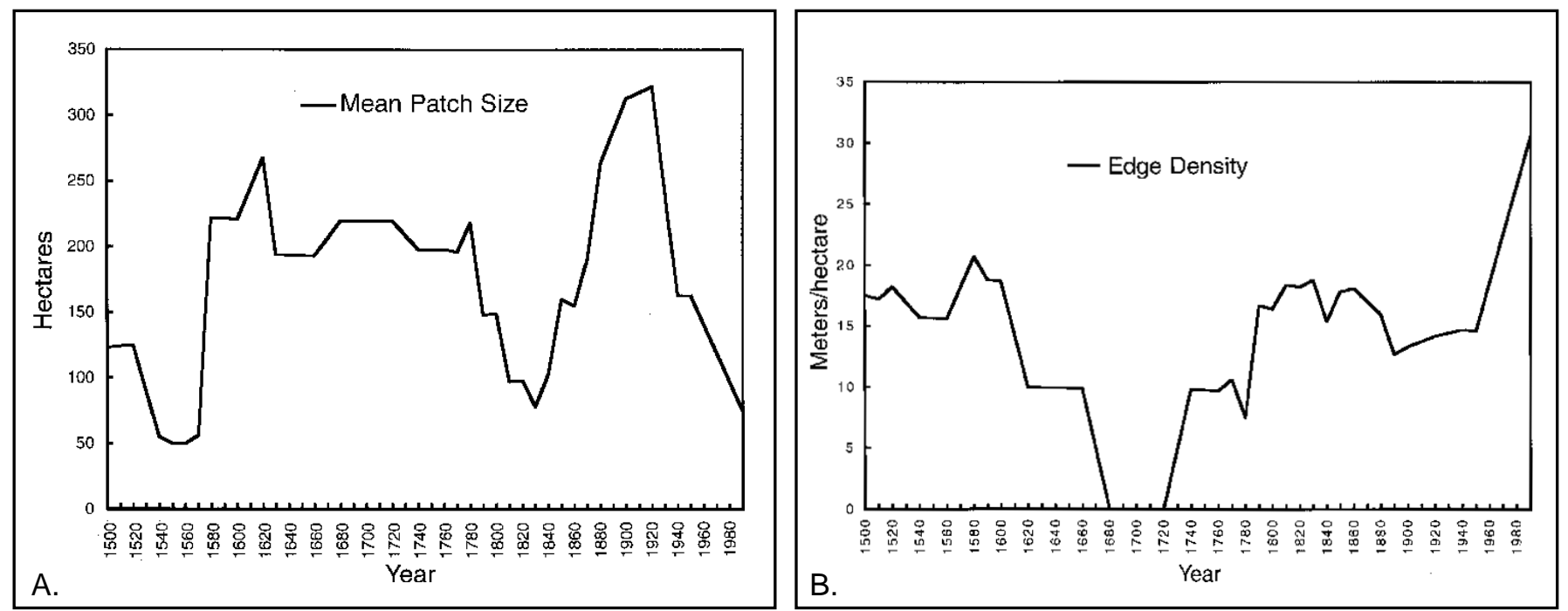

Figure 6-Historical area of (A) interior closed-canopy forest and (B) edge densities in Augusta Creek.

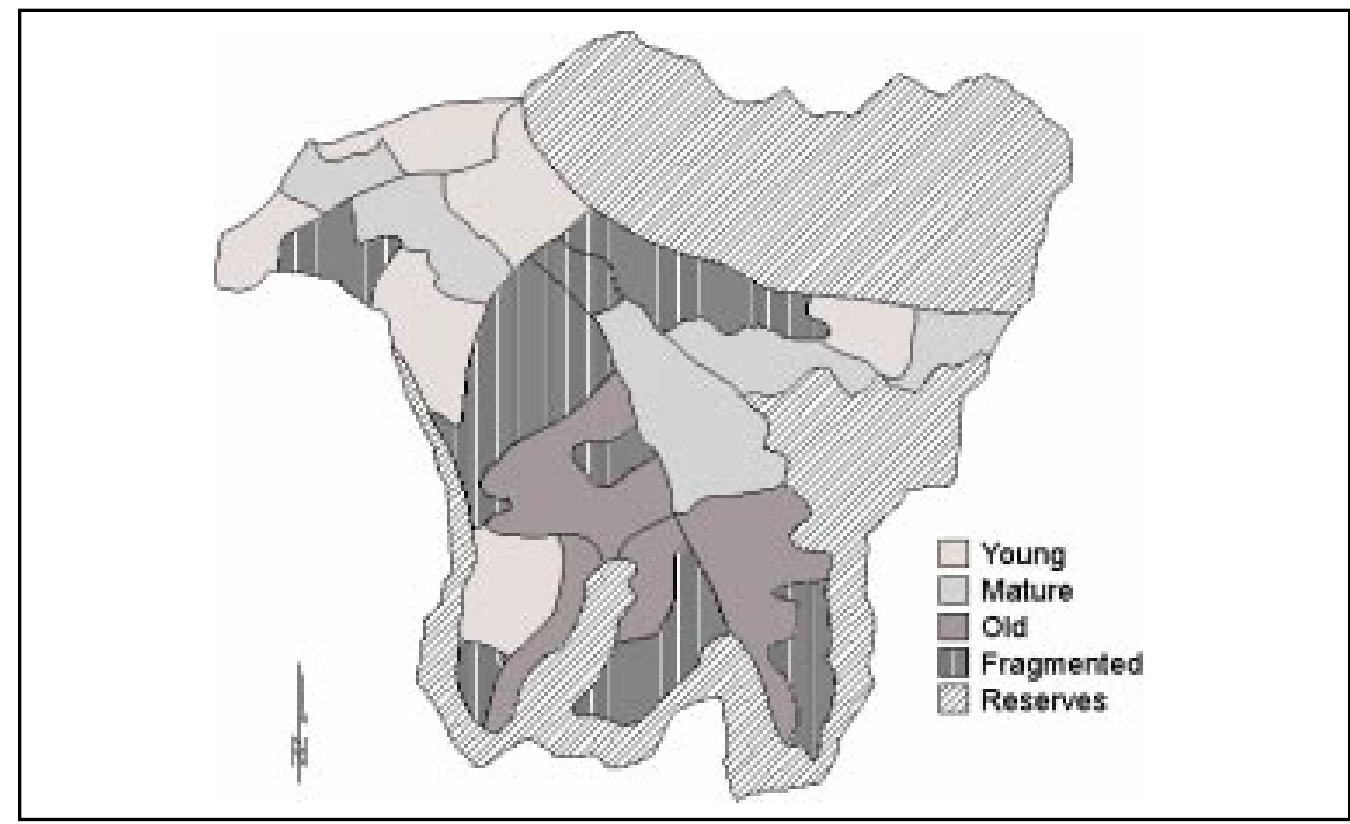

Figure 7-Large blocks of vegetation within the existing landscape.

Although significant portions of the area have been fragmented by clearcutting over the last 40 years, several large blocks of mature and old forest remain (fig. 7). In other places, large blocks of young forest have been created through forest cutting and regrowth (fig. 7). Because large blocks of old forest are difficult to restore once fragmented and are believed to be critical habitat for some species (FEMAT 1993), they are considered particularly important landscape elements. 
Table 6-Potential susceptibility to rain-on-snow peak flows within the Augusta Creek study area

\begin{tabular}{|c|c|c|c|}
\hline Elevation range $^{a}$ & Aspects $^{b}$ & Soil depthc & $\begin{array}{l}\text { Rain-on-snow } \\
\text { susceptibility }\end{array}$ \\
\hline \multicolumn{4}{|l|}{ Meters } \\
\hline$<1000$ & W, SW, S & Shallow & High \\
\hline$<1000$ & SE, NW & Shallow & Moderate \\
\hline$<1000$ & $\mathrm{~N}, \mathrm{NE}, \mathrm{E}$ & Shallow & Low \\
\hline$<1000$ & W, SW, S & Deep & Moderate \\
\hline$<1000$ & SE, NW & Deep & Low \\
\hline$<1000$ & $\mathrm{~N}, \mathrm{NE}, \mathrm{E}$ & Deep & Low \\
\hline $1000-1400$ & W, SW, S & Shallow & High \\
\hline $1000-1400$ & SE, NW & Shallow & High \\
\hline $1000-1400$ & $\mathrm{~N}, \mathrm{NE}, \mathrm{E}$ & Shallow & Moderate \\
\hline $1000-1400$ & W, SW, S & Deep & High \\
\hline $1000-1400$ & SE, NW & Deep & Moderate \\
\hline $1000-1400$ & $\mathrm{~N}, \mathrm{NE}, \mathrm{E}$ & Deep & Low \\
\hline$>1400$ & W, SW, S & Shallow & Moderate \\
\hline$>1400$ & SE, NW & Shallow & Moderate \\
\hline$>1400$ & $\mathrm{~N}, \mathrm{NE}, \mathrm{E}$ & Shallow & Low \\
\hline$>1400$ & W, SW, S & Deep & Moderate \\
\hline$>1400$ & SE, NW & Deep & Low \\
\hline$>1400$ & $\mathrm{~N}, \mathrm{NE}, \mathrm{E}$ & Deep & \\
\hline
\end{tabular}

a Elevation ranges define 3 zones of increasing snow accumulation with increasing elevation.

$b$ Aspects were used in combination with elevation zones to define 3 levels of potential snow melt during rain-on-snow events.

c 2 soil depth classes were assumed to correlate with potential ground water storage.

Approach-Rain-on-snow events are generally thought to be the major flood producers along the west side of the Cascade Range (Berris and Harr 1987; Coffin and Harr 1992; Harr 1981, 1986). Peak flows were analyzed by assessing the potential of different parts of the watershed to accumulate and melt snow and store ground water. Zones of potential snow accumulation were modeled as a simple function of elevation based on analysis of Soil Conservation Service SnoTel site data. ${ }^{3}$ Susceptibility of different parts of the landscape to snowmelt was modeled in a GIS by assigning highest melt rates to south- and west-facing slopes and to elevations below 900 meters (3,000 ft) (table 6). Melt rates diminished with increasingly northern or eastern exposures and increasing elevation. Snow accumulation and melt maps were combined with a map of groundwater storage (interpreted from the Soil Resource Inven-

${ }^{3}$ Personal communication. 1993. S.A. Ferguson, atmospheric scientist, Pacific Northwest Research Station, 4043 Roosevelt Way, NE, Seattle, WA 
tory $[\mathrm{SRI}])^{4}$ according to a matrix algorithm (table 6) to produce a map of the potential susceptibility to peak flows from rain-on-snow events in different portions of the landscape.

Late season summer baseflow was assumed to be related to locations of late melting snowpacks, which were modeled as differing by elevation and aspect. Areas lower in the watershed and with southwest- to southeast-facing aspects were assumed to lose their seasonal snowpacks first, followed by mid and higher elevation zones and more north-facing slopes. Snow accumulation, seasonal snowpack melt rate, and groundwater storage were combined to map the estimated contribution to summer base flow from different parts of the landscape, according to a matrix algorithm (table 7).

Results-The map of potential contribution to rain-on-snow peak flows (fig. 8) is based on our current understanding of the factors controlling these processes. Data were not available to validate this map. A key area of uncertainty is the timing of the contribution from each tributary basin to flood events. The synchronicity of tributary flows is a critical factor affecting the magnitude and duration of peak flows, which requires detailed and data-intensive modeling and monitoring to firmly establish. The rain-on-snow potential map does show, however, two extensive areas of highest risk. About 23 percent of the area is at relatively high risk of augmenting rain-on-snow runoff if forest cover were removed. The high risk areas are mid-elevation zones with a southerly aspect on shallow soils.

The map of potential contribution to summer baseflows (fig. 9) shows areas assumed to provide water for late-season stream flows. Data were not available to validate this map. About 19 percent of the area is in a high contribution category. Most of the area that contributes to late-season baseflows lies in the upper elevation, north-facing slopes in the unroaded area along Chucksney and Grasshopper Mountains and adjoining ridgelines.

Approach-Landslide potential maps were created from the existing Willamette National Forest SRI (see footnote 4). We mapped landslide potential as a function of soil depth, bedrock type, and slope steepness, as interpreted from the SRI. This map distinguishes general areas with similar risk of landsliding, based on inventories and quantitative assessments conducted in nearby areas. ${ }^{5}$ Each soil type was assigned a risk rating of low, moderate, or high slide potential. ${ }^{6}$

\footnotetext{
${ }^{4}$ Legard, H.A.; Meyer, L.C. 1990. Soil resource inventory for the Willamette National Forest. Eugene, OR: U.S. Department of Agriculture, Forest Service, Willamette National Forest. [unpaged]. Administrative report. On file with: Blue River Ranger District, Willamette National Forest, Blue River, OR 97413.
}

${ }^{5}$ Swanson, F.J.; Grant, G. 1982. Rates of soil erosion by surface and mass erosion processes in the Willamette National Forest: report prepared for the Willamette National Forest, Eugene, OR. Corvallis, OR: U.S. Department of Agriculture, Forest Service, Pacific Northwest Research Station. 50 p. On file with: Ecosystem Team, USDA Forest Service, Pacific Northwest Research Station, Forestry Sciences Laboratory, 3200 SW Jefferson Way, Corvallis, OR 97331.

${ }^{6}$ McSwain, M.D. 1993. Report on Augusta watershed analysis. Blue River, OR: Blue River Ranger District. 29 p. Administrative report. On file with: Blue River Ranger District, Willamette National Forest, P.O. Box 199, Blue River, OR 97413. 
Table 7-Potential contribution to late-season summer baseflows within the Augusta Creek study area

\begin{tabular}{llll}
\hline Elevation range & Soil depthc & Contribution to \\
Meters & Aspects & & \\
$<1000$ & & & \\
$<1000$ & SW, S, SE & Shallow & Low \\
$<1000$ & E, W & Shallow & Low \\
$<1000$ & NW, N, NE & Shallow & Moderate \\
$<1000$ & SW, S, SE & Deep & Low \\
$<1000$ & E, W & Deep & Moderate \\
$1000-1400$ & NW, N, NE & Deep & Moderate \\
$1000-1400$ & SW, S, SE & Shallow & Low \\
$1000-1400$ & E, W & Shallow & Moderate \\
$1000-1400$ & NW, N, NE & Shallow & Moderate \\
$1000-1400$ & SW, S, SE & Deep & Moderate \\
$1000-1400$ & E, W & Deep & Moderate \\
$>1400$ & NW, N, NE & Deep & High \\
$>1400$ & SW, S, SE & Shallow & Low \\
$>1400$ & E, W & Shallow & Moderate \\
$>1400$ & NW, N, NE & Shallow & High \\
$>1400$ & SW, S, SE & Deep & Moderate \\
$>1400$ & E, W & Deep & High \\
\hline & NW, N, NE & Deep & High \\
\hline
\end{tabular}

a Elevation ranges define 3 zones of increasing snow accumulation with increasing elevation.

$b$ Aspects were used in combination with elevation zones to define 3 levels of potential snow melt during rain-on-snow events.

c 2 soil depth classes were assumed to correlate with potential ground water storage.

Landslide occurrence was mapped from a time series of aerial photographs (1959, 1967, 1979, and 1990) for the Augusta Creek watershed portion of the planning area. Each landslide was mapped on the photograph in which it first appeared. Landslides recorded on the 1967, 1979, and 1990 photographs were those that occurred since the last photograph for that location. The location, size, and initiation type (i.e., clearcut, roads, forest) were identified for each landslide in each photographic series (see footnote 6).

Results-The map of landslide potential interpreted from the Willamette National Forest SRI shows broad areas in three general categories of risk (fig. 10). About onethird of the area was found to be in a relatively high risk category. 


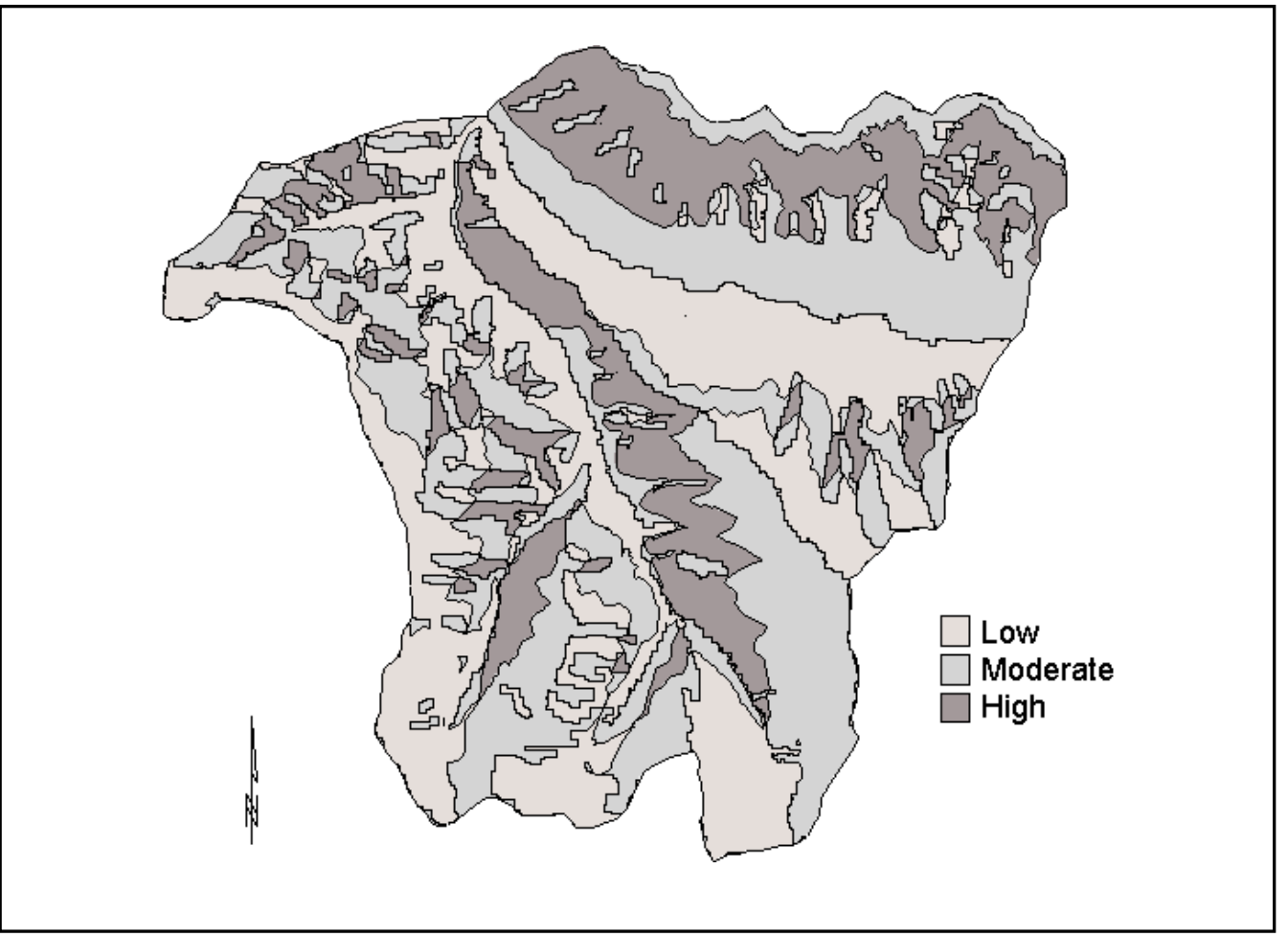

Figure 8-Potential rain-on-snow peak flow susceptibility.

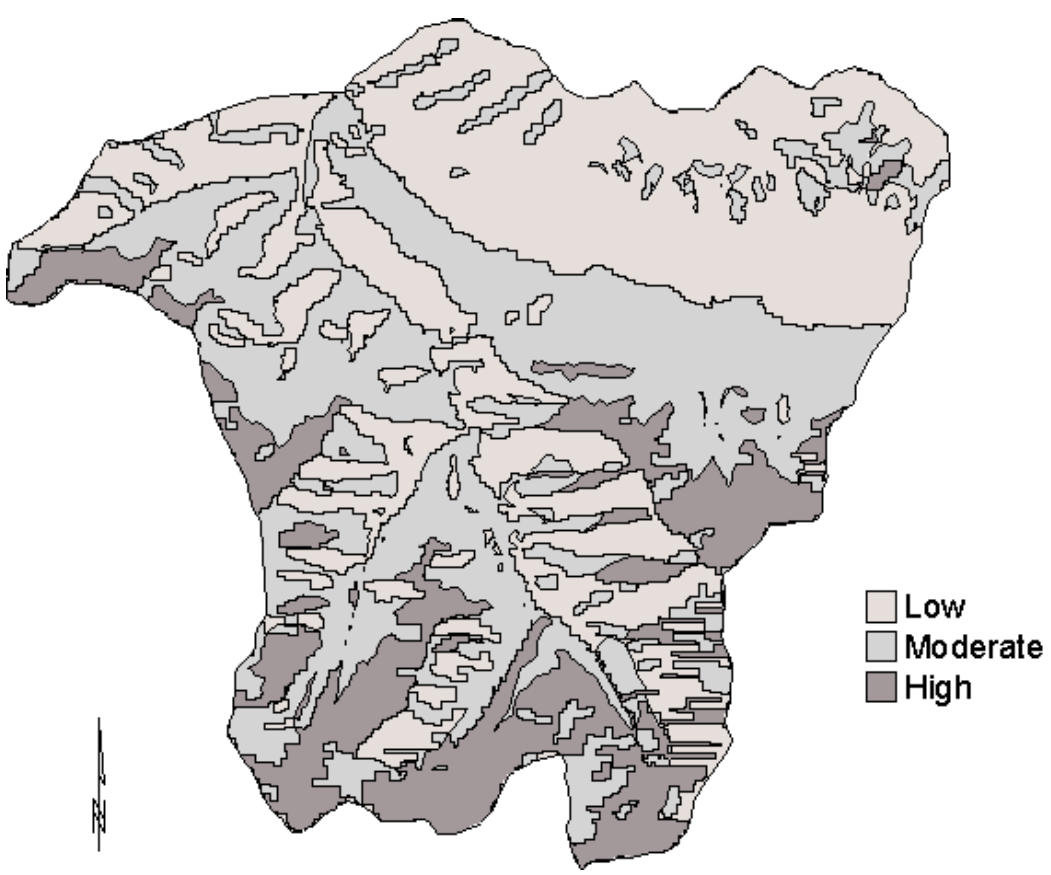

Figure 9-Potential contribution to summer baseflows. 


\section{Riparian Habitat and Fauna}

Seventy-three landslides were mapped from the time series of aerial photographs (fig. 11). Fifteen of these were evident in the 1959 photographs taken before forest cutting and road construction in the area. Sites of clearcutting and road construction accounted for an additional 41 landslides from 1967 to 1990; the remaining landslides occurred in undisturbed forest during the same period.

Most of the observed landslides occurred as small slides dispersed over the watershed. Two large areas of chronic landslides with a high potential for future landslides also were identified (fig. 11). These areas experienced mass movements before any road construction or timber harvest had occurred in the Augusta Creek area, and they continue to move periodically (see footnote 6).

Approach-Riparian forest canopy condition along perennial streams was mapped by using the same time series of aerial photographs used for the landslide assessment (see footnote 6). For each photo series, the riparian canopy was identified as either closed or open (Grant 1988). Closed-canopy reaches were further classified as either deciduous or coniferous, and open-canopy reaches were identified as nonvegetated, vegetated-deciduous, or vegetated-coniferous. Cause of canopy openings was mapped as clearcut, partial cut, road right-of-way, debris flow runout, streamside slide, blowdown, fire, or unknown. Each streambank was individually coded.

Riparian forest canopy conditions along intermittent streams were coded as either open or closed canopy from a GIS overlay of existing vegetative condition (fig. 5) with the stream network (see footnote 6 ). Intermittent streams were mapped from aerial photographs and contour maps and generally placed wherever contour crenulations occurred.

Stream research in the upper McKenzie River basin has identified the important ecological roles of large woody debris in streams (Harmon and others 1986, Lienkaemper and Swanson 1987, Swanson and Lienkaemper 1978). Consequently, woody debris delivery to streams is a useful index of effectiveness of management plans to sustain riparian habitat quality. Stream surveys for the mainstem of both Augusta Creek and South Fork McKenzie River described general amounts and distributions of wood in stream channels ${ }^{7}$ (also see footnote 1). For the remainder of the stream network, relations among riparian forest conditions and large woody debris in streams were established based on empirical studies in the nearby H.J. Andrews Experimental Forest (Harmon and others 1986, Lienkaemper and Swanson 1987, Swanson and Lienkaemper 1978). The existing vegetative condition map was electronically overlain with a riparian area map (defined as one tree height on each side of all streams for the purpose of this analysis) to yield area of riparian forest capable of delivering large wood to streams.

The geometry of the stream network influences the array of available habitats and the potential for postdisturbance recolonization by aquatic and riparian biota of sites affected by floods, debris flows, or timber cutting. We identified four general types of small-watershed systems (fig. 12):

${ }^{7}$ Heller, D.; Baker, C. 1974. An inventory of fisheries and habitat on selected forest streams. Eugene, OR: Willamette National Forest. 215 p. Administrative report. On file with: Willamette National Forest, Box 10607, Eugene, OR 97440. 


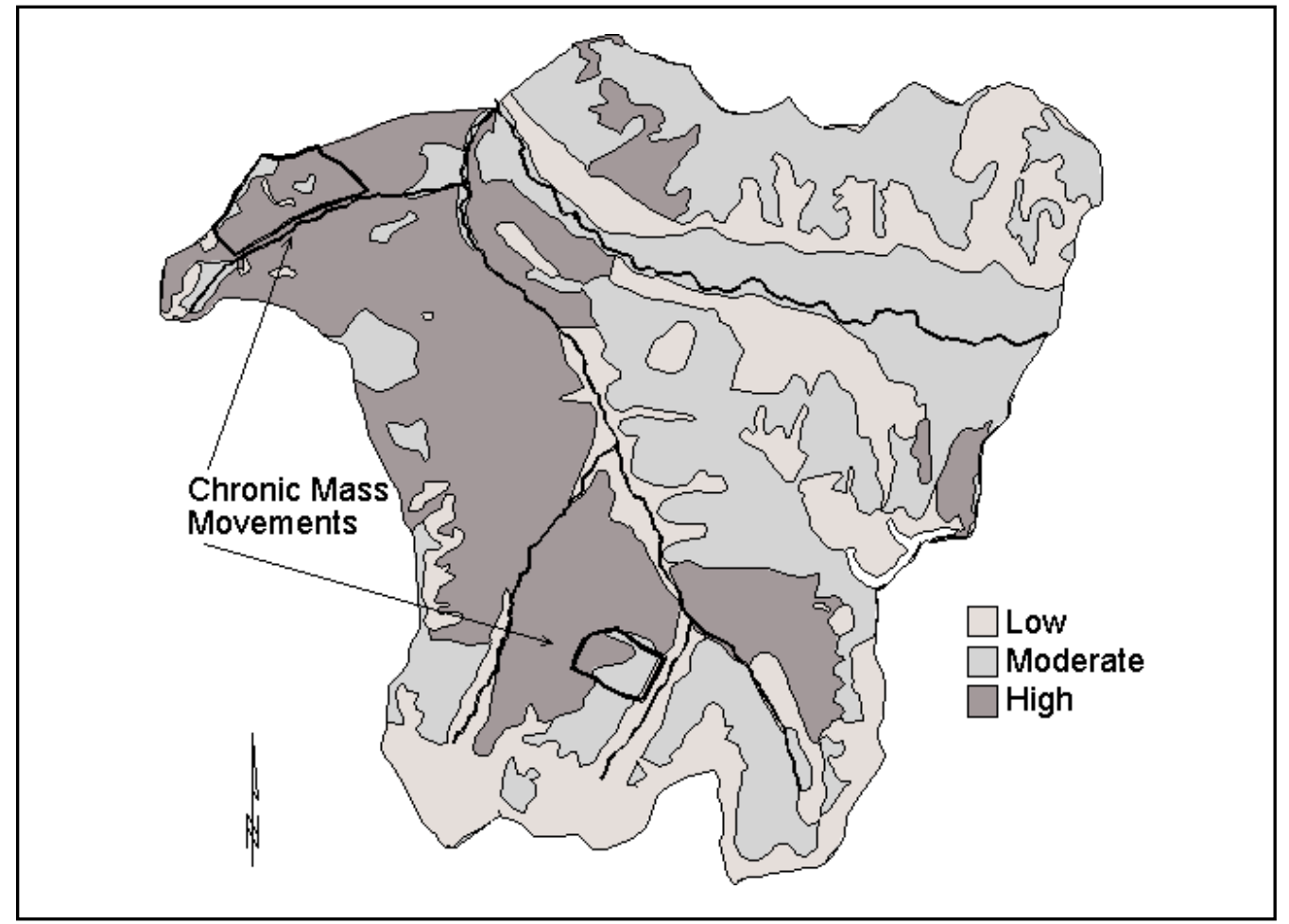

Figure 10-Landslide potential as interpreted from the Soil Resource Inventory.

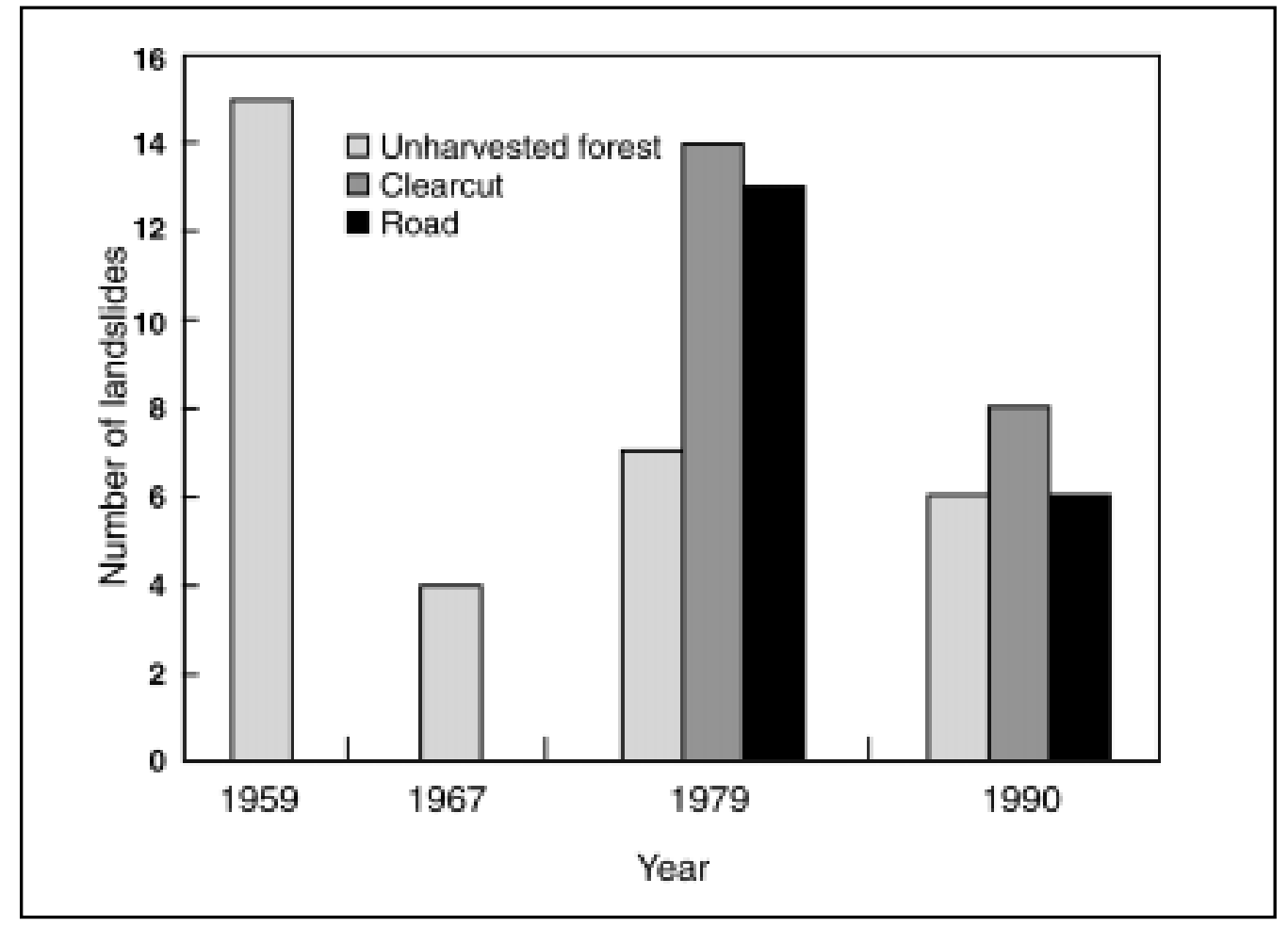

Figure 11-Landslide occurrence over time. 


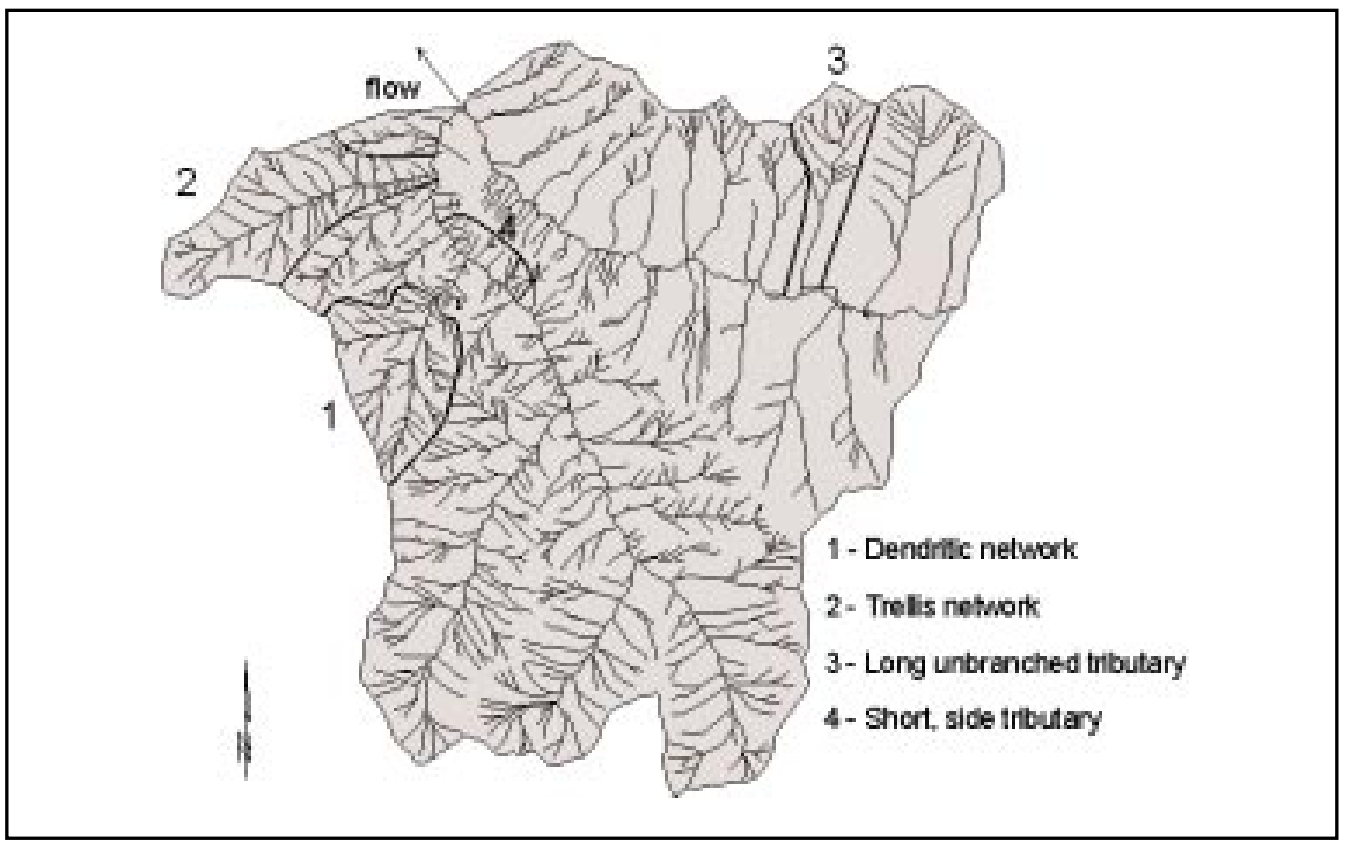

Figure 12-Stream network in the Augusta Creek project area.

1. Highly dendritic, complex networks.

2. Trellis networks.

3. Branched headwaters with long, straight channels downstream.

4. Short side tributaries.

The highly dendritic, complex networks were thought to have a greater range of habitats and more opportunities for postdisturbance recolonization than the other systems. The higher number and closer proximity of tributary junctions in these systems allows movement of organisms from nearby undisturbed streams into impacted stream reaches (e.g., debris-flows, fires, local flood damage) (Sedell and others 1990).

Patterns of faunal distribution were compiled from studies in the Augusta Creek drainage, the South Fork of the McKenzie River, and creeks in neighboring watersheds. For fauna not studied in this area, spatial distributions were estimated from known habitat associations elsewhere. For several reasons, our primary taxonomic focus was on fishes and amphibians. First, many stream habitat surveys have been conducted in this area, and there is a great deal of knowledge of the distributions and abundances of these aquatic-dependent fauna. Second, aquatic fauna are considered to be well protected by the Riparian Reserves in the Northwest Forest Plan. Third, amphibians are a diverse taxonomic group, using streams from headwaters to main-stem channels as well as terrestrial habitats from streamside to ridgelines. Protection of these aquatic-dependent vertebrates with diverse habitat requirements could be potential surrogates for other taxa, especially those associated with moisture and those using both riparian and upland terrestrial habitats. 
Fish distributions in the main stream channels were evaluated from habitat and distributional surveys over the last two decades. We relied on previous surveys from Augusta Creek (see footnotes 1 and 7) and from the South Fork McKenzie River ${ }^{8}$ to provide basic data for the main stream channels. Previous work conducted in Grasshopper Creek (a tributary of Augusta Creek) and other streams near Augusta Creek served as a basis for assessing invertebrate and fish distribution and abundance in response to riparian vegetation patterns and channel morphology (Hawkins and others 1982, Hawkins and others 1983, Murphy and others 1981, Wilzbach 1985, Wilzbach and others 1986). Data on ecological processes affecting aquatic fauna also were available from other nearby basins, including South Fork McKenzie, Horse Creek, Lookout Creek, Quartz Creek, and North Fork Quartz Creek. Studies examined both individual species or populations, including cutthroat trout (Oncorhynchus clarki) (Aho 1976; Moore and Gregory 1988a, 1988b; Murphy 1979; Wustenberg 1954; Wyatt 1959), speckled (Rhinichthys occulus) and longnose dace (R. cataractae) (Dodge 1993), and bull trout (Goetz 1994), as well as broader community or ecosystem responses to disturbances, including management practices (D'Angelo and others 1995, Gregory and others 1991, Lamberti and Gregory 1989, Lamberti and others 1991, Moore and Gregory 1989). Many of these surveys have incidental records of amphibian sitings or have incorporated amphibian data into the fish-based surveys. These data and known habitat associations for amphibians (e.g., Blaustein and others 1995, Leonard and others 1993) were used to assess spatial distributions of amphibians in the basin.

Results-Riparian forest canopy conditions have changed markedly over the period analyzed, as seen through data generated from aerial photographs (fig. 13). In general, the trend has been toward more open-canopy conditions over time (from 17 percent open in 1959 to 35 percent open in 1990). The trend differs, however, between lower and higher order streams. Lower order streams (orders 1 and 2) went from 11 percent open in 1959 to 32 percent open in 1990, primarily the result of clearcutting, and higher order streams (order 3+) moved from 70 percent open in 1959 to 56 percent open in 1990. Debris flows, streamside slides, and steep, ravelly slopes adjacent to some higher order streams contributed to open canopy conditions historically present in some reaches of the larger streams (see footnote 6).

The amounts and distribution of large woody debris in streams differs greatly across the planning area. About 23 percent of the riparian areas have been harvested for timber over the last 35 years (table 8 ) and currently lack large wood sources. About 59 percent of the riparian areas are in mature or old forest (table 8) that could supply an abundance of large wood in streams, but portions of these areas have been salvaged for timber products or have had large wood removed from the stream channel. Much of the large woody debris historically present in the South Fork McKenzie was salvaged during the 1960 s and 1970s. As a result, abundance of large wood within this section of the South Fork is significantly lower than would be expected in a similar undisturbed stream.

${ }^{8}$ Gregory, S.V.; Ashkenas L.R. 1991. Overview of basin surveys, Willamette

National Forest, 1988-1989. Corvallis, OR: Oregon State University. 46 p.

On file with: Blue River Ranger District, Willamette National Forest,

Blue River, OR 97413. 


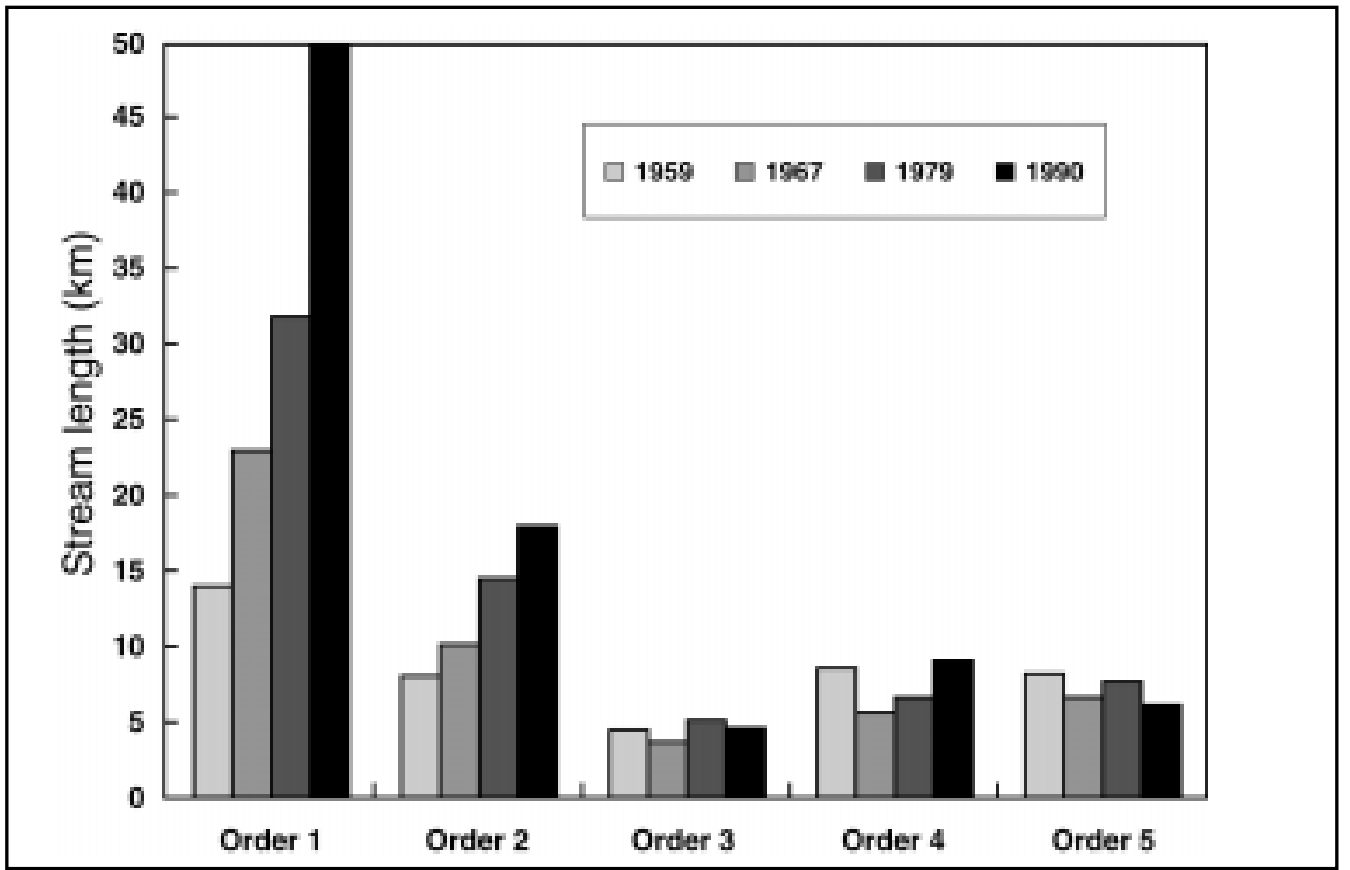

Figure 13-Open-canopy riparian forest over time in Augusta Creek.

Table 8-Existing distribution of stand structure classes in riparian areas within the Augusta Creek study area

\begin{tabular}{lrrrrrr}
\hline & \multicolumn{7}{c}{ Stream order } & \\
\cline { 2 - 5 } Stand structure class & 1 & 2 & 3 & 4 & 5 & Total \\
\hline & & & Hectares & & \\
Early: & & & & & & \\
$\quad$ Light retention & 410 & 130 & 51 & 48 & 17 & 656 \\
$\quad$ Moderate to heavy retention & 0 & 0 & 0 & 0 & 0 & 0 \\
Young: & & & & & & \\
$\quad$ Light retention & 104 & 8 & 0 & 0 & 0 & 14 \\
$\quad$ Moderate to heavy retention & & & 38 & 5 & 14 & 201 \\
Mature: & 355 & 135 & 87 & 8 & 13 & 598 \\
$\quad$ Light retention & 0 & 0 & 0 & 0 & 0 & 0 \\
$\quad$ Moderate to heavy retention & 641 & 225 & 134 & 70 & 32 & 1102 \\
Old & 226 & 72 & 8 & 0 & 0 & 306 \\
Meadows and rocks & 1742 & 613 & 318 & 128 & 76 & 2877 \\
Totals & & & & & & \\
\hline
\end{tabular}


The streams of the Augusta Creek study area form a highly dissected network, with two main-stem fifth- to sixth-order streams (Augusta Creek and South Fork McKenzie River) and numerous subbasins (fig. 12). Field observations indicated that the stream map accurately represented the extent of the stream network over the basin as a whole but slightly underrepresented or overrepresented the true extent of intermittent streams in some areas. ${ }^{9}$ Two discrete patterns of stream networks are apparent between the main stem drainages: (1) the South Fork McKenzie basin is primarily comprised of subdrainages having multiple first- and second-order headwater streams flowing into the upper portions of long, straight second- and third-order reaches lacking tributary junctions; while (2) the Augusta Creek network is much more dendritic. The Loon Creek basin is an exception to this pattern, exhibiting a strong trellis pattern with numerous unbranched tributaries draining directly into Loon Creek.

The types of aquatic vertebrates present in the Augusta Creek area differ with stream size and position within the network. Species composition in Augusta Creek is probably similar to that found in the adjacent portion of the South Fork McKenzie, with exceptions as noted. The lower portion of Augusta Creek contains both cutthroat and rainbow trout (O. mykiss) (see footnotes 1 and 7 ). Cutthroat extend higher in the drainage than any other fish species and likely occur in all second-order or larger streams with gradients of less than 15 percent. The adjacent section of South Fork McKenzie also has bull trout and mountain whitefish (Prosopium williamsoni). Both species conceivably could use the lower end of Augusta Creek but have not been observed in those reaches. Before installation of Cougar Dam, both areas also provided spawning and rearing habitat for chinook salmon (O. tshawytscha) and potentially could do so again if fish passage around the dam is established.

Nonsalmonid fish species have never been sampled in the Augusta area. It is probable that both speckled and longnose dace are found in the mainstem of Augusta Creek, up to the Grasshopper Creek confluence. Sculpin species most likely to be found include Cottus beldingi, C. bairdi, C. confusus and C. rhotheus. Cottus bairdi and $C$. rhotheus likely are limited to the lower portion of the drainage, but the other two species could continue upstream in reaches with gradients less than 5 to 10 percent.

Among all aquatic vertebrates, the Pacific giant salamander (Dicamptodon tenebrosus) is probably the most abundant vertebrate predator in the Augusta drainage in terms of biomass. It is found in headwater streams above the distribution limits of fish and comprises 10 to 90 percent of the vertebrate biomass in stream reaches containing trout and other fish species (Hawkins and others 1983, Murphy and others 1981). It most likely is found in all perennial streams. Additionally, tailed frog (Ascaphus truei) tadpoles are common in sections of Grasshopper Creek and could be expected in similar areas.

Although Pacific giant salamanders and tailed frogs are considered stream-dependent species, they have terrestrial life history stages and can be found in upland habitats. In contrast, Cascade torrent salamanders (Rhyacotriton cascadae) are more restricted to aquatic habitat. They are found in small streams, seeps, and headwaters with cool, clear water, below about 1220 meters $(4,000 \mathrm{ft})$ in elevation (Blaustein and

\footnotetext{
${ }^{9}$ Personal communication. 1993. M.D. McSwain, hydrologist, Blue River Ranger District, Willamette National Forest, P.O. Box 199, Blue River, OR 97413.
} 


\section{Human Uses}

others 1995) and should occur in the watershed. Several other amphibians are anticipated to occur within the watershed and may be found along streams, in riparian zones, and in upland areas.

Approach-A narrative description of general human use patterns from 11,000 B.C. to 1940 A.D. was prepared from available literature and the archaeological record in the central western Oregon Cascade Range. ${ }^{10}$ Willamette National Forest cultural resource inventory report files, maps, and databases were used to identify archaeological sites within the Augusta Creek area that were found previously through standard field inventories. Potential explanatory features were examined for each of these archaeological sites and used to construct a probability map of potential undiscovered sites within the Augusta Creek area. Variables examined included the proximity of water, meadows, travelways, and topographic features (landforms, elevation, aspect, and slope). A statistically valid model specific to this planning area could not be built owing to the low number of known sites (see footnote 10). Modern human uses in the Augusta Creek area were compiled and mapped by using Willamette National Forest maps, aerial photographs, and cultural artifact databases.

Results-Human use of the Augusta Creek area has been a longstanding and significant factor affecting landscape pattern. Human use most likely began about 13,000 years ago with possible visits by Paleoindian populations (see footnote 10). Little is known about these cultures, but it is believed that small family groups traveled widely along the west side of the Cascades in search of food and other subsistence items.

An 1851 map shows the Augusta area to be within the territory of the Santiam band of the Molala Tribe. Based on very limited Molala ethnographies, the area likely was used from late spring to fall for hunting and gathering by mobile, family based groups who wintered in the lower elevation river valleys (Beckman and others 1981).

Initial contacts between aboriginal populations and Euro-American explorers, fur trappers, and early pioneer settlers occurred in the early 19th century. The latter half of the 19th century was a time of major cultural change as the Euro-American settlers displaced native inhabitants. Settlers from the McKenzie River valley and groups from the Warm Springs Indian Reservation used areas such as Augusta Creek for hunting, fishing, and huckleberry (Vaccinium spp.) picking. The upper ridges in the Augusta area support numerous, productive meadows and huckleberry patches and were regularly used. These meadows were grazed extensively by sheep around the turn of the 20th century (see footnote 10).

Anecdotal evidence indicates that fire was used by both the Native Americans and sheepherders (Burke 1979, Coville 1898). Reported and suggested motivations include meadow and huckleberry maintenance, attracting or herding deer, roasting grasshoppers, and the sheer delight of watching a fire burn.

\footnotetext{
${ }^{10}$ McAllister, J. 1991. Cultural resource management planning report for the Augusta integrated resource analysis area. Eugene, OR: U.S. Department of Agriculture, Forest Service, Willamette National Forest. 22 p. Administrative report. On file with: Blue River Ranger District, Willamette National Forest, P.O. Box 199, Blue River, OR 97413.
} 
Phase 2Landscape Plan
The beginning of the 20th century ushered in an era of vigorous fire suppression, leading to construction of fire lookouts, access trails, and telephone lines within the Augusta area. Trails generally followed travel routes long established by the Indians (see footnote 10). The Civilian Conservation Corps built a lookout on Grasshopper Mountain, trails in the Augusta area, and small dispersed campgrounds along the South Fork of the McKenzie River during the 1930s.

Human use of the area expanded and intensified considerably in the post-World War II development era (fig. 14). Roads were built and large-scale forest cutting began in the 1950s. Recreational use of the area rose concurrently. There are now trail systems along Rebel Ridge (in the Three Sisters Wilderness), Chucksney Mountain, and Grasshopper Mountain. Dispersed and developed campsites are spread along the South Fork of the McKenzie River, which is eligible for status as a wild and scenic river owing to its scenic, recreation, fish, and cultural values. Angling is popular along the South Fork, and hunting occurs throughout much of the Augusta area. A road closure in the upper Augusta area during fall is intended to promote a highquality, nonmotorized big-game hunting experience. Other relatively low impact uses, such as berry picking, mushroom gathering, and beargrass harvesting, occur in localized areas at various times of the year.

The landscape planning phase followed three general steps:

1. "Special area reserves" allocated in the Willamette National Forest Plan, as amended by the Northwest Forest Plan, were delineated. We adopted the reserve boundaries and general management prescriptions in the Northwest Forest Plan for these areas.

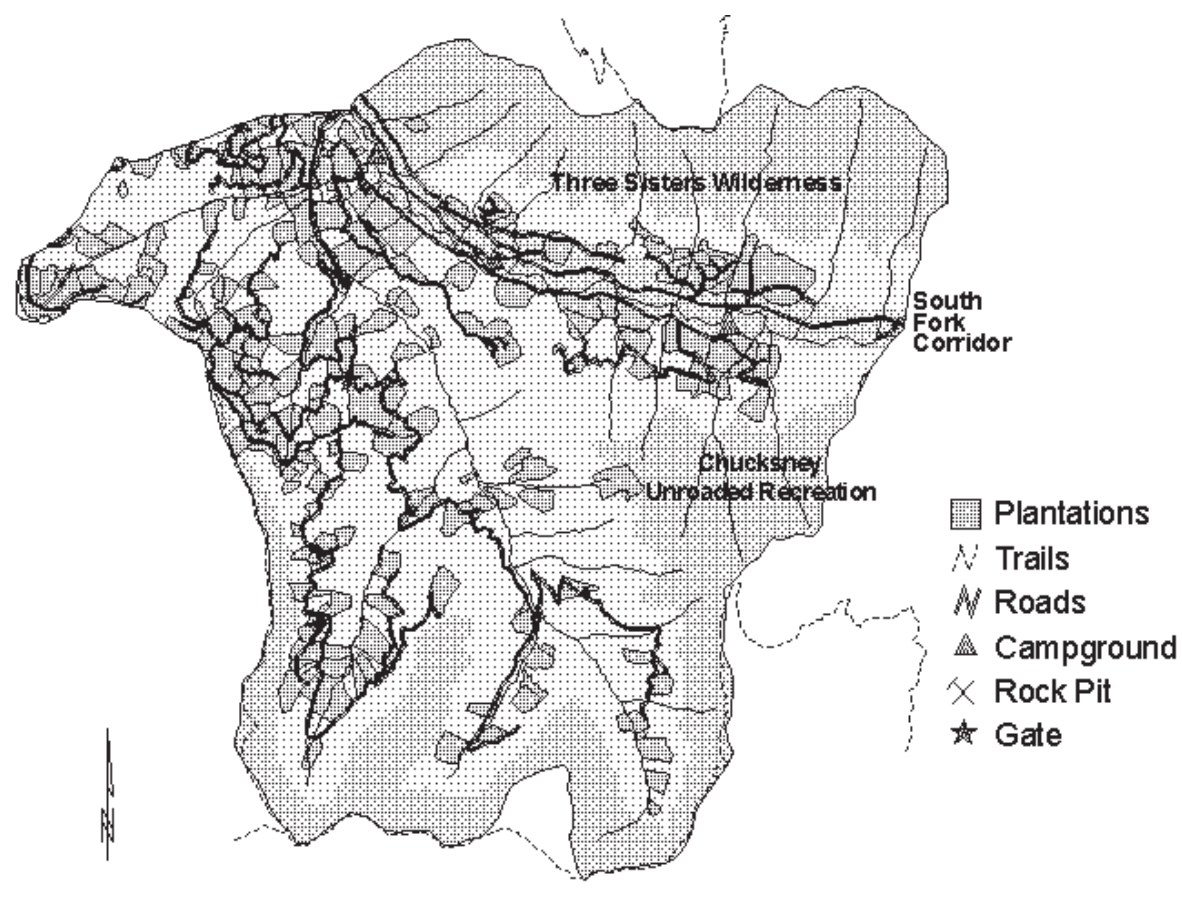

Figure 14-Existing human uses of the Augusta Creek area. 
2. The remainder of the planning area was subdivided into zones of similar ecological conditions and disturbance regimes. Prescriptions were developed for each zone based on the interpreted range of historical conditions. These zones were termed "landscape areas."

3. "Aquatic reserves" were established to ensure that the full range of objectives in the Northwest Forest Plan would be met, with particular attention given to the Aquatic Conservation Strategy (USDA and USDI 1994). These reserves were based, in part, on the type and intensity of upslope management in the local landscape area and were designed to reflect general patterns of disturbance processes.

The resulting set of allocations (fig. 15, table 9) provided the basis for specific landscape prescriptions (table 10). The decisions we made in steps two and three did not follow the decisionmaking processes required of the Forest Service for such decisions but were made for the purposes of this case study. We recognize that in actuality these decisions (e.g., establishing new management allocations) require formal decisionmaking processes and public involvement before adoption.

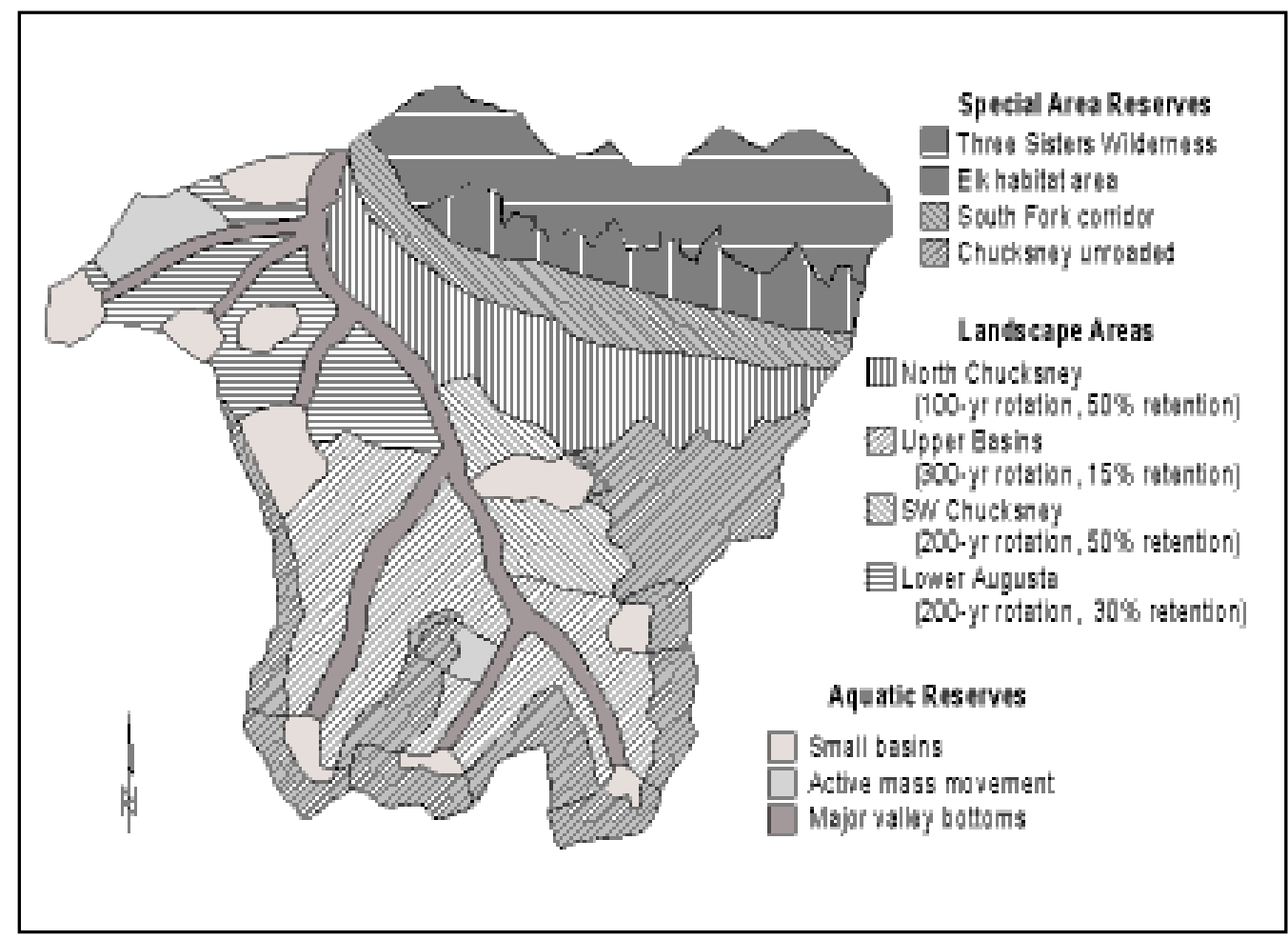

Figure 15-Management categories for the Augusta Creek Landscape Plan. 
Table 9-Management categories for the Augusta Creek Landscape Plan

\begin{tabular}{lr}
\hline Management category & Area \\
\hline & Hectares \\
Special area reserves & 3351 \\
Aquatic reserves & 1311 \\
North Chucksney 1 (100-year rotation, 50\% retention) & 890 \\
Lower Augusta 2 (200-year rotation, 30\% retention) & 632 \\
SW Chucksney 3 (200-year rotation, 50\% retention) & 323 \\
Upper Basins 4 (300-year rotation, 15\% retention) & 1130 \\
\hline
\end{tabular}

\section{Special Area Reserves}

\section{Landscape Areas}

Approach-We adopted the reserve boundaries and general management prescriptions for four special area reserves from the Willamette National Forest Plan, as amended by the Northwest Forest Plan. Areas with either legislated reserve status (e.g., the Three Sisters Wilderness), or established reserve status based on the unique characteristics of the place (e.g., an unroaded area with a trail system and established use patterns), were assumed to continue in a reserve status. The humanuse analyses were used to determine if historical patterns were accommodated by these reserve decisions. Guidelines for the frequency of low-severity fires, from either natural or human ignitions, were established based on information from the fire history analysis (see footnote 2).

Results-The four special area reserves encompass 3351 hectares $(8,281$ acres, or 44 percent of the area) and include a portion of the Three Sisters Wilderness, a corridor along the South Fork of the McKenzie River (a Federal Wild and Scenic Study River), a special wildlife Elk Habitat Area between the South Fork and the wilderness, and the Chucksney Mountain Unroaded Recreation Area (fig. 15). Historical human uses and current recreational uses of the planning area are concentrated within these four places.

Prescriptions for these four areas generally call for natural succession. Low-severity fires are to be reintroduced on a once-every-100-year cycle in the Three Sisters Wilderness and Chucksney Mountain Unroaded Recreation Area, where feasible. An additional related objective is to maintain the extensive dry meadow communities in the Chucksney Mountain area. For the past 75 years, fire suppression has effectively removed a primary agent of meadow maintenance, and the areal extent of these communities is shrinking over time as a result of conifer succession. Until fire can play a more natural role in the dynamics of these communities, active management may be required to retard conifer succession.

Approach-The remaining landscape was expected to provide some level of timber harvest while meeting a variety of additional ecological and social objectives (e.g., scenic views, riparian areas, and unique habitats). Four landscape areas were mapped, each having distinctly different ecological conditions and disturbance 
regimes. The fire regime map (fig. 4) was the primary basis for these delineations. To draw boundaries around landscape areas, fire regimes $D, G$, and $H$ were combined, as were fire regimes $\mathrm{C}$ and $\mathrm{E}$.

Table 10-General objectives for each management category in the Augusta Creek Landscape Plan

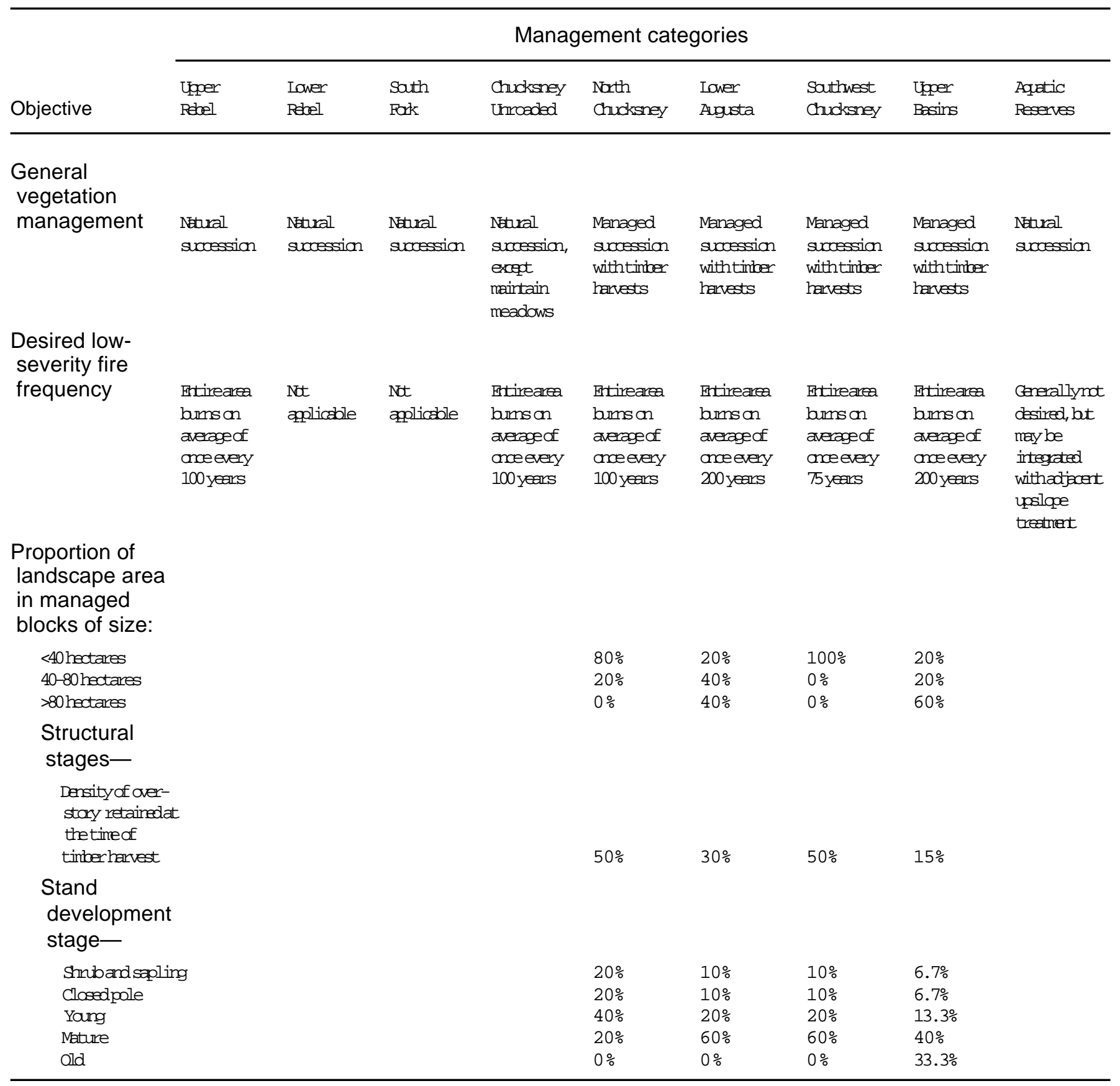


Prescriptions for each of these four landscape areas were drawn from an examination of the fire history, historical landscape structure, and the watershed process analyses described in phase 1 (see footnotes 2, 3, and 6, respectively). First, we matched parameters of timber harvest regimes with corresponding parameters of fire regimes. Timber harvest rates and rotation ages were linked to the frequency of stand- or partial stand-replacing fires for each landscape area. The amount of forest cover retained at the time of regeneration harvest was tied to the perceived severity of stand- or partial stand-replacing fires in each area. Spatial pattern objectives for each landscape area were developed from inspection of individual fire event sizes and from the pattern of patch sizes resulting from recurring fires over time within each area.

The correlation between the desired characteristics of future human-initiated disturbances with past disturbance regimes was general. For example, we tried to reflect the variability of patch sizes in the historical landscape and the tendency for some parts of the landscape to have smaller patches than others. The landscape plan calls for a range of created patch sizes across the landscape, with small patches emphasized in certain landscape areas and larger patches in others. We assumed, however, that it would be socially unacceptable to reflect the full range of historical conditions, which included some very large and intense fires.

Prescriptions were further developed based on results from the stand simulator ZELIG.PNW (Garman and others 1992, Urban 1993) to provide more details for silvicultural prescriptions and to evaluate the feasibility of these prescriptions. This model is capable of simulating stand dynamics over long rotations (200+ years) with varying levels of overstory retention. Variables considered in the analysis of prescriptions included reforestation composition and density, precommercial thinning density and residual composition, and commercial thinning timing and density. The ability of ZELIG.PNW to simulate stand development under previous, standard silvicultural prescriptions was first demonstrated by comparing model results with the Willamette National Forest stand projection tables. Sensitivity analyses identified prescriptions providing sustainable production of wood fiber volume over multiple rotations when starting with a mature stand.

The hydrologic analyses also were used to evaluate and adjust landscape prescriptions. Prescriptions set for areas of potential high susceptibility to rain-on-snow flood events or high contribution to late-summer baseflow were adjusted if necessary to ensure that these hydrologic processes would not be substantially affected by management activities.

General objectives were established for the occurrence of fire. Timber production objectives and continuation of a fire suppression policy significantly constrain the ability to maintain the historical roles of fire. Moderate- to high-severity fires were replaced in this management approach by the use of prescribed fire following timber harvest activities and by the anticipated occasional escaped fire. Objectives were established for low-severity fires, through either natural or human ignitions, based on fire frequency information from the fire history analysis (see footnote 2). The degree to which these practices simulate the historical roles of fire is largely unknown. 
Table 11-General silvicultural prescriptions for the Augusta Creek Landscape Plan

\begin{tabular}{|c|c|c|c|c|}
\hline \multirow[b]{2}{*}{$\begin{array}{l}\text { Prescription } \\
\text { elements }\end{array}$} & \multicolumn{4}{|c|}{ Landscape area } \\
\hline & $\begin{array}{l}\text { North } \\
\text { Chucksney }\end{array}$ & $\begin{array}{l}\text { Lower } \\
\text { Augusta }\end{array}$ & $\begin{array}{l}\text { Southwest } \\
\text { Chucksney }\end{array}$ & $\begin{array}{l}\text { Upper } \\
\text { Basins }\end{array}$ \\
\hline Rotation age (years) & 100 & 200 & 200 & 300 \\
\hline $\begin{array}{l}\text { Retention level } \\
\text { (\% volume retained) }\end{array}$ & 50 & 30 & 50 & 15 \\
\hline \multirow[t]{3}{*}{ Retention mixture $(\%)^{a}$} & DF-75 & DF-85 & DF-75 & DF-95 \\
\hline & WH-20 & $\mathrm{WH}-10$ & WH-20 & WH-3 \\
\hline & WRC-5 & WRC-5 & WRC-5 & WRC-2 \\
\hline $\begin{array}{l}\text { Reforestation density } \\
\text { (trees per hectare) }\end{array}$ & 500 & 750 & 500 & 1000 \\
\hline \multicolumn{5}{|l|}{ Reforestation mixture } \\
\hline$(\%)^{a}$ & $\mathrm{DF}-40$ & DF-60 & DF-40 & DF-75 \\
\hline & $\mathrm{WH}-40$ & WH-30 & WH-40 & WH-20 \\
\hline & WRC-20 & WRC-10 & WRC-20 & WRC-5 \\
\hline $\begin{array}{l}\text { First thinning } \\
\text { (trees per hectare) }\end{array}$ & 80 at year 12 to 15 & 80 at year 20 to 25 & 60 at year 20 to 25 & 80 at year 12 to 15 \\
\hline $\begin{array}{l}\text { Second thinning } \\
\text { (trees per hectare) }\end{array}$ & 40 at year 35 & 50 at year 40 & 50 at year 40 & 50 at year 40 \\
\hline $\begin{array}{l}\text { Third thinning } \\
\text { (trees per hectare) }\end{array}$ & 20 at year 65 & 30 at year 70 & 30 at year 70 & 30 at year 60 \\
\hline $\begin{array}{l}\text { Fourth thinning } \\
\text { (trees per hectare) }\end{array}$ & Not planned & 20 at year 100 & 20 at year 100 & 20 at year 100 \\
\hline $\begin{array}{l}\text { Low-severity fire (in ad- } \\
\text { dition to fuel treatments) }\end{array}$ & Not planned & $\begin{array}{l}\text { Once or twice } \\
\text { between years } \\
100 \text { and } 200\end{array}$ & $\begin{array}{l}\text { Twice between } \\
\text { years } 100 \text { and } 200\end{array}$ & $\begin{array}{l}\text { Once or twice } \\
\text { between years } \\
100 \text { and } 300\end{array}$ \\
\hline
\end{tabular}

a $\mathrm{DF}=$ Douglas-fir; $\mathrm{WH}=$ western hemlock; and $\mathrm{WRC}=$ western redcedar. 
This phase of the process was inherently subjective. Integration of the team's expertise and experience to form cohesive prescriptions required multiple iterations and active information exchange with many individuals. Numerous field trips by managers and scientists to the Augusta area and to the nearby Warner Creek fire area helped to refine concepts.

Results-Four landscape areas were delineated (fig. 15, table 9) that together occupy about 3000 hectares (7,348 acres, or 39 percent of the planning area). Prescriptions for timber harvest differed for the four areas (tables 10 and 11). Timber harvest rotation ages ranged from a low of 100 years (North Chucksney) to a high of 300 years (Upper Basins). Levels of live overstory trees retained at the time of regeneration harvest spanned a range from 15 percent (Upper Basins) to 50 percent (North Chucksney and Southwest Chucksney). Guidelines call for patch sizes created by cutting to range from mostly less than 40 hectares (100 acres; North Chucksney) to mostly 80 to 120 hectares (200 to 300 acres; Upper Basins).

The silvicultural prescriptions in table 11 were selected for each of the four landscape areas where timber harvest will occur based, in part, on simulation experiments with ZELIG.PNW. They have not been field-tested and should be regarded as tentative. The species mixture to be retained at the time of regeneration harvest differs with the level of retention. Higher levels of retention are associated with greater proportions of shade-tolerant species. Similarly, higher proportions of shade-tolerant species are prescribed in the reforestation mix in landscape areas with higher levels of retention. Lower densities of planted trees also are prescribed in areas of higher green-tree retention because of potential overstory-understory competition and higher densities of natural regeneration. The prescribed timing and density of thinnings differ slightly based on rotation ages and overstory retention levels.

Review of the hydrologic analyses led to one adjustment in landscape area prescriptions. Because of a potential for increased peak streamflows as the result of timber cutting activities in the Southwest Chucksney landscape area, desired created patch sizes were reduced and rotation ages lengthened to minimize the area in opencanopy condition.

Low-severity fires were prescribed when stands reach ages older than 100 years for all but the North Chucksney area, where the rotation age is 100 years (table 10). Prescribed fire was delayed until after year 100 to allow for the completion of silvicultural activities prescribed relatively early in the life of a stand, such as commercial thinning. Also, dominant trees become relatively fire resistant after age 100.

The following sections provide additional details of the landscape plan.

Spatial pattern of retention trees-These guidelines are intended to help translate spatial objectives for overstory retention from the landscape level to the stand level and to provide a basis for evaluation of the landscape plan. The intent is to create a variable pattern of retention trees within landscape blocks. Final placement of retention trees should integrate these criteria and fit on-the-ground conditions assessed at the time of site-specific timber harvest planning. To the degree allowed by the need to protect ecological values, spatial patterns of retention trees should use site-specific disturbance patterns as a general template. Criteria for placement are as follows: 
- Retention trees should be both clumped and scattered individuals. Clumps should range in size from 0.1 to 8 hectares ( 0.25 to 20 acres). Larger blocks should have larger clumps. Scattered individual trees can range from 40 to 70 percent of the total retention trees.

- Higher levels of retention should be located near streams and lower slope positions.

- Retention trees should be placed on sites of potentially unstable ground to the degree needed to minimize mass movement risks, as determined by on-theground assessment.

- No trees should be cut along any streambank, and trees should not be cut that directly contribute to streambank stability.

- Rock outcrops, wet areas, or other special or unique habitats needing protection from harvest and silvicultural activities should be used to anchor retention clumps.

- Spatial patterns should consider the structure and timing of future cutting in adjacent blocks and minimize edge contrast if feasible.

- Retention trees generally should include the largest, oldest live trees, decadent or leaning trees, open-grown trees, and hard snags.

- Scattered retention trees generally should be left in the larger tree size classes.

- If on-the-ground conditions indicate that higher levels of retention trees are needed to meet ecological objectives, prescriptions should be modified accordingly. Similarly, reductions in retention levels may be appropriate in some instances to improve operational feasibility, so long so ecological objectives are met.

Retention trees are intended to maintain a natural forest pattern and to integrate upslope and riparian management. Placement of retention trees along edges of cutting blocks should be designed to (1) minimize edge contrast, (2) avoid sharp boundaries with high windthrow potential or abrupt microclimate shifts, (3) emulate common postfire patterns, and (4) maintain nutrient uptake capacity across the hillslope down to the riparian zone.

Prescribed fire - In keeping with the objective of maintaining ecosystem processes, we included low-severity fire in landscape prescriptions at approximate mean historic frequencies. Goals for prescribed fire include:

- Kill a small proportion of overstory trees to create snags and future down wood.

- Reduce fuel loading and fuel ladders.

- Stimulate herb and shrub growth.

- Provide horizontal heterogeneity to understory habitats.

Because the fire history analysis was designed primarily to detect moderate- to highseverity events, these prescriptions should be regarded as first approximations. 
Low-severity fire was prescribed for some of the reserves (table 10). The intent was to reintroduce fire where operationally feasible and where there are no unacceptable risks to other values. Lack of road access may substantially increase costs of treatment and reduce options for fire ignition, holding and mop-up tactics. Low-severity fire in aquatic reserves would be appropriate for sites where fire has substantially influenced plant communities in the past and no significant risk to ecological processes or communities exists. Fire also may be appropriate in aquatic reserves to better integrate upslope and riparian habitats.

Low-severity fire also was prescribed in landscape areas where timber harvest is scheduled (table 11). The timing of prescribed fires differs depending on timber harvest scheduling. Fire may be prescribed in the near term where mature or old stands are not scheduled for cutting for several decades. Natural postfire processes then could occur for several decades before timber harvest. Where timber harvests occur in the near term, prescribed fire after timber removal can reduce logging slash where needed and restore fire to the site. As a part of the long-term prescription, lowto moderate-severity fires were prescribed to occur one or two times between age 100 and the timber harvest rotation age (100 to 300 years, depending on landscape area). Before year 100 , fires may cause high levels of mortality to overstory dominants and interfere with early stand silvicultural activities (e.g., precommercial and commercial thinnings).

Site-specific analysis will be needed to determine locations where fire can be prudently used. Stand conditions, fire history, wind patterns, potential fuel breaks, slope position, aspect, and elevation all have to be considered. We expect that some areas will not be suitable for prescribed fire for operational and safety reasons. In areas where timber management was prescribed, landscape blocks were intended as operational units and should provide a basis for site-specific planning for prescribed fire. Where feasible, the upper boundaries of a block were placed along ridgelines or roads to help establish safe firelines.

Inclusion of areas unsuited for timber harvest-Inclusions of small areas of land considered "unsuitable for timber harvest" (USDA 1990) occur in blocks where timber harvest is scheduled. For example, rocky shallow soils and wet areas are scattered throughout the landscape. In many cases, fires burned through these areas in a similar fashion as in adjacent forests and have historically been important in shaping plant community dynamics. Absence of disturbance has resulted in development of closed-canopy forests in some areas where more open conditions were common in the past.

Managed disturbances may be appropriate in these areas in conjunction with scheduled timber harvests or prescribed fire. Site-specific analysis should be conducted to ensure that negative effects on rare species will not occur and that unwanted exotic species will not invade. Risks at the site level should be balanced against larger scale goals and conditions. Potential treatments for these areas include prescribed lowseverity fire or felling of trees to open up the canopy and leaving the trees on the ground. The overall intent is to integrate these areas with surrounding lands and create natural environmental gradients and conditions similar to those created with historical disturbance regimes. 
Response to unplanned disturbances-Changes in future conditions undoubtedly will occur through unplanned disturbances. Small-scale disturbances (e.g., small pockets of windthrow, insect-induced mortality, or small fires) create additional diversity and generally should be viewed as biologically desirable. Changes in the overall schedule of activities generally would not be necessary, and salvage logging of these small patches of mortality generally should be avoided.

Large-scale disturbances should trigger reevaluation of landscape objectives and projected management activities. Even though long-term landscape and watershed objectives likely still would be applicable, changes in short-term plans may be appropriate. For example, a large, severe fire may produce early seral conditions over a significant proportion of the planning area. An appropriate response might be to reschedule timber cutting to delay further regeneration harvests of live forest until the postfire stands have closed their canopies. Salvage logging of an area of timber approximately equal to that scheduled to be removed over that period may be appropriate in this instance to maintain the scheduled flow of timber.

Our recommended management response to disturbance depends on current conditions and knowledge and should include consideration of these factors:

- Location of disturbance in the area: If reserves burned, for example, the landscape blocks might need to be reconfigured to provide new reserves; or if fire occurred in landscape areas where timber harvest was planned, it might be desirable to redraw blocks to better align block boundaries with new, postdisturbance edges.

- Timing of disturbance relative to the block schedule: For example, if a fire occurred relatively close in time to a block being scheduled for timber harvest, the block could be salvaged as a substitute for its scheduled cutting. If timber harvest is not scheduled for many decades, though, it may be appropriate to leave the block unsalvaged.

- Extent of disturbance: For example, small areas of blowdown might be considered a biological bonus adding diversity to the landscape. Large areas of blowdown might trigger a reevaluation of block configuration and scheduling.

- Condition of surrounding watersheds: Burned patches, for example, may serve particularly important ecological roles if they are the only patches of high snag densities in the entire watershed.

Ecological functions of dead wood need to be considered if salvage for timber values is contemplated. Relative to natural conditions, the low levels of snags, and especially the lack of high-density snag patches, is a key element characterizing managed landscapes. Leaving mortality patches unsalvaged and maintaining the overall block harvesting schedule may be the most appropriate response to unplanned disturbance in many cases.

Aquatic Reserves

Approach-Aquatic reserves were established to ensure that aquatic habitats and processes were protected and that management for aquatic features was integrated with upslope management. The pattern of aquatic reserves was based on the likely frequency, intensity, and spatial pattern of future timber harvests; the context of the surrounding watershed; and the degree to which the landscape has been altered by 
past, intensive human use (e.g., dams, roads, timber cutting). The general strategy followed from our basic assumption that the more the resulting landscape resembled the historical or "natural" landscape, the higher the likelihood of retaining native species and ecological functions. We therefore avoided the historically unprecedented, stringerlike patterns created by riparian buffers on every stream and provided more contiguous reserves that protect entire small watersheds strategically dispersed across the watershed. Fewer reserves were needed where the Augusta area is bounded by wilderness, but more were required where the basin is surrounded by lands heavily impacted by past human uses.

Aquatic reserves are generally comprised of entire small subdrainages (40 to 120 hectares [100 to 300 acres]). They are intended to provide long-term maintenance of ecosystem function (e.g., flow regimes, water quality, wood delivery, food inputs) and aquatic biodiversity (e.g., aquatic plants, invertebrates, amphibians, and fish). Species requiring both riparian and upland interior, closed-forest habitat benefit from these reserves. Reserves also provide potential sources for recolonization of biota after natural or human-caused disturbances. Recolonization pathways along streams and over ridgetops are incorporated into the aquatic reserve network.

Aquatic reserves were positioned throughout the landscape to provide a range of habitat types, topographic settings, and disturbance regimes representative of headwater, middle, and lower portions of the drainage. Their locations incorporated local topography and drainage patterns to take advantage of areas with high ecological value and biological diversity. Areas of high stream density with a dendritic aquatic network of first-order streams and portions of second- and third-order streams were intended to provide a wide range of aquatic habitats for amphibians, invertebrates, and fish. Tributary junctions have inherently heterogeneous habitats and diverse biota, ${ }^{11}$ and thus were incorporated into reserves. In addition, reserves were established in headwall areas thought to be important for some sensitive species, such as the Cascade torrent salamander. Steep, unstable areas with a simple drainage pattern that have potentially long debris-flow runout distances were placed in reserves, as were two areas of chronic mass movement. Protection of these areas reduces the risks of human disturbances on naturally unstable slopes. This system of reserves includes habitat for most of the known aquatic species within the basin and known patches of unique habitat or biota.

Aquatic reserves also took the form of large riparian corridors along both sides of all major streams. These areas appeared to have maintained older forests through many past fire events. The corridor reserves were essentially linear and occupy the entire valley bottom and adjacent toeslopes. These corridors connect aquatic and riparian areas throughout the basin, link with the small watershed reserves, and include most fish-bearing streams in the area.

Results-Aquatic reserves (fig. 15) were established in the form of small watersheds (570 hectares [1,410 acres]; 7.5 percent of the area), chronic mass-movement areas (164 hectares [405 acres]; 2 percent of the area), and riparian corridors on valley

\footnotetext{
${ }^{11}$ Olson, D.H.; Applegarth, J.; Bury, R.B. [and others]. Management recommendations for survey and manage amphibians in Pacific Northwest Federal forests. Manuscript in preparation.
} 


\section{Phase 3- Projection of Future Conditions}

\section{Landscape Blocks}

bottoms along large streams (577 hectares [1,425 acres]; 7.6 percent of the area). Many of the headwater basins are in the small watershed reserves, which are connected through the large valley-bottom corridors.

General prescriptions for these areas are to allow natural succession and avoid human-initiated disturbances. Low-severity fires may be prescribed in the smallwatershed reserves to reduce fuel loads and introduce diversity of understory conditions based on site-specific conditions. Fires should be avoided in the chronic massmovement reserves. Low-severity fires may be allowed in portions of the valleybottom reserves if implemented as part of a prescription for adjacent upslope lands.

In phase 3, we developed a spatially and temporally specific portrayal of the landscape plan created in phase 2. Our purposes were to:

1. Test the feasibility of the landscape plan.

2. Provide an explicit basis for evaluation of future landscape conditions.

3. Link landscape objectives to future project-level activities.

We first delineated management blocks, termed "landscape blocks," in the four landscape areas where future timber harvest is prescribed; we then used these blocks as scheduling units to project future landscape conditions.

Approach-Landscape blocks are management units representing the spatial locations of future vegetation patches created and maintained through timber harvest, prescribed fire, and other vegetation management activities. The same general ageclass structure will prevail within a block after timber harvest, but the spatial patterning and composition may be quite variable. Objectives for individual landscape areas provided specific guidance for the range of landscape block sizes and for the spatial distribution of the blocks. Landscape blocks range in size from 20 to 150 hectares (49 to 370 acres) and may be further subdivided into operational units, such as cutting units, to implement management activities. Existing stand conditions may be quite variable within a block and range from very young plantations to old growth.

Landscape blocks were mapped according to the landscape objectives for block sizes and spatial distribution and the following mapping criteria, listed in order of decreasing priority:

1. Use existing large patches of a similar structural stage wherever possible. Rationale: Large patches with interior forest habitat are the most critical because they are hardest to establish and maintain.

2. Use ridges and streams for boundaries whenever feasible. Rationale: They are definable on the ground and are relevant to ecosystem processes and operational realities.

3. Delineate blocks stream to stream, rather than ridge to ridge, where applicable. Rationale: Spreads management effects over more than one basin, and increases the stability of riparian reserves by having a mature forest bordering riparian zones on at least one side. 


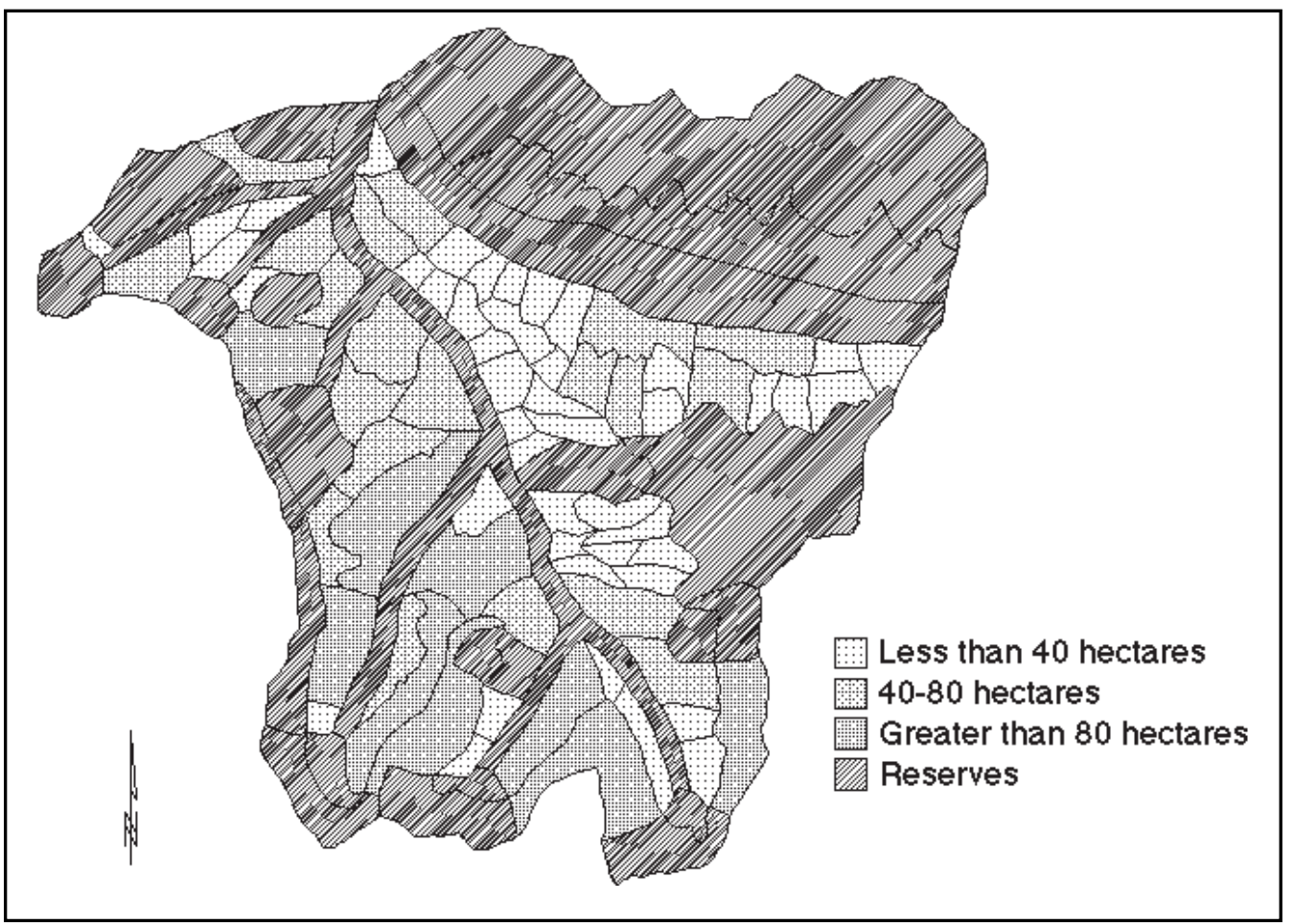

Figure 16-Landscape blocks for the Augusta Creek Landscape Plan.

4. Use roads as boundaries where feasible, if ridges and streams are not feasible. Rationale: Roads are definable on the ground and influence habitat conditions through edge effects.

5. Place smaller blocks in most visually sensitive areas. Rationale: Degree of perceived change in the landscape is less with smaller blocks.

Results-The map of landscape blocks (fig. 16) depicts a range of block sizes throughout the planning area. Each of the four landscape areas where timber harvest is prescribed contains a mix of large and small blocks, although the proportion of each differs significantly among areas (table 10). The Upper Basins area, for example, is dominated by large blocks with a few small blocks, but the North Chucksney area contains mostly small blocks with a few larger blocks. This variability and distribution of landscape blocks reflects the general pattern historically expressed across the landscape.

Future Landscape Conditions
Approach-Long-term projection of landscape conditions requires a method to account for forest growth and development and to schedule silvicultural actions. We adapted and simplified forest planning procedures for long-term analysis. We used landscape blocks as the basic land units for scheduling timber management actions. Landscape blocks were scheduled for cutting according to the cutting rate associated with the rotation age assigned to each landscape area and the following criteria: 
- Disperse cutting of landscape blocks so that adjacent blocks are not cut in consecutive periods. Rationale: Spatial pattern objectives are designed directly into the landscape block pattern itself.

- Delay cutting in blocks where stream surveys show channel and riparian conditions are in need of recovery (e.g., levels of shade or large wood are currently low as a result of past cutting or road construction practices). Rationale: Recovery of stream ecosystem functions will proceed most rapidly in these areas if additional disturbance is minimized in the short term.

- Schedule initial cuttings in blocks that are currently the most fragmented. Rationale: Retains existing large blocks for the maximum potential time, and establishes the desired landscape pattern most quickly by creating larger blocks where fragmented conditions currently exist.

- Delay cutting of a landscape block that is adjacent to blocks containing large openings. Rationale: Because spatial pattern objectives are designed directly into the landscape block pattern itself, cutting a block next to existing openings would create an opening larger than the landscape objectives call for.

- Schedule block harvests so that the mix of block sizes cut in any period is directly proportional to the desired mix of block sizes within that landscape area. Rationale: Ensures that the desired range of block sizes is present at all times.

We selected 20 years as the length of time in each period for the scheduling analysis. We assumed that when a timber harvest, prescribed fire, or silvicultural activity is scheduled to occur in a landscape block, it will be completed within 20 years. Several factors were considered in selecting 20 years for the period length. Habitat objectives are generally better met if an entire landscape block is treated within a relatively short time to minimize the period over which disturbance occurs. Potential problems may arise, however, if large blocks are cut within a short time. People may judge the visual appearance unacceptable. Detrimental effects to soil, water, riparian, and fish resources can potentially result when cutting occurs rapidly over a large area. This concern was partly obviated by the levels of canopy retention planned within landscape blocks (table 10) and the placement of landscape blocks so that they frequently span multiple drainages and run stream to stream. The exact timing of cutting within landscape blocks will be determined by individual landscape block at the project level.

The block scheduling was performed by hand. Following the criteria listed above, a set of blocks was selected for the first period (1995 to 2014 A.D.) and the results checked against the criteria. Then, a second set of blocks was selected for the second period (2015 to 2034 A.D.) and checked against the scheduling criteria, and so on for 20 periods (400 years). The complexity and judgment required to interpret the four criteria required several modifications and partial iterations to achieve a satisfactory pattern.

We used GIS to portray long-term landscape conditions. First, the landscape block map was coded according to the block schedule developed above, so that each landscape block was assigned a structural stage code for each of the 20 periods. Then, the existing stand conditions map was given a structural stage code as if it would grow without further harvest or disturbance (using the structural stage age 


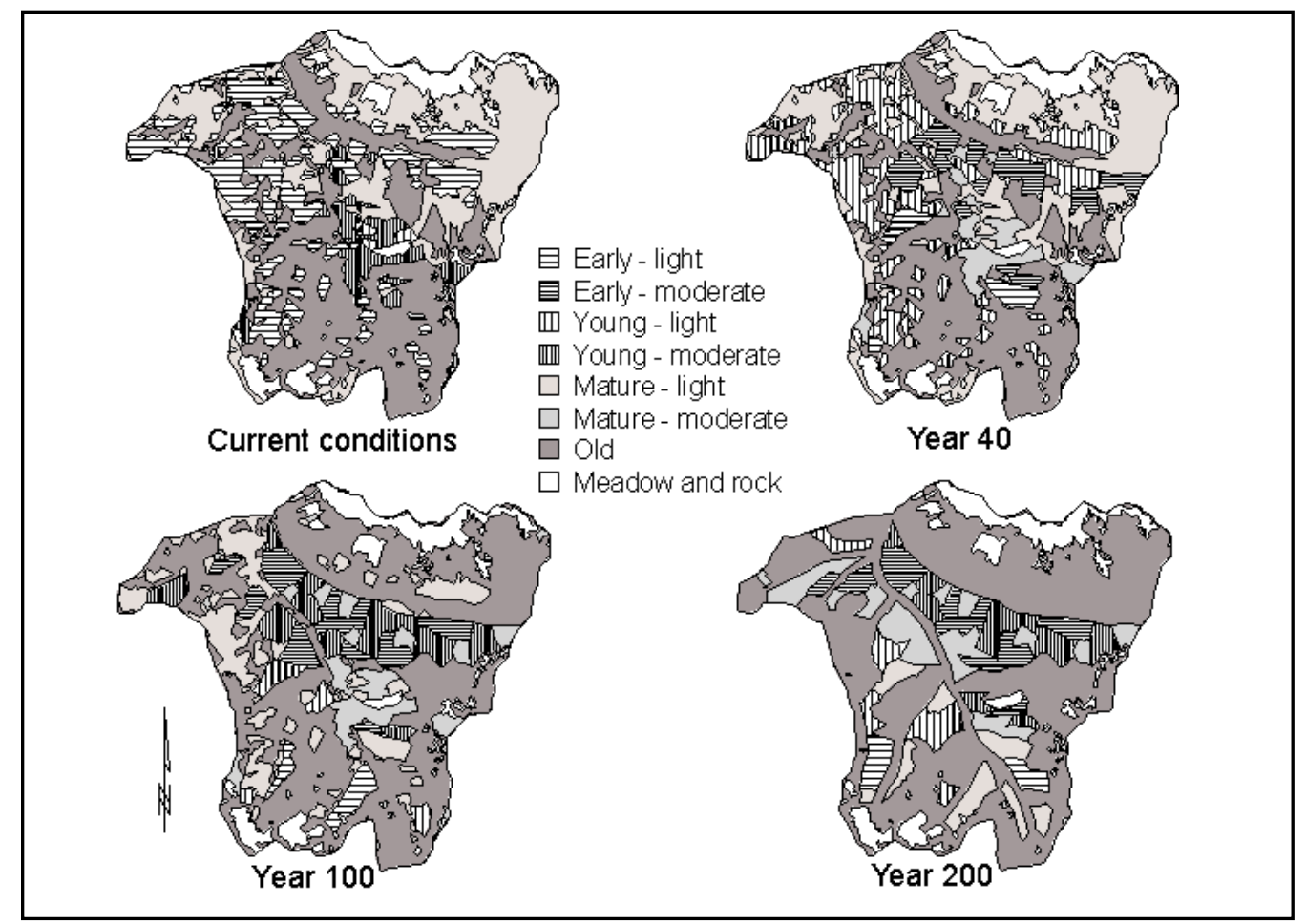

Figure 17-Future landscape conditions under the Augusta Creek Landscape Plan.

progression in table 4) for 20 periods. Then, the landscape block map was electronically overlaid with the current stand conditions map. Each resulting current stand and landscape block combination thus had two sets of attributes for all 20 periods. A relatively simple if-then algorithm was used to select an attribute for each period from either the current stand growth series or from the landscape block series, depending on whether the block had been previously selected for timber harvest. Once the first cutting for a given block was encountered in the landscape block series, the remainder of the periods were filled in from the landscape block attributes. Stands within reserves followed the structural stage progression throughout the planning horizon.

Results-Transformation of the current landscape toward the landscape envisioned in the landscape plan occurs at different rates within different landscape areas. This differs depending on the degree of past fragmentation and the rate and intensity of future cutting (fig. 17, table 10). The desired landscape pattern is mostly in place within 100 years and firmly established by year 200 . The projected pattern remains stable beyond year 200 as stands grow and landscape blocks are reset to early seral conditions through timber cutting at rates and intensities designed to achieve the landscape objectives.

No attempt was made to incorporate unplanned disturbances (e.g., windthrow, wildfire) into our projections. Clearly such events will occur in the future, some processes with lower frequency than in the natural state (e.g., the results of wildfire suppression), and perhaps other processes with higher frequency (e.g., increased windthrow associated with edges of cutting units, debris slides from roads). Analysis 


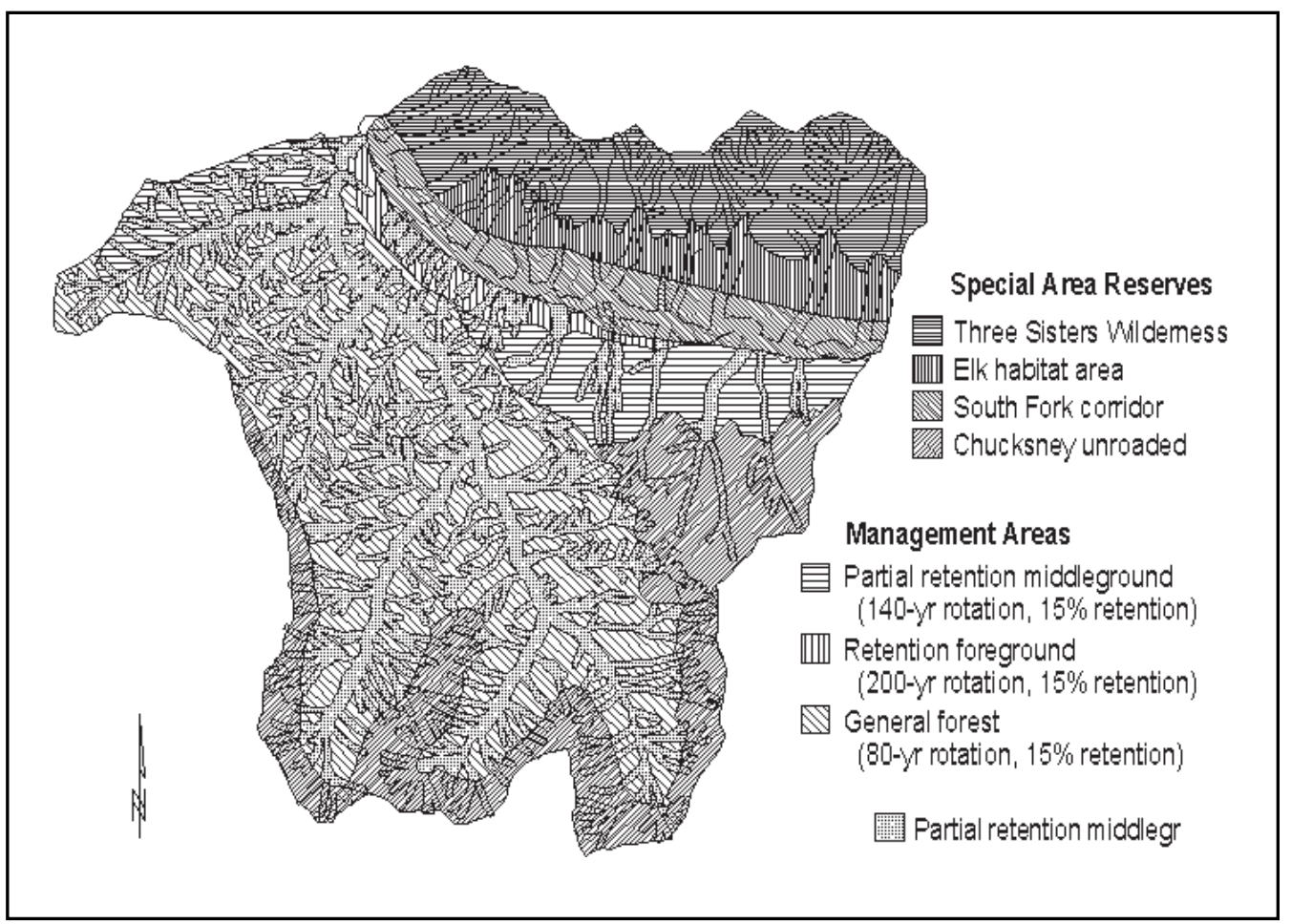

Figure 18-Management areas for the Augusta Creek Interim Plan.

of these factors is rather speculative and beyond the scope of this paper. It is clear, however, that such disturbances will interact with the human-engineered landscape pattern to create more temporal and spatial variability in landscape structure than projected in this analysis.

Phase 4Evaluation

Interim Plan
The Northwest Forest Plan (USDA and USDI 1994) established a set of land allocations and associated standards and guidelines to direct management activities. In addition, the Northwest Forest Plan mandates a watershed analysis process that may be used as a basis for modifying the plan through normal plan amendment procedures. We elected to evaluate the landscape plan described above by comparing it to the direction in the Northwest Forest Plan, unmodified by any plan amendments based on watershed analysis. This comparison should provide a reasonable basis to determine if plan amendments based on the results of watershed analysis would be desirable in the Augusta Creek area. For purposes of this comparison, we labeled these two management approaches the "Interim Plan" and the "Landscape Plan." The Landscape Plan is described in the previous sections (phases 1 through 3); the next section presents the key assumptions used for the Interim Plan.

For purposes of comparison, we projected future landscape conditions for the Interim Plan by using procedures similar to those used for the Landscape Plan.

Prescriptions-General prescriptions were derived from the allocations (fig. 18) and standards and guidelines in the Willamette National Forest Plan as amended by the Northwest Forest Plan. Assumptions from the Willamette National Forest timber harvest scheduling model also were applied. The following specific guidance was used as a basis for projecting future landscape conditions: 


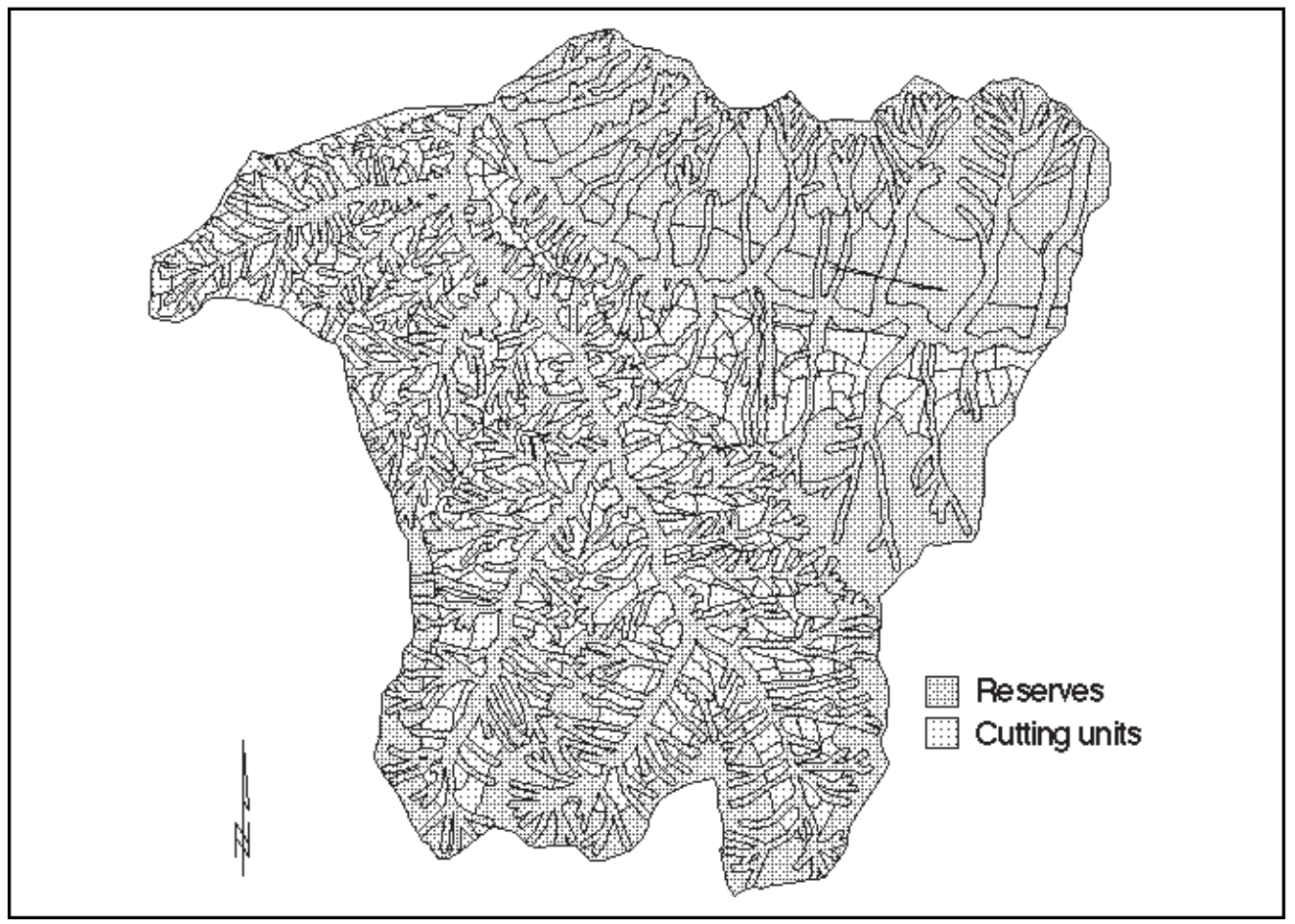

Figure 19-Cutting units for the Augusta Creek Interim Plan.

- Reserves from the Willamette National Forest Plan, as modified by the Northwest Forest Plan, were applied (fig. 18), except for spotted owl core area reserves. We did not include the spotted owl reserves in either scenario to prevent disclosure of owl pair locations.

- Riparian Reserve widths were either one or two tree heights distance from the stream, depending on stream flow and fish presence. We used a site potential tree height of 55 meters $(180 \mathrm{ft})$.

- No timber harvest was scheduled within Riparian Reserves.

- Within General Forest management areas, timber harvest was scheduled for an 80-year rotation with 15-percent retention of green trees at the time of regeneration harvest.

- Within Scenic-Partial Retention Middleground management areas, timber harvest was scheduled for a 140-year rotation with 15-percent retention of green trees at the time of regeneration harvest.

- Within Scenic-Retention Foreground management areas, timber harvest was scheduled for a 200-year rotation with 15-percent retention of green trees at the time of regeneration harvest.

Cutting unit delineation-Conventional approaches to timber harvest unit delineation do not work effectively in this area with the prescriptions in the Northwest Forest Plan. The combination of the existing landscape pattern, consisting of 2- to 20hectare (5- to 50-acre) plantations dispersed over the landscape in both riparian and 
upslope areas, and the extensive Riparian Reserve network results in a myriad of small stands eligible for timber harvest. The topographic setting of many of these stands makes logging operations difficult. We attempted to redraw future timber cutting units (fig. 19) with sizes similar to recent practices (2- to 20-hectare [5- to 50-acre] units) by using the following process:

1. We overlaid the existing timber cutting unit map and the stand age map from the Blue River Ranger District database with the interim Riparian Reserve map.

2. Within the zones between Riparian Reserves, stands with an age difference of less than 20 years were joined, and stands less than 0.4 hectare ( 1 acre) were merged with the most similar adjacent stand.

3. Within the zones between Riparian Reserves, future cutting unit boundaries were drawn; stand age boundaries were followed where stands were small enough to be treated as one cutting unit. In larger stands, cutting unit boundaries were drawn following the existing timber cutting unit map where feasible. Where cutting unit designations no longer made sense because of Riparian Reserves, cutting areas were redrawn to correspond with ridgelines and existing roads.

4. Minor adjustments were made in future cutting unit boundaries to yield a more operationally feasible set of cutting units.

This step is analogous to the landscape block delineation process for the Landscape Plan, as previously described (phase 3).

Future landscape condition-The future cutting unit map defined the spatial units used for long-term timber harvest scheduling. The prescriptions provided the rules governing the frequency and intensity of cutting and the resulting stand structures. A simple area control method was used to schedule timber harvests over time. In addition, the following criteria guided the actual selection of individual cutting units for each 20-year period:

\section{Within general forest management areas-}

1. Units designated for cutting were selected first from mature stands, then old, then young, and last from existing plantations.

2. Cutting units for a given time period were selected from the same zone between Riparian Reserves where the group of cutting units totaled less than 100 acres, and 80 percent or more of the group was composed of stand structures from the same or similar age classes. This rule was applied to minimize fragmentation created by this prescription. This rule was not applied to the southwest-facing slopes on Chucksney Ridge owing to concerns over the potential effects of large openings on peak stream flows.

3. On the southwest-facing slopes of Chucksney Ridge, cutting units were dispersed over time and space, as feasible.

4. The inter-Riparian Reserve blocks selected for cutting within a period were dispersed across the larger landscape in succeeding periods to achieve a mix of stand structures among differing elevations and aspects. 


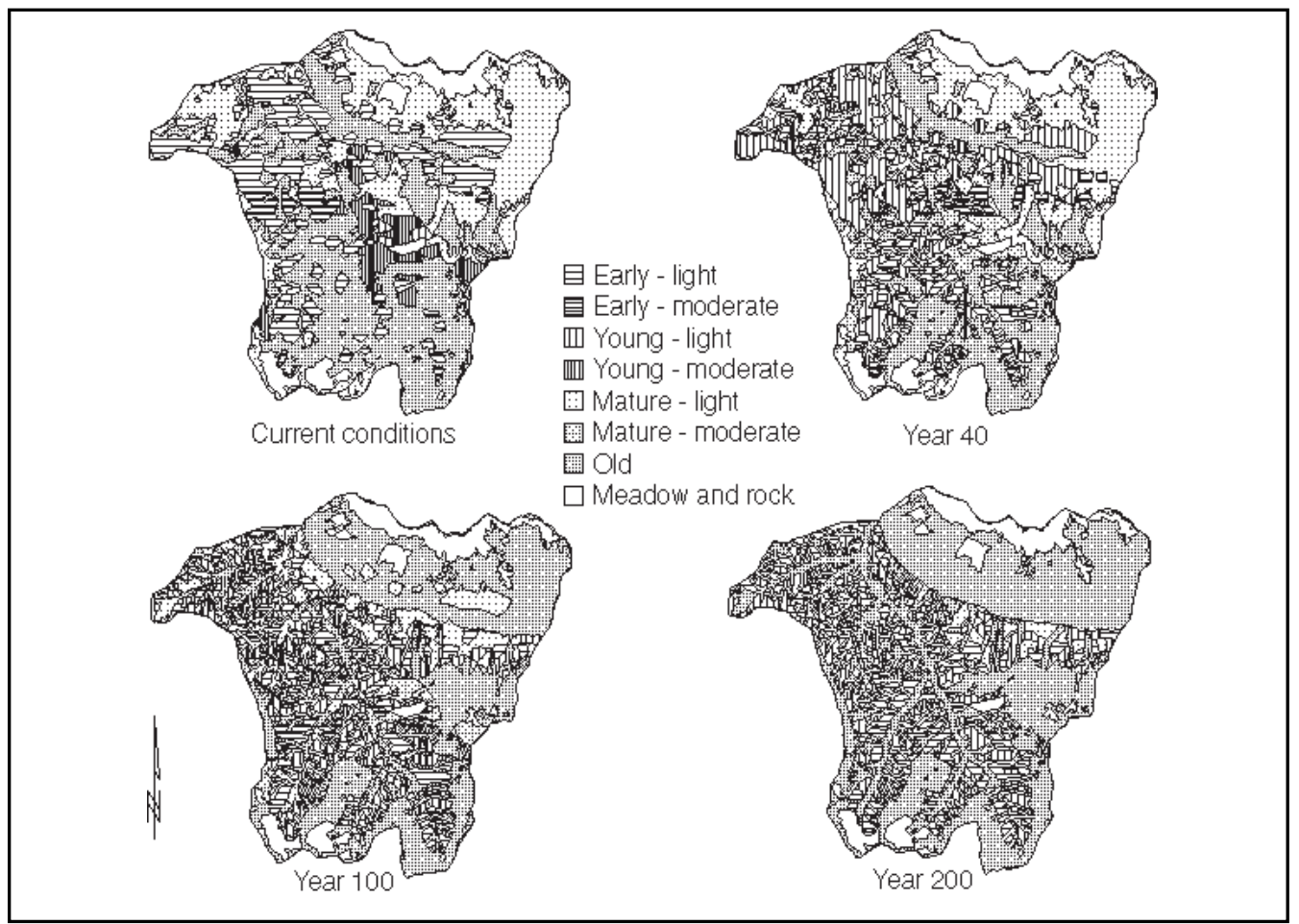

Figure 20-Future landscape conditions under the Augusta Creek Interim Plan.

\section{Within scenic management areas-}

1. Units were selected first from mature stands, then old, then young, and last from existing plantations.

2. Cutting units were dispersed over time and space, as feasible.

Figure 20 shows the resulting pattern of forest conditions. This step was analogous to the projection of future conditions step described for the Landscape Plan (phase 3).

\section{Comparison of Scenarios}

Assumptions-To simplify analyses, we made the following assumptions. Road systems were treated as identical for both scenarios. Fire suppression was assumed to be 100-percent effective, and other disturbance processes were assumed to not modify the projected landscape pattern, although we compared the likelihood of this. Prescribed fire, or other management practices, were assumed to be effective in maintaining the meadow component of the Augusta landscape. We did not account for the potential effects of long-term climatic change on our projections of stand dynamics and timber production over the 400-year planning horizon. Prescribed practices affecting endangered species require consultation with the U.S. Fish and Wildlife Service before implementation.

Evaluation factors-We compared the two scenarios by landscape structure (i.e., composition, shapes, sizes, and dispersion of different vegetative patches) and landscape function, specifically streamflows, soil mass-movement processes, habitat 
Landscape
Structure $^{12}$

for select taxa (amphibians, fish, birds with special emphasis on northern spotted owl, and mammals), timber supply, and operational feasibility. Results of this comparison are summarized in table 12 . We included in our analyses those ecological factors that have been extensively studied within similar watersheds or for which a general knowledge base exists. We did not consider all species of concern, such as many taxa on the survey and manage list (USDA and USDI 1994), because of limited knowledge of the habitat requirements and population demographics of many of these species. We expect that many of the conclusions we draw would be applicable to these taxa as well. The comparison of management scenarios is concluded with consideration of disturbance regimes involving natural processes (fire, wind, insects, and disease), which may interact with the managed landscape structure, changing landscape pattern from the intended design.

The forest landscape changes over time in response to timber harvest and the development of vegetation through structural stages. Stands were modeled as a function of two characteristics: age and the density of overstory trees retained at the time of stand regeneration. Total hectares in each structural stage over time are presented in table 13 for both plans.

Special Area Reserves (44 percent of the planning area) are common to both scenarios. In these reserves, stands progress toward old-forest conditions and are assumed to remain old forest through the modeling horizon. The remainder of this section compares conditions in the rest of the planning area.

The Interim Plan develops a distinct, high-contrast landscape composition within the remaining portion of the planning area (56 percent). Upper slopes within the General Forest management area (20 percent of the planning area) contain early ( 1 to 40 years) and young ( 41 to 80 years) stands with light retention (15 percent of the overstory). Timber harvest rates based on 80 -year rotations truncate the successional sequence before mature or old stands are allowed to develop. Minor amounts of mature stands (81 to 200 years) occur in the upper slopes of scenic management areas close to the South Fork of the McKenzie River (8 percent of the planning area) where rotation ages are 140 and 200 years. Lower slopes within Riparian Reserves (27 percent of the planning area) all grow into and remain in the old-growth stage (>200 years) over time. Forest stands with zero retention levels created during the last 35 years of clearcut timber harvest eventually disappear from the landscape and are not replaced in this scenario. The overall landscape is missing the higher retention-level, mixed-age stands found in this area over the past 500 years and develops a large gap in structural stages as a result of the low amount of mature age class ( 81 to 200 years; see table 13 ).

The Landscape Plan develops a more complex and varied landscape composition in the remaining portion (56 percent) of the planning area (table 13). The portion of the planning area where timber harvest was prescribed (39 percent) was further subdivided into four Landscape Areas, each developing a different mix of structural stages. The Upper Basin Landscape Area attains a mix of all age classes in response to a

${ }^{12}$ This section prepared by $\mathrm{J}$. Cissel. 
Table 12-Comparative summary of management prescriptions, patterns, and ecosystem responses of the Landscape Plan and the Interim Plan, Augusta Creek

\begin{tabular}{|c|c|c|}
\hline Management prescriptions and patterns & Interim Plan & Landscape Plan \\
\hline \multicolumn{3}{|l|}{ Landscape: } \\
\hline Percent of study area subject to cutting & 29 & 39 \\
\hline \multicolumn{3}{|l|}{$\begin{array}{l}\text { Percent of study area managed for } \\
\text { rotation ages- }\end{array}$} \\
\hline $\begin{array}{l}<100 \text { year } \\
100-200 \text { years }\end{array}$ & $\begin{array}{l}20 \\
8\end{array}$ & $\begin{array}{l}0 \\
24\end{array}$ \\
\hline$>200$ years & 0 & 15 \\
\hline Size range of cutting units (hectares) & $2-20$ & $2-120$ \\
\hline \multirow[t]{3}{*}{ Riparian reserves } & $\begin{array}{l}\text { No-cut reserves throughout } \\
\text { stream network }\end{array}$ & $\begin{array}{l}\text { Small watershed reserves in areas of } \\
\text { high biodiversity or landslide hazard }\end{array}$ \\
\hline & & Reserves along major valley bottoms \\
\hline & & $\begin{array}{l}\text { Some cutting in remaining riparian } \\
\text { areas-integrated with upslope } \\
\text { management }\end{array}$ \\
\hline \multicolumn{3}{|l|}{ Stand: } \\
\hline \multicolumn{3}{|l|}{$\begin{array}{l}\text { Live-tree overstory retention levels } \\
\text { (\% of canopy closure) }\end{array}$} \\
\hline \multicolumn{3}{|l|}{ Landscape pattern: } \\
\hline \multicolumn{3}{|l|}{ Stand edge density } \\
\hline \multicolumn{3}{|l|}{ Patch size at year 100 (number)- } \\
\hline $\begin{array}{l}<20 \text { hectare } \\
>60 \text { hectare }\end{array}$ & $\begin{array}{l}453 \\
11\end{array}$ & $\begin{array}{l}137 \\
24\end{array}$ \\
\hline \multicolumn{3}{|l|}{ Hydrology: } \\
\hline Peak flows & Little potential for increase & Little potential for increase \\
\hline Low flows & $\begin{array}{l}\text { Minor decrease in summer } \\
\text { low flows }\end{array}$ & No detectable change \\
\hline Annual streamflow & No detectable difference & No detectable difference \\
\hline Debris slides and flows & No detectable difference & No detectable difference \\
\hline \multirow[t]{5}{*}{ Amphibians } & $\begin{array}{l}\text { Aquatic networks and } \\
\text { associated species well } \\
\text { protected by Riparian } \\
\text { Reserve network }\end{array}$ & $\begin{array}{l}\text { Harvest impacts to species reduced } \\
\text { by large subdrainage reserve blocks } \\
\text { and widespread late-successional } \\
\text { forest }\end{array}$ \\
\hline & $\begin{array}{l}\text { Upslope habitats at risk for } \\
\text { some species }\end{array}$ & $\begin{array}{l}\text { Connectivity maintained between } \\
\text { upland areas of interior forest habitat } \\
\text { and streams, favoring terrestrial species }\end{array}$ \\
\hline & & Lower impacts of silvicultural practices \\
\hline & & $\begin{array}{l}\text { in uplands (higher levels of live-tree } \\
\text { retention) }\end{array}$ \\
\hline & & Greater diversity of riparian habitat \\
\hline
\end{tabular}




\section{Table 12 (continued)}

\begin{tabular}{|c|c|c|}
\hline Management prescriptions and patterns & Interim Plan & Landscape Plan \\
\hline \multirow[t]{3}{*}{ Fish and selected additional aquatic taxa } & $\begin{array}{l}\text { Aquatic networks and species } \\
\text { well protected by Riparian } \\
\text { Reserve network }\end{array}$ & $\begin{array}{l}\text { Long rotations allow significant } \\
\text { development of late-successional } \\
\text { forest in managed riparian areas }\end{array}$ \\
\hline & & $\begin{array}{l}\text { Higher light levels in selected stream } \\
\text { reaches benefit some species }\end{array}$ \\
\hline & & $\begin{array}{l}\text { More habitat for broader array of } \\
\text { species }\end{array}$ \\
\hline Birds and mammals & $\begin{array}{l}\text { More early seral habitat, } \\
\text { used by } 1 / 3 \text { of bird species; } \\
\text { more edge habitat }\end{array}$ & $\begin{array}{l}\text { Higher connectivity, within stand struct- } \\
\text { ural complexity, and amount of interior } \\
\text { mature and old-growth habitat poten- } \\
\text { tially increase persistence, refugia, dis- } \\
\text { persal, and colonization potential of } \\
\text { some species, particularly those asso- } \\
\text { ciated with late-successional forests }\end{array}$ \\
\hline \multicolumn{3}{|l|}{ Northern spotted owl: } \\
\hline $\begin{array}{l}\text { Territory habitat (number of the present } \\
10 \text { activity centers subject to partial or } \\
\text { complete habitat loss) }\end{array}$ & 5 & 1 \\
\hline $\begin{array}{l}\text { Competitive interactions with } \\
\text { other species }\end{array}$ & $\begin{array}{l}\text { Greater competitive interactions } \\
\text { with edge species-barred } \\
\text { and great horned owls }\end{array}$ & \\
\hline $\begin{array}{l}\text { Dispersal habitat (hectares meeting } \\
11-40 \text { after } 40 \text { years) }\end{array}$ & 6030 & $\begin{array}{l}6678 \\
\text { Better habitat and lower risk of } \\
\text { negative competitive interactions with } \\
\text { other species }\end{array}$ \\
\hline \multicolumn{3}{|l|}{ Timber yield (long-term average annual): } \\
\hline Cubic feet & $+16 \%$ & Larger, higher value trees to market \\
\hline Board feet & $+6 \%$ & \\
\hline Operability & $\begin{array}{l}\text { Lower complexity of planning } \\
\text { and implementing harvest } \\
\text { operations; difficult access to } \\
\text { numerous, small cutting units } \\
\text { heavily dissected by Riparian } \\
\text { Reserves }\end{array}$ & $\begin{array}{l}\text { Greater flexibility in prescribing } \\
\text { site ecological objectives and } \\
\text { and harvest operations } \\
\text { Prescriptions require more intensive } \\
\text { timber sale planning and layout }\end{array}$ \\
\hline \multicolumn{3}{|l|}{$\begin{array}{l}\text { Disturbances that can alter landscape } \\
\text { prescription: }\end{array}$} \\
\hline Fire & & $\begin{array}{l}\text { Lower potential for spread under } \\
\text { extreme conditions; greater ability to } \\
\text { predict spread }\end{array}$ \\
\hline Windthrow & & $\begin{array}{l}\text { Lower windthrow potential at stand } \\
\text { edges, including riparian zones }\end{array}$ \\
\hline Insects and disease & $\begin{array}{l}\text { More of landscape in stand } \\
\text { conditions with lower densities } \\
\text { of endemic insects }\end{array}$ & \\
\hline
\end{tabular}


Table 13-Area of stand structure classes over time for the Landscape Plan and Interim Plan, Augusta Creek

\begin{tabular}{|c|c|c|c|c|c|c|c|c|c|c|c|}
\hline \multirow[b]{2}{*}{ Stand structure class } & \multicolumn{10}{|c|}{ Time from present } & \multirow[b]{2}{*}{$\begin{array}{l}\text { Year } \\
400\end{array}$} \\
\hline & Existing & $\begin{array}{l}\text { Year } \\
20\end{array}$ & $\begin{array}{l}\text { Year } \\
40\end{array}$ & $\begin{array}{l}\text { Year } \\
60\end{array}$ & $\begin{array}{l}\text { Year } \\
80\end{array}$ & $\begin{array}{l}\text { Year } \\
100\end{array}$ & $\begin{array}{l}\text { Year } \\
120\end{array}$ & $\begin{array}{l}\text { Year } \\
160\end{array}$ & $\begin{array}{l}\text { Year } \\
200\end{array}$ & $\begin{array}{l}\text { Year } \\
300\end{array}$ & \\
\hline \multicolumn{12}{|c|}{$\begin{array}{c}\text { Hectares } \\
\text { Interim plan }\end{array}$} \\
\hline \multicolumn{12}{|l|}{ Early: } \\
\hline Light retention ${ }^{b}$ & 1550 & 1529 & 925 & 922 & 913 & 914 & 926 & 915 & 925 & 924 & 916 \\
\hline Mbderate to heavy retention ${ }^{c}$ & 0 & 0 & 0 & 0 & 0 & 0 & 0 & 0 & 0 & 0 & 0 \\
\hline \multicolumn{12}{|l|}{ Young: ${ }^{d}$} \\
\hline Light retention ${ }^{b}$ & 51 & 520 & 1510 & 1370 & 925 & 922 & 913 & 926 & 915 & 915 & 924 \\
\hline Moderate to heavy retention ${ }^{c}$ & 465 & 444 & 0 & 0 & 0 & 0 & 0 & 0 & 0 & 0 & 0 \\
\hline \multicolumn{12}{|l|}{ Mature:e } \\
\hline Light retention ${ }^{b}$ & 2100 & 1969 & 1890 & 2249 & 1129 & 1183 & 1193 & 1168 & 291 & 291 & 291 \\
\hline Mbderate to heavy retention ${ }^{c}$ & 0 & 0 & 391 & 338 & 310 & 310 & 310 & 0 & 0 & 0 & 0 \\
\hline Oldf & 2780 & 2486 & 2230 & 2067 & 3669 & 3617 & 3605 & 3937 & 4815 & 4815 & 4815 \\
\hline Meadows and rocks & 688 & 688 & 688 & 688 & 688 & 688 & 688 & 688 & 688 & 688 & 688 \\
\hline \multicolumn{12}{|c|}{ Landscape Plan } \\
\hline \multicolumn{12}{|l|}{ Early: } \\
\hline Light retention ${ }^{b}$ & 1549 & 1109 & 159 & 154 & 171 & 143 & 83 & 192 & 160 & 154 & 143 \\
\hline Mboderate to heavy retention ${ }^{c}$ & 0 & 199 & 484 & 571 & 535 & 529 & 537 & 527 & 486 & 529 & 486 \\
\hline \multicolumn{12}{|l|}{ Young: ${ }^{d}$} \\
\hline Light retention ${ }^{b}$ & 50 & 508 & 1366 & 913 & 159 & 154 & 171 & 83 & 192 & 160 & 154 \\
\hline Moderate to heavy retention ${ }^{c}$ & 461 & 426 & 0 & 199 & 484 & 571 & 535 & 537 & 527 & 571 & 527 \\
\hline \multicolumn{12}{|l|}{ Mature: ${ }^{e}$} \\
\hline Light retention ${ }^{b}$ & 2104 & 2018 & 1961 & 2231 & 1222 & 1090 & 1152 & 1168 & 412 & 447 & 446 \\
\hline Moderate to heavy retention ${ }^{c}$ & 0 & 0 & 416 & 404 & 368 & 540 & 624 & 487 & 678 & 692 & 779 \\
\hline Oldf & 2779 & 2684 & 2559 & 2472 & 4006 & 3918 & 3842 & 3950 & 4488 & 4391 & 4409 \\
\hline Meadows and rocks & 688 & 688 & 688 & 688 & 688 & 688 & 688 & 688 & 688 & 688 & 688 \\
\hline
\end{tabular}

a Early $=1$ to 40 years since establishment of the most recent cohort.

$b$ Light retention=0- to 25-percent retention of overstory at time of establishment of the most recent cohort.

c Moderate to heavy retention=26- to 50-percent retention of overstory at time of establishment of the most recent cohort.

d Young $=41$ to 80 years since establishment of the most recent cohort.

e Mature $=81$ to 200 years since establishment of the most recent cohort.

$f$ Old=greater than 200 years since establishment of the most recent cohort. 
very long rotation age (300 years). Young stands have a relatively low level of overstory (15 percent). The other three Landscape Areas subject to timber harvest contain all age classes except old, in response to moderate or long rotations (100 or 200 years), with 30- or 50-percent overstory retention levels. Aquatic Reserves (17 percent of the planning area) provide blocks of old forest intermingled with areas managed for timber removal. Forest stands with zero retention levels created from the last 35 years of timber harvest eventually disappear from the landscape and are not replaced in this scenario. The mix of rotation ages and retention levels prescribed for different Landscape Areas results in substantial amounts of all structural stages and more closely resembles the landscape composition of the previous 500 years. Although it takes many decades for these conditions to be fully expressed in the landscape, differences between the two scenarios are evident at the close of the first period (year 20).

Distribution of structural stages across slope positions differs markedly. In the Interim Plan, old forests are confined to riparian areas and lower slope positions. Old and mature forests are not allowed to develop in middle and upper slope positions because of the relatively short rotation age of the Interim Plan. Similarly, young forests in riparian areas and lower slope positions phase out of the landscape in the Interim Plan because Riparian Reserves are designated along all streams. The Landscape Plan distributes a wider range of structural stages across all slope positions. Long rotations and moderate to high levels of canopy retention allow development of mature and old forests within harvested areas. Low- to moderate-intensity cutting would occur within some riparian areas and lower slope positions at a low frequency in the Landscape Plan.

The Interim Plan leads to a more fragmented future landscape than either existing conditions or the Landscape Plan. Differences in the distribution of patch sizes between the two plans are striking (table 14). Frequent cutting due to relatively short rotations and generally narrow areas where cutting occurs between Riparian Reserves result in an increasing number of small patches in the Interim Plan. Conversely, the number of small patches gradually decreases over time in the Landscape Plan as cutting occurs in larger blocks and at lower frequencies. Larger patch size classes, especially the 60- to 400-hectare (150- to 1,000-acre) class, show the opposite trend. Patches of this size decrease from 17 to 3 in the Interim Plan and increase from 17 to 24 in the Landscape Plan. Mature and old-forest patches in the Interim Plan are found in either the relatively narrow, linear Riparian Reserve network or in the larger Special Area Reserves. The Landscape Plan provides large patches of mature and old forest distributed across the landscape.

The amount of edge between forest and open areas also differs significantly between the two plans (fig. 21). The Interim Plan results in a 60-percent increase in edge compared to existing conditions, primarily as a result of cutting units in upslope positions bordering old forests in Riparian Reserves. This relatively abrupt transition from riparian areas and lower slopes to upper slopes introduces artificial gradients in environmental conditions, such as light, temperature, soil moisture, and wind penetration (Chen and others 1995a). Plant communities and mortality rates may be affected by abrupt edges (Chen and others 1995a). The Landscape Plan decreases the amount of edge in the landscape by almost 40 percent relative to existing conditions. 
Table 14-Comparison of patch density by patch size class for the Landscape Plan and Interim Plan, Augusta Creek

\begin{tabular}{|c|c|c|c|c|c|}
\hline \multirow[b]{2}{*}{ Time from present by plan } & \multicolumn{5}{|c|}{ Number of patches } \\
\hline & $\begin{array}{l}<10 \\
\text { hectares }\end{array}$ & $\begin{array}{l}10-19 \\
\text { hectares }\end{array}$ & $\begin{array}{l}20-59 \\
\text { hectares }\end{array}$ & $\begin{array}{l}60-400 \\
\text { hectares }\end{array}$ & $\begin{array}{l}400+ \\
\text { hectares }\end{array}$ \\
\hline \multicolumn{6}{|l|}{ Existing } \\
\hline Interim Plan: & 121 & 30 & 22 & 17 & 2 \\
\hline Year 20 & 188 & 45 & 34 & 18 & 2 \\
\hline Year 40 & 273 & 49 & 30 & 15 & 2 \\
\hline Year 60 & 343 & 55 & 36 & 18 & 2 \\
\hline Year 80 & 383 & 62 & 37 & 10 & 1 \\
\hline Year 100 & 389 & 64 & 36 & 10 & 1 \\
\hline Year 120 & 389 & 63 & 42 & 9 & 1 \\
\hline Year 160 & 346 & 55 & 40 & 8 & 1 \\
\hline Year 200 & 237 & 49 & 31 & 3 & 1 \\
\hline Year 300 & 239 & 49 & 31 & 3 & 1 \\
\hline Year 400 & 243 & 45 & 34 & 3 & 1 \\
\hline \multicolumn{6}{|l|}{ Landscape Plan: } \\
\hline Year 20 & 142 & 49 & 35 & 17 & 2 \\
\hline Year 40 & 123 & 30 & 25 & 24 & 2 \\
\hline Year 60 & 130 & 39 & 33 & 22 & 2 \\
\hline Year 80 & 112 & 27 & 23 & 20 & 2 \\
\hline Year 100 & 114 & 23 & 24 & 22 & 2 \\
\hline Year 120 & 115 & 27 & 24 & 22 & 2 \\
\hline Year 160 & 91 & 19 & 23 & 24 & 2 \\
\hline Year 200 & 43 & 9 & 22 & 21 & 1 \\
\hline Year 300 & 44 & 11 & 20 & 22 & 1 \\
\hline Year 400 & 44 & 10 & 21 & 21 & 1 \\
\hline
\end{tabular}




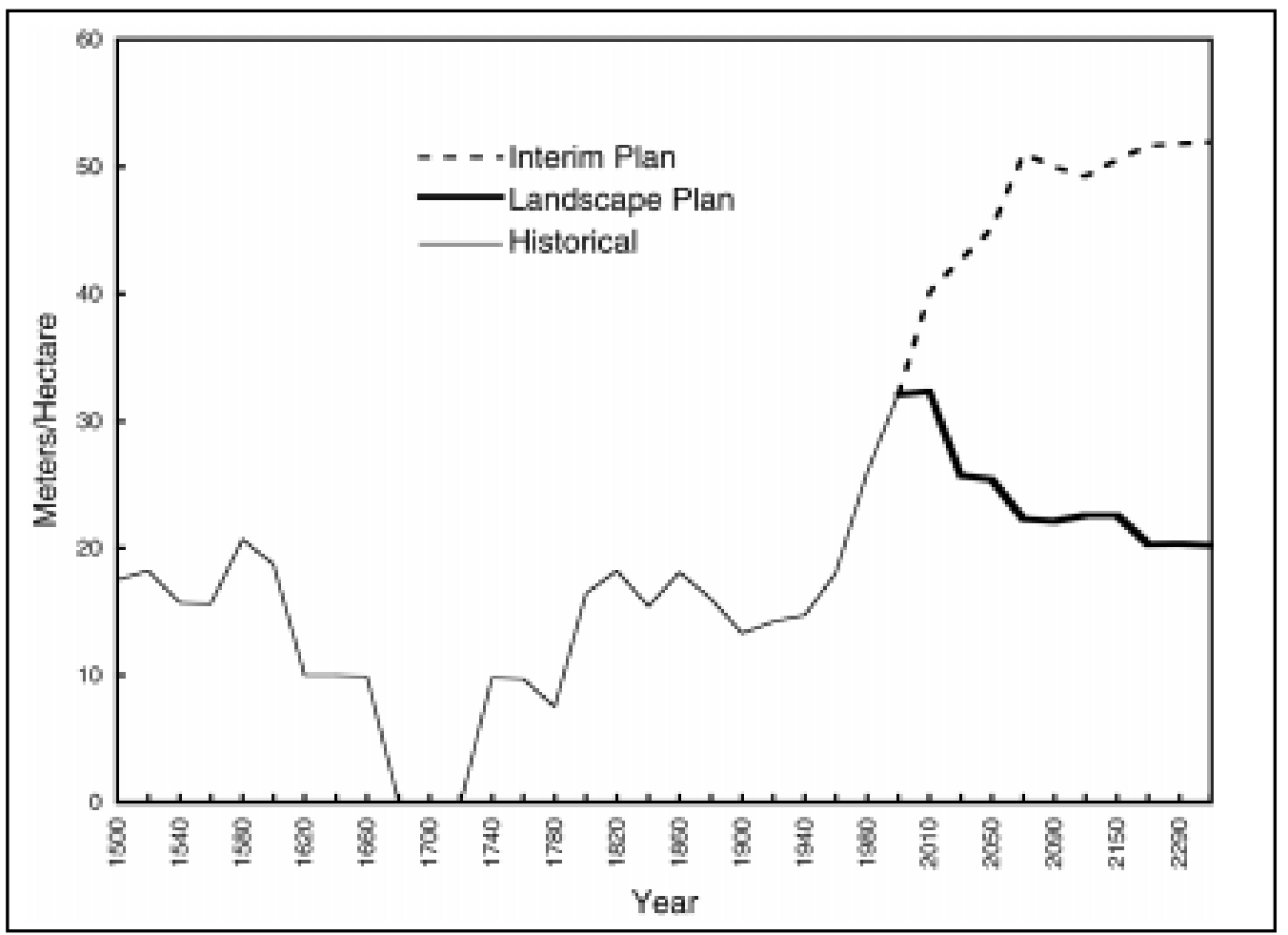

Figure 21-Comparison of edge density for the Augusta Creek Landscape Plan and Interim Plan.

Long rotations reduce the rate of change in forest conditions over time, and moderate to high levels of overstory retention reduce contrasts between cutting units and adjacent stands.

Hydrology ${ }^{13}$

Land-use activities that change the volume of water accumulating within a landscape or the rate at which water travels through the landscape can alter the hydrology of a watershed. Changes can occur in the total annual or seasonal streamflow or in the magnitude or timing of peak (flood) or low flows. Such hydrologic effects are of concern because they determine the availability and movement of water on hillslopes and in channels. The amount and movement of water, in turn, can trigger landslides, debris flows, and channel changes, which affect aquatic or riparian habitat. Here we consider the effects of the Interim Plan and the Landscape Plan on hydrologic processes based largely on studies in nearby watersheds (e.g., Harr 1981, Jones and Grant 1996).

Factors considered in evaluating the hydrologic effects of the two scenarios included the (1) size of landscape blocks, (2) within-block treatments (i.e., density of residual stands), and (3) location of blocks within the watershed. Key aspects of the block distribution included their location with respect to rain-on-snow zones (defined by elevation and aspect), streams, and subwatersheds. Their relation to roads was not considered, because roads were considered similar in the two scenarios. Roads, however, seem to have significant effects on peak flows (Jones and Grant 1996, Wemple 1994, Wemple and others 1996).

${ }^{13}$ This section prepared by G. Grant. 
A qualitative analysis of the relative effects of the two management scenarios was conducted for peak flows, low flows, and average annual streamflow. The Augusta watershed does not have gauges, so quantitative analysis was not feasible. From a hydrologic standpoint, the key difference between scenarios is the area of open canopy having relatively low evapotranspiration and higher potential for rain-on-snow increases in peak flows (Harr 1981). In this discussion, open vegetation conditions are those with shrubs or saplings at less than 50-percent retention or pole stands at less than 30-percent retention plus all open meadows or rock areas.

Effects on peak flows-Principal concerns in examining effects of forest management on peak flows include extent and geographic pattern of areas of open vegetation conditions where snow may accumulate to greater depths and melt more rapidly than in forested areas (Harr 1981). The contrasting patterns of cutting units and old forest that emerge under the Interim Plan will result in considerable spatial heterogeneity in rates of water accumulation and runoff during either rain-on-snow or spring snowmelt events. Consequently, there is little likelihood for synchronous runoff from different parts of the basin with resulting increases in major peak flows. The greatest effects on peak flows are likely to be experienced by the small, north-facing subwatersheds draining into the South Fork McKenzie River. If the scale of cutting unit approaches the size of the individual subwatersheds, a high proportion of trees in the watershed may be cut at one time. Under these conditions, higher fall and winter peak flows may result; peak flow increases may be as great as 20 to 50 percent, depending on the type of storm and antecedent conditions (Jones and Grant 1996). Consequences for channel habitat, however, are likely to be minor, because these north-facing drainages are quite steep and boulder-dominated and can absorb increased flows without significant channel adjustments.

Under the Landscape Plan, there is also considerable heterogeneity of landscape pattern at the scale of the Augusta Creek analysis area. Consequently, both snow accumulation and melt rates will be quite varied over the basin as a whole, resulting in little tendency for synchronization of runoff from different landscape elements.

Overall, there is likely to be little potential for further increase in peak flows, particularly for larger channels, under either scenario. The existing road system may generate increased peak flows that will persist into the planning period.

Effects on low flows-Late summer low streamflow, which influences streamwater temperature and extent of aquatic habitat, is evaluated in terms of likely leaf area of hardwood and conifer vegetation in riparian zones. Early successional hardwood stands in riparian zones, especially red alder (Alnus rubra Bong.), have high potential to remove water from flood-plain groundwater systems, thereby reducing summer low flows (Hicks and others 1991). Conifers, on the other hand, have much lower rates of transpiration during hot, dry summer periods and, therefore, have less potential to draw down summer low flows.

Under both plans, summer low flows may decrease slightly in the next few decades in response to increased evapotranspiration associated with growth of upland vegetation in clearcuts and riparian hardwoods. The magnitude of these effects is difficult to predict, however, and may be strongly conditioned by any major floods that occur within this time frame that could disturb riparian zones and reset succession. One 
direct consequence of lower late-summer flows may be slightly elevated stream temperatures; this would be offset, however, by development of fully shaded riparian zones through time.

The high degree of spatial heterogeneity in block size, treatment, and location under the Landscape Plan minimizes effects on low flows. Stream temperatures may be somewhat more elevated in parts of the landscape as a result of reduced canopy cover in the very limited area subject to cutting in riparian zones. This effect, however, probably will be undetectable in the mainstem channel.

Effects on total annual streamflows-Effects of management practices on total annual streamflow were considered in terms of altered evapotranspiration in response to vegetation change, which would appear mainly in late spring and summer low flows.

Under both scenarios and at the scale of the entire watershed, there may be a small decrease in total annual streamflow relative to the current condition within the first 20 years, due to regrowth of trees in uplands and riparian zones. About 29 percent of the Augusta Creek area currently is in open stand conditions. In the Interim Plan, the area of open stand conditions declines to 21 percent within 20 years as trees mature, primarily in Riparian Reserves, and remains essentially constant thereafter. Because evapotranspiration (ET) is about 20 percent of the total water budget (Rothacher and others 1967), an 8-percent decrease in area in open vegetation conditions may decrease water yields by less than 2 percent (the ET component is recovered in an additional 8 percent of the area). This magnitude of stream flow change is undetectable with standard gauging techniques.

In summary, the extent and intensity of cutting treatment under the two scenarios differ little in their effects on streamflow at the scale of Augusta Creek. Individual subwatersheds may experience altered peak, low, and annual flows when cutting is concentrated in them, but such conditions are limited in time and space.

Debris Slides and Flows $^{14}$
Vegetation disturbance, such as wildfire and logging, and the presence of roads can increase the frequency and magnitude of soil movements by debris slides (small, shallow, rapid movements of soil down steep hillslopes) (Sidle and others 1985, Swanson and Dyrness 1975). Analysis of debris slide inventory data from areas near Augusta Creek and elsewhere in the Pacific Northwest indicates that clearcuts and road rights-of-way experience higher frequencies of debris slides than forested areas (Marion 1981, Morrison 1975; also see footnote 5). The sliding rate for clearcut areas may be increased for about 20 years postcutting owing to changed water balance and loss of rooting strength on unstable slopes. No analysis of effects of partial cuts has been conducted in the Douglas-fir region because partial cutting has been limited in extent and, where done, has occurred on gentle slopes.

There seems to be little difference in debris slide hazard between the two scenarios. The primary areas of concern (roads and known areas of unstable soils) are treated similarly in both scenarios. The greater area subject to cutting in the Landscape Plan (39 percent compared to 29 percent of area subject to cutting in the Interim Plan) may create more cutting-related sliding. This effect may be offset, however, by the longer

${ }^{14}$ This section prepared by F. Swanson. 


\section{Amphibians $^{15}$}

rotation lengths and higher levels of retention in the Landscape Plan, which would result in less area in a state of high debris-slide hazard at any particular time. The Interim Plan, for example, would result in 37 percent more area cut per year, and this would be at 15-percent retention compared with 15- to 50-percent retention in the case of the Landscape Plan (table 12).

Debris flows (rapid movements of soil, sediment, and organic debris down stream channels) are infrequent in the Augusta Creek landscape, and most are triggered by debris slides from hillslopes. Hence, the above analysis would apply as well to debris flows, so we expect the two scenarios to be similar in likelihood of debris flow occurrence.

In summary, the potential for debris movements in hillslopes or in channels is similar between the two scenarios because of similarities in extent of roads, cutting, and avoidance of slope stability problem areas.

Three broad assemblages of Pacific Northwest amphibians in forested landscapes are distinguished by habitat preference: (1) terrestrial species-roughly a third of the Pacific Northwest forest amphibians occur only in riparian and upland forest; (2) stream species-about another third have life history stages that require flowing water (seeps, headwater tributaries, first- through fifth-order streams); and (3) pond-breeding species-about a third require still water (ponds, lakes, slow portions of streams) for reproduction. Some stream and most pond-breeding species have complex life histories involving multiple habitat types. Although linear Riparian Reserves may protect the rearing habitat of aquatic-breeding amphibians, upslope habitats may be important for dispersal, foraging, and winter refuge of terrestrial forms (e.g., tailed frogs, Pacific giant salamanders, Northwestern salamanders [Ambystoma gracile], and red-legged frogs [Rana aurora aurora]). Consequently, forest management plans that maintain connectivity of critical combinations of habitat types can better assure persistence of these species.

The qualitative assessment of the two scenarios with regard to forest amphibian habitats and populations focuses on parts of the Augusta basin where forest cutting is prescribed. This is both the area where the plans differ significantly and the area of highest expected amphibian diversity. Upper elevation reserves (e.g., Three Sisters Wilderness and Chucksney unroaded area) are expected to have fewer amphibian species because of habitat constraints, including climate.

Key amphibian taxa are evaluated and the scenarios compared by habitat and population persistence. Habitat considerations include habitat quality, patch size and shape distributions, connectivity, and refuges for planned and unplanned disturbances.

Habitat-The main benefit for amphibians in the Interim Plan is the direct habitat protection offered to the aquatic and riparian life-history forms by the Riparian Reserves. These buffer zones adjacent to aquatic habitats are expected to offer extensive protection of the most critical habitats required by all life history stages of about a quarter of the 27 forest-dwelling species in the Pacific Northwest. Forest cutting plans in the Interim Plan are anticipated, however, to put amphibians using upland habitats at risk, including members of the terrestrial, stream, and pond-breeding assemblages. Amphibians in upland forests are generally ground-dwellers that use surface debris

\footnotetext{
${ }^{15}$ This section prepared by D. Olson.
} 
as refuges during active seasons and retreat to these refuges or farther subsurface during inactive seasons. Disturbance of soil, litter, woody debris, and rocks by tree felling and yarding and by piling and burning of slash can destroy microhabitats. Retention of a small portion of live trees and downed woody material may do relatively little to offset upland disturbances to soil surface and subsurface microhabitats. In addition to these immediate, direct effects, inputs of large, downed woody material, necessary for the creation of microhabitats for many amphibian species, would be quite limited over the long term in the 80-year rotation prescribed for the Interim Plan.

The Interim Plan substantially changes the microclimate of logged upland sites. The 80 -year rotation and 15-percent retention can produce xeric conditions that few forest amphibians may tolerate (Blaustein and others 1995). Development of a shrub layer and canopy closure should ameliorate the harshest microclimate conditions, but species associated with old-growth forest conditions, in particular, may not remain in upland areas repeatedly cycling through unsuitable temperature and moisture regimes. Alteration of microclimates in Riparian Reserves also may be detrimental to amphibians. Chen and others (1995a) observed microclimatic effects of sharp forest edges extending from an opening to more than 240 meters $(790 \mathrm{ft}$ ) into the adjacent forest. Such an edge effect could potentially reach all the way to the stream. Altered temperature and moisture regimes in riparian zones may reduce the distribution and abundance of terrestrial- and aquatic-dependent amphibians known to be associated with "interior" old-growth conditions (Blaustein and others 1995). A shift in the microclimate of Riparian Reserves also may affect amphibian habitat by accelerating decay of surface litter and wood (Chen and others 1995b).

The Landscape Plan provides several mechanisms for retaining and renewing the upland microhabitats required by amphibians. First, aquatic reserve blocks include contiguous riparian and upland habitats. Old-growth habitat will develop and persist in these reserves, offering refuges to protect entire life cycles of amphibian species, both aquatic and terrestrial. Second, the long intervals between timber harvests (rotation lengths up to 300 years) allow old-forest conditions to develop in upland areas and be sustained across much of the watershed. Such long rotations allow accumulation of large downed wood and bark piles, necessary habitat components for some amphibian species. Third, the greater retention levels (up to 50 percent) provide habitat and reduce the severity of microclimate changes postharvest.

A large proportion of the harvestable riparian and upland areas of the Landscape Plan is expected to have suitable microclimate for amphibians, thus providing connectivity across all important habitat types and landscape positions. Interior forest microclimate conditions can persist in the large reserves and landscape blocks with long rotations (fig. 17). The Landscape Plan should provide better source areas from which recolonization may occur across the watershed after planned or unplanned disturbances.

Population persistence-Amphibian persistence in the Interim Plan should be highest for aquatic-dependent amphibians. Persistence of the terrestrial amphibian assemblage is at higher risk in the Interim Plan. Populations may become fragmented by the unit sizes of upland forest blocks and the frequency and intensity of harvest. Riparian Reserves may function as source areas for recolonization of upland habitats. 
Fish and Selected Aquatic Taxa ${ }^{16}$
Several features of the harvestable part of the Landscape Plan lead to greater probability of persistence of amphibians. The larger block sizes of the Landscape Plan, the fewer impacts to habitats and microclimate conditions within blocks where logging takes place, the broader distribution of refuges in riparian and upland areas, and the greater connectivity result in greater potential for persistence. All amphibian life history stages and assemblages gain substantial protection in the Landscape Plan. Old-growth forest conditions from streams to ridgelines allow for dispersal of amphibians among watersheds.

In summary, the Landscape Plan was designed in part to specifically meet habitat needs of amphibians ranging from aquatic to uplands. Therefore, this plan is rated as superior in terms of providing better habitat and greater likelihood of persistence of species using uplands habitats.

Forest management can directly affect aquatic communities of streams in steep terrain, such as the Augusta Creek area. Fish are useful indicators of environmental and ecological change because they (1) have the longest life spans of most aquatic organisms, (2) occupy higher trophic levels and integrate responses of lower trophic levels, (3) have strict habitat requirements, and (4) are species of interest to humans. Fish species occupy third-order and larger streams in the Augusta Creek watershed and locally occur in second-order streams draining into larger streams (fig. 12). Headwater streams not containing fish are important to fish-bearing streams for maintaining input of cold water with low levels of suspended sediment and supplying food for fish, their prey, and other elements of native aquatic communities.

Critical points for comparison of the scenarios are habitat structure, refuges from disturbances, and light levels reaching the stream as they may affect primary production, water temperature, and foraging efficiency.

Habitat-The Interim Plan provides a high degree of protection for existing riparian areas along intermittent and perennial streams throughout the Augusta Creek analysis area. The high density of intermittent, first-order, and second-order streams within the basin creates a dense network of Riparian Reserves. This Riparian Reserve system gives a high level of protection to sources of wood delivery to streams, canopy cover, and streambanks and provides intact corridors across the full stream network from the confluence of Augusta Creek and the South Fork of the McKenzie River to the ridgeline reserves.

The Landscape Plan provides for similar levels of protection for riparian areas along larger, fish-bearing streams and along many of the smaller streams throughout the Augusta Creek area. Old-growth corridors would not occupy all streams within each subbasin at all times in the Landscape Plan. Partial harvest planned in riparian zones along small streams would locally reduce the potential sources of wood delivery, canopy cover, and streambank protection.

In general, in-stream habitat for fish would be protected or restored in the Landscape Plan, but openings along smaller streams could create warmer conditions in patches within the harvested areas. Thermal effects would be of short duration because of

${ }^{16}$ This section prepared by S. Gregory and L. Ashkenas. 
vegetation regrowth, and no warming of the mainstem stream is expected because of the wide Riparian Reserves along fish-bearing streams. With continuation of firesuppression policies, several species of concern (USDA and USDI 1994: table C3)e.g., algae-grazers such as Fluminicola sp., Juga sp., Helisoma sp., Lanx patelloides, and Ascaphus trueii larvae-may benefit from higher light levels resulting from local, temporary open-forest conditions created by limited cutting in riparian areas under the Landscape Plan. Plants that require higher inputs of solar radiation also may benefit (e.g., aquatic lichen [Hydrothyria venosa]).

Large woody debris is a critical habitat feature for many aquatic species. Under the Landscape Plan, loading of large woody debris in nonfish-bearing streams would be lower than the level expected in old-growth systems as a result of partial cutting in adjacent riparian zones. When we consider all fish-bearing streams within the basin, the Interim Plan is expected to deliver slightly more large woody debris to streams; but some of this delivery may come from unnatural concentrations of blowdown at the abrupt edges of Riparian Reserves. Management activities could compensate for these differences through designed delivery of wood to streams.

The scenarios offer equal levels of protection for critical refuges for fish, including flood plains and secondary channels along larger channels. Hydrologic analysis suggests little difference between the two scenarios. However, analysis of effects of past cutting and roads in other basins in the Willamette National Forest suggests that peak flows may be increased substantially in areas on 80-year rotations with the road networks traditionally used to support forest management (Jones and Grant 1996). This effect of earlier practices common to both future scenarios could result in greater disturbance and episodic mortality to stream fauna than would be expected in unmanaged basins.

Population persistence-Aquatic species, including trout and other fish species, would benefit from the water quality, in-stream habitat, and riparian habitat quality provided by the full Riparian Reserve system of the Interim Plan; however, abundances of native populations may decline somewhat from reduced food production and feeding efficiency in shaded reaches. Studies of trout populations within this drainage have demonstrated that food abundance is generally greater in stream reaches with canopy openings, because higher light levels result in greater food production and feeding efficiency (Murphy and others 1981, Wilzbach and others 1986). The cool stream temperatures fostered by the full Riparian Reserve system of the Interim Plan would benefit bull trout, which is particularly dependent on cold water conditions.

Trout populations and other fish species would not be adversely affected by the Landscape Plan, but conditions differ in some minor respects from the Interim Plan. The higher light levels along the limited extent of stream reaches where some logging occurs in riparian zones may lead to higher fish production in response to greater food production and feeding efficiency. Wind and wildfire historically created canopy openings along streams; wind may be an increased factor in the Interim Plan because of increased susceptibility of trees along edges of Riparian Reserves.

In summary, long-term persistence of fish communities within the Augusta Creek planning area is predicted to be similar between the two plans. Aquatic species that benefit from higher light levels would be locally favored by the Landscape Plan where partial harvest occurs in riparian areas. 


\section{Birds and Mammals ${ }^{17}$}

Most of the birds and mammals in the Augusta area are forest-dwelling, closedcanopy species with relatively small home ranges. Only 13 of the 53 indigenous species of mammals in the Augusta Creek watershed are associated with early seral stages, and 7 species demonstrate a strong preference for late-successional conditions. The other species are either habitat generalists or riparian dependent, or they require closed-canopy forests. Based on the habitat assessment by McGarigal and McComb (1993), more than half of the bird and mammal species are associated with some type of coarse woody debris. Home-range size for about half of the species is less than 4 hectares (10 acres). Wide-ranging species, such as elk and cougar, have home ranges crossing multiple drainages within the study area. About a third of the 99 indigenous species of birds use early seral habitat. The remaining 66 percent of the species are closed-canopy species or are associated with streams. The northern spotted owl is the primary old-growth associate. Most (87 percent) of the bird species have a minimum home range of less than 5 hectares (12 acres).

Habitat - In the Interim Plan, the portion of the landscape managed on an 80-year rotation with 15-percent overstory retention will never develop old-forest structures and, thus, is unlikely to function as habitat for late-successional species. These sites will provide habitat for early seral species, however.

The Landscape Plan will provide more habitat for most species because of the greater range and maximum level of green-tree retention and amount of older, structurally diverse forests. The high-retention areas in the Landscape Plan probably will function as old-forest habitat at ages 50 to 80 years postharvest for some species. The Landscape Plan offers greater amounts and more widely dispersed nesting and denning habitat for species using large trees (e.g, pileated woodpecker [Dryocopus pileatus]) or logs (e.g., American marten [Martes americana]).

Habitat conditions within riparian areas are functionally similar between scenarios. Species that feed extensively in streams but nest in forests would find similar quality of nesting habitat in the two plans. Stream-associated species, such as the American dipper (Cinclus mexicanus), spotted sandpiper (Actitis macrularia), and mink (Mustela vison), would be little affected by the minor differences in vegetative pattern between scenarios.

Landscape patterns in harvestable areas differ substantially between scenarios and provide different benefits to mammals and bird species. The larger block design of the Landscape Plan provides more suitable habitat for species associated with latesuccessional forests or with interior habitat of older forests. For species with small home ranges, these larger blocks buffer against the displacement of populations due to the loss of suitable habitat by disturbance events. That is, loss of pieces of habitat within the larger block could have little effect on the connectivity of suitable habitat or the interior conditions of the forest. This is in contrast to smaller habitat patches in which degradation of even small portions may render the patch unsuitable and force individuals to disperse. The Interim Plan lacks large blocks except in the high-elevation reserves, which are common to both scenarios.

\footnotetext{
${ }^{17}$ This section prepared by S. Garman and M. Hunter.
} 
The amount of edge between grass-forb-shrubs and closed-canopy forested habitats is greater in the Interim Plan. Edge species, such as elk, black-tailed deer (Odocoileus hemionus), great-horned owl (Bubo virginianus), and olive-sided flycatcher (Contopus borealis), will be favored by the Interim Plan. Accompanying these benefits are potential detrimental effects. The potential for displacing northern spotted owls is higher because of the negative interactions with barred (Strix varia) and great-horned owls.

The larger number of small patches of early seral habitat in the Interim Plan decreases habitat availability for species requiring large patches of habitat. For example, the American kestrel (Falco sparverius) requires relatively large openings (greater than 12 hectares [30 acres]) in proximity to its cavity nest. Most early seral habitat produced in the Landscape Plan is of sufficient size and configuration for this species; whereas the small, early seral patches produced in the Interim Plan have less potential as habitat for this species.

Connectivity among old forest features differs greatly between the two plans. In the Interim Plan, connectivity through the landscape is provided only by the Riparian Reserve network. In the Landscape Plan, connectivity among old-forest blocks is provided by Aquatic Reserves along large streams linking larger blocks of mature and old forest. In addition, areas with long rotations (200 to 300 years) have a significant portion of the area in mature or old forest distributed throughout the area at all times. For example, in the Upper Basins where there is a very long rotation (300 years), species requiring mature or old forest for dispersal will have a 100- to 200-year window for dispersal. Landscape areas with 30- to 50-percent overstory retention have a significant component of large trees over the whole area at all times. For example, the North Chucksney Landscape Area will have 100-year rotations but relatively high amounts of large woody debris and high overstory retention (50 percent). Species requiring large woody debris for dispersal will find most of this entire slope suitable over most of the planning period.

Connectivity of early seral habitat differs between scenarios. The open-canopy, early seral habitat in the Interim Plan is maintained in relatively numerous, small, scattered patches. In the Landscape Plan, this habitat is distributed in fewer but larger blocks. Many of the mammal species primarily associated with early seral habitats seem to have the ability to disperse through closed-canopy forests, as many are occasionally observed or captured in forests (e.g., pocket gophers [Thomomys spp.] and meadow voles [Microtus spp.]). Most early seral bird species can disperse through forests and simply fly over forested areas to reach suitable habitat. The Interim Plan may be more favorable for early seral species with low-dispersal capabilities compared to the Landscape Plan.

Concerning refuge from major disturbances, the two scenarios share some protection of habitat by virtue of the large area of nearby wilderness. The larger block design of the Landscape Plan provides a greater buffer against loss of habitat from catastrophic disturbance events for species requiring habitat patches ranging from 160 to 1010 hectares (400 to 2,500 acres) (fig. 17). The more numerous, smaller patches in the area subject to cutting in the Interim Plan present greater potential for habitat loss for species dependent on large patches (table 14). 
Population persistence-Long-term persistence of mammal species over the study area potentially will differ little between scenarios. However, areas in the Interim Plan experiencing repeated harvest with low levels of retention may result in the localized extinction of low-mobility species requiring overstory cover (e.g., red-tree vole [Phenacomys longicaudus]). The higher levels of retention and longer rotations of the Landscape Plan provide greater opportunity for species to persist on harvested sites. Doyle (1990) found riparian zones in a nearby watershed to function as source habitat for a variety of small mammals. The extent of Riparian Reserves in each scenario should provide adequate levels of source habitat for these species.

A more detailed analysis was conducted based on use of a bird-habitat association model that takes into account patch size and patch interior requirements. This analysis revealed that habitat for early seral species is greatly limited in both scenarios. Habitat availability for these species averages about 5 percent of the planning area over much of the 400-year planning period as a result of the emphasis on older forests and smaller sizes of early seral patches. Long-term persistence for these species depends on their ability to colonize newly created habitat patches. Most early seral species indigenous to the study area are common on intensively managed, privately owned forest lands northwest of Augusta Creek. Additional early seral habitat is expected to be produced by unplanned fire and wind disturbances that were not factored into the bird-habitat model assessment.

Persistence of bird species associated with late-successional forests is potentially enhanced in the Landscape Plan owing to the larger amount and patch sizes of suitable habitat. For instance, predicted habitat availability for late-successional species, such as the pileated woodpecker, is about 20 percent greater over much of the planning period compared to the Interim Plan.

In summary, the Interim Plan provides more edge and early seral habitat of benefit to some birds and mammals; but overall, the Landscape Plan provides more habitat for the broader array of species because of the greater range and broader distribution of habitat conditions (tables 12 and 13).

Northern Spotted Owls $^{18}$
Extent of late-successional forest habitat is positively associated with northern spotted owl site occupancy (Ripple and others 1991, Thomas and others 1990, USDI 1992). The effects of forest fragmentation on spotted owl survival and reproduction are unclear, however, but are generally hypothesized to be detrimental (Thomas and others 1990, USDI 1992). Some possible detrimental effects are changes in microclimate (Chen and others 1995a) that may affect thermoregulation of owls, improved conditions for spotted owl competitors and predators (Johnson 1992), and reduced dispersal opportunities. Although exact prescriptions for dispersal habitat are unknown, it has been hypothesized that forested stands meeting or exceeding "11-40" criteria (i.e., stands having $>40$-percent canopy cover of trees at least 28 centimeters [11 in] d.b.h.) are conducive to the dispersal of juvenile spotted owls (Thomas and others 1990). Critical points for comparison of the scenarios are live tree retention levels, number and arrangement of large patches of late-successional forest, amount and type of stand edge, and amount of habitat meeting 11-40 criteria.

${ }^{18}$ This section prepared by K. Swindle. 
Although northern spotted owls have been extensively studied, attempts such as these to predict how they might respond to specific, hypothetical landscapes are highly speculative.

Habitat-Forests most often selected by northern spotted owls in this area occur below 1600 meters $(5,000 \mathrm{ft})$ in elevation and exhibit a high degree of structural complexity, such as multilayered, multispecies canopies dominated by large overstory trees with moderate to high canopy closure and a high incidence of standing and downed woody debris. Portions of the Augusta Creek study area contribute little to the habitat needs of spotted owls, including portions of the Chucksney Unroaded Area and the Three Sisters Wilderness which are above 1600 meters $(5,000 \mathrm{ft})$. Most of the area, however, is comprised of forests that provide suitable to optimum habitat for dispersing and resident northern spotted owls.

A limited number of surveys in the Augusta Creek study area over the past decade have identified activity centers (defined as an area about 40 hectares [100 acres]) of concentrated activity of either a pair of spotted owls or a territorial single owl) of 10 pairs of northern spotted owls. This is likely to be close to the total territorial owl population for the entire area, and for purposes of this comparison, is assumed to be the entire population. Recent surveys indicate that one of the owl activity centers appears to have dissipated. A second owl activity center appears to be unstable since 1992, and a third seems to be marginal (i.e., not holding a territorial pair for consecutive years). All three of these sites have experienced timber harvest in or close to their activity centers during the past decade; harvest was most extensive near the site abandoned by owls. The remaining seven activity centers have been occupied for numerous years and are considered stable.

Two of the $10 \mathrm{owl}$ activity centers fall within the special area reserves common to both scenarios. Successional development after year 200 may create habitat for one to two additional pairs in these reserves. Under the Interim Plan, the remaining eight pairs are likely to be impacted in the first several decades by timber harvest within their home ranges (defined as the total area used by a pair of spotted owls for hunting, nesting, and roosting; about 400+ hectares [1,000+ acres]). Five pairs will experience partial or complete loss of their activity centers. Under the Landscape Plan, four pairs would experience loss of habitat within their home ranges, and one would experience partial or complete loss of its activity center in this same period.

Population persistence-The area managed for wood production in the Interim Plan is less favorable for both dispersing and resident northern spotted owls due to (1) rapid and permanent loss of large patches of late-successional forest, (2) increase in edge density and high edge-contrast which favor predators, and (3) less area meeting 11-40 criteria for dispersal. The Interim Plan quickly degrades the harvestable portions of the study area as a landscape through which owls could disperse to and from neighboring Late-Successional Reserves and in which several pairs may reside and reproduce ephemerally over the next several centuries. In contrast, the Landscape Plan better maintains current owl habitat over the next several decades and centuries. In the case of either scenario, decisions and actions tailored to meet the needs of owls in specific activity centers may reduce impacts on owls. The Landscape Plan, however, offers managers greater flexibility to positively affect northern spotted owls in areas managed for timber production. 
Table 15-Comparison of area by long-term timber yield categories for the Landscape Plan and Interim Plan, Augusta Creek

\begin{tabular}{lc}
\hline Long-term yield category by plan & Area \\
\hline & Hectares \\
Interim Plan: & 3351 \\
1990 plan reserves & 2070 \\
Riparian Reserves & 1559 \\
80 -year rotation at 15\% retention & 537 \\
140 -year rotation at 15\% retention & 109 \\
200 -year rotation at 15\% retention & \\
Landscape Plan: & 3351 \\
1990 plan reserves & 1311 \\
Aquatic Reserves & 890 \\
100 -year rotation at 50\% retention & 632 \\
200 -year rotation at 30\% retention & 323 \\
200 -year rotation at 50\% retention & 1130 \\
300 -year rotation at 15\% retention & \\
\hline
\end{tabular}

Timber Production and Operational Feasibility ${ }^{19}$
In summary, for northern spotted owls, the Landscape Plan provides significantly better habitat and lower risk of negative competitive interactions with other species. In addition, if activity centers had been considered when aquatic reserves were mapped, the Landscape Plan could have offered additional protection for these centers by providing larger core area reserves than those mandated by the Northwest Forest Plan.

Simulations used to develop and test prescriptions (described above in phase 2) also were used to calculate average, per hectare, long-term yields of merchantable timber volume. All volumes expected to be produced by intermediate and regeneration harvests over an entire rotation were summed and divided by the rotation length to produce an average annual yield. Simulated average annual yields of timber volume for each silvicultural treatment were multiplied by the respective area and summed to obtain a long-term average yield for each scenario (table 15). The Landscape Plan produces about 16 percent less timber volume (cubic feet) than the Interim Plan. This difference narrows to just 6 percent in terms of board feet, because the Landscape Plan produces bigger trees under the longer rotations.

The differences in timber production would narrow still further if the 40-hectare (100acre) spotted owl activity center reserves mandated by the Northwest Forest Plan had been taken into account when aquatic reserves were delineated in the Landscape Plan. Neither scenario incorporated these reserves to protect the specific locations

${ }^{19}$ This section prepared by S. Garman and J. Mayo. 
from disclosure. In the Landscape Plan, however, these reserves could overlap the small watershed reserves and not further reduce timber yields. In the Interim Plan, these reserves would reduce the area available for cutting to a greater extent.

Results of our projection of multiple rotations of treatments with high levels of greentree retention indicate a slight decrease in the dominance of Douglas-fir, starting with the second rotation. This is due to the increased shading by residual stems, which inhibits establishment of Douglas-fir, but in turn promotes the development of shadetolerant species, such as western hemlock and to a lesser extent, western redcedar. This decrease in dominance of Douglas-fir is not as apparent in the silvicultural prescriptions of the Interim Plan. These results should be viewed as highly speculative, however, because empirical data are not available to corroborate model predictions under the combinations of retention level and rotation ages used in these scenarios.

The operational feasibility of timber removal differs between the two scenarios because of the greater complexity of silvicultural prescriptions in the Landscape Plan. Given the higher levels of retention and the need to pay more attention to the dispersion of retained stems within a harvest block, the Landscape Plan may require a greater effort to plan harvests and mark trees for removal or retention. Different and probably more intensive tracking protocols also are required in the Landscape Plan to ensure compliance with the prescriptions. The biggest change in operational procedures will be to accomplish the retention levels and spacing of cutting units across the landscape. Even though silvicultural prescriptions are simpler in the Interim Plan, this plan will be challenging to implement in terms of gaining access to the numerous, small cutting units between Riparian Reserves. Either plan will require new and innovative methods of extraction and likely increase harvest costs as compared to traditional practices.

Road management may present more options in the Landscape Plan because the longer rotation and bigger blocks will result in short periods of high use interspersed with long intervals of low activity. This means that many roads would have to be open for only short periods.

Collectively, more complex prescriptions of the Landscape Plan will result in higher costs for planning and implementing harvest of less extracted timber. This may result in reduced revenues, but this will depend on trends in the timber market. Increasing value of older, larger volume trees grown in the Landscape Plan may offset the higher costs. Also, greater opportunity for harvesting special forest products from older forest in the Landscape Plan may partially offset the potential reduction in timber revenue.

In summary, slightly lower timber volume yield projected for the Landscape Plan may be offset by higher economic returns in wood quality from the long-rotation stands and harvest of other forest products. Both plans present operational difficulties that will require creative management approaches.

Future, unplanned wildfire will affect landscape pattern. Even with active fire suppression, the Willamette National Forest has experienced an average of 470 hectares $(1,165$ acres) burned per year from 1960 to 1995 when there has been significant

${ }^{20}$ This section prepared by S. Swetland and F. Swanson. 
road access for suppression efforts. This averages 5 hectares (13 acres) per year for an area the size of the Augusta study area; the only actual reported fire in the study area during this period totaled 55 hectares (136 acres) in 1973 (see footnote 2). For reference, from 1497 to 1850, the Augusta area experienced about 34 hectares (84 acres) of burning per year (see footnote 2). This indicates that fire suppression is less than 100 percent effective. If we assume that the Augusta area is representative of the Willamette National Forest, in the past 35 years the study area burned at a rate of 15 percent of the rate in the presuppression period represented by dendrochronologic analysis.

Arrangement of stands across the landscape differ between the two scenarios in ways that affect fire risk and behavior. The fragmented and lower canopy density of managed stands in the Interim Plan would leave stands more exposed to wind, which allows increased drying of fuels and, thus, more rapid rates of spread and more heat release per unit area in the event of fire. In normal periods of high fire danger, spatial variation in fuel type presents opportunities to control fires. The small size of blocks and arrangement upslope and downslope of cut and leave blocks in the Interim Plan may not allow space or time for this strategy. During periods of high fire danger, fire in the fragmented, smaller blocks of this plan could spot from one upslope harvest area to another or run along fingers of cut or reserve stands. Although the less fragmented landscape in the Landscape Plan may offer conditions for a larger, continuous fuel bed and potentially larger fire, suppression strategies are more easily determined. Fire-behavior prediction models are based on single fuel models with a continuous fire front. More complicated arrangements reduce accuracy of predictions.

In summary, wildfire can be anticipated in the Augusta area under any likely future management scenario. The Interim Plan is likely to present higher potential for spread under extreme conditions, and fire managers are likely to have lower ability to predict spread.

\section{Windthrow ${ }^{21}$}

Windthrow in the Cascade Range can significantly alter the intended pattern of managed stands across a landscape and the intended functions of landscape pattern. Several windthrow effects of the two management plans can be considered, but interpretations based on past experience and research must be tempered by differences between past and prospective management systems. Most past windthrow studies focused on the extent of wind effects at forest-clearcut edges in upland areas (Gratkowski 1956, Sinton 1996). This type of windthrow alters the intended landscape management pattern. However, the types of edges that existed under the past dispersed clearcutting system may not be duplicated in either management plan considered here. A second concern is windthrow of riparian buffer strips, which has been investigated (Sherwood 1993, Steinblums and others 1984) in the central Oregon Cascade Range area for much narrower riparian strips than those prescribed in the Northwest Forest Plan. A third windthrow effect is toppling of live trees retained in cutting units. Knowledge of extent of this type of blowdown is limited by the short period of use of this practice. In a preliminary study, Adler (1994) examined 44 cutting units harvested 1 to 10 years previously in the central Willamette National Forest.

\footnotetext{
${ }^{21}$ This section prepared by F. Swanson.
} 
Insects and Diseases $^{22}$
Retention levels ranged from 0.8 to 8 trees per hectare ( 2 to 20 trees per acre). From 0 to 58 percent (mean $=15.6$ percent) of retained live trees had blown down, and an additional 16 percent died standing. Using a simulation model and assuming retained trees became windfirm after 5 years, Adler estimated that 25 to 75 percent of trees would be blown down after 10 years.

In terms of edge-related blowdown, we believe that the edge characterization typed by degree of contrast between adjacent stands and by edge density (fig. 21) is a useful representation of relative susceptibility to windthrow of landscapes under the two scenarios. Edge density under the Landscape Plan is within the range of variability for the past 500 years (fig. 6). Edge density under the Interim Plan is 150 percent higher than in the Landscape Plan after 80 years of implementation (fig. 21).

Windthrow of riparian zones also is likely to be higher in the Interim Plan. Higher density of Riparian Reserves, shorter rotation lengths and lower levels of green-tree retention in stands adjacent to riparian reserves, and potentially more abrupt stand edges under the Interim Plan result in more extensive areas of high windthrow susceptibility.

We currently lack ability to evaluate the relative consequences of the two management plans in terms of blowdown of dispersed, retained, live trees in cutting units. To make such an assessment, it is necessary to know effects of density of retained trees and cutting frequency on windthrow susceptibility.

In summary, we expect that the Landscape Plan would result in substantially less windthrow along stand edges and that higher levels of standing trees in cutting units would remain as compared to the Interim Plan.

Insects and pathogens of trees are ecologically important disturbance agents, drivers of nutrient cycling, and regulators of productivity in both positive and negative senses (Perry 1994; Schowalter 1995a, 1995b). Here we focus on their roles in limiting tree survival and growth.

The susceptibility of individual trees or stands to damage by insects or disease, or both, is a result of environmental factors, such as climate, light, mechanical injury, windthrow, slash, and fire. These factors often occur in various combinations, thereby increasing susceptibility. A weakened tree is more prone to disease, which in turn makes it less resistant to attack by insects. Insects are present at all times but usually are kept in check by environmental conditions and predators.

The two plans differ little in terms of risk of insect and disease damage. However, stand characteristics distinctive to each plan could, in the event of an outbreak, result in different rates of spread and levels of damage.

Under the Interim Plan, 75 percent of the managed area will be on an 80-year rotation with 15-percent retention. Thinning entries in these areas can maintain stand health and vigor of the understory, and the low retention level will minimize damage to the residual stand. The low number of residual trees will be at a high risk for windthrow,

${ }^{22}$ This section prepared by J. Mayo. 


\section{Links to Project-Scale Planning}

but the small amount will not provide enough habitat for an outbreak of insects. As stand conditions change, endemic levels of insects could gradually increase in the 25 percent of the managed area on a 200 -year rotation.

In the Landscape Plan, about 30 percent of the managed area will be on a short rotation (100 years) but with 50-percent retention of the overstory. With this amount of retention, more damage to the residual trees is likely, and slash treatment will be more difficult, thereby resulting in increased fire risk. Thinnings scheduled in the understory will help to maintain vigor and allow the necessary adjustments in stand composition to keep the risk of insect damage at a minimum. The remaining managed area (200- to 300-year rotations) may experience increased competition between the overstory and understory as the stand develops for more than a century after the last scheduled thinning. Endemic levels of insects may increase gradually as the understory matures and slows in growth.

In summary, the Landscape Plan would have more area in stand conditions with higher endemic populations of insects. This would not result in a significantly higher risk for the Augusta analysis area as a whole because of the relatively small area where the differences occur.

The Landscape Plan developed in phase 2, and integrated into a spatially and temporally specific landscape pattern in phase 3, lays the groundwork for an efficient project-level planning process. Larger landscape- and watershed-scale issues have been addressed and reconciled as best our collective judgment allowed. The context and Landscape Plan provided by this analysis can focus project-level planning for timber sales, prescribed fire, silvicultural activities, and restoration or recovery projects.

Within the four landscape areas where timber harvest was prescribed, the next logical step is to develop specific prescriptions for management activities at the scale of the individual landscape block. Landscape blocks delineate areas where silvicultural activities and fire may be prescribed to create future stands of a similar structural stage (fig. 16). The type and timing of future activities can be established by comparing existing conditions within a block to projected future conditions. Detailed prescriptions for individual landscape blocks provide the context and direction for locating project unit boundaries and specifying contract language. Landscape block prescriptions should include the specific levels and patterns of canopy retention within the block, the potential use of fire, dead wood levels and distribution, treatment of areas not managed for timber production, logging systems, and the timing of activities within the block. For example, landscape block number 33 (65 hectares [160 acres]; fig. 16) is in a landscape area where the Landscape Plan calls for a timber harvest to establish a new cohort in the first 20 years with a general retention level of 30 percent. The landscape block prescription might include the following guidance:

1. Mature forest in this block should be cut early in the 20-year period. Rationale: Will better create a block of similar structure because existing plantations in the block are less than 10 years old.

2. Cutting should occur at the same general time within the block. Rationale: Will minimize the time during which disturbance is occurring. 
3. Retention level of mature forest cutting should average 40 percent. Rationale: There are already 18 hectares (44 acres) of plantations in the block with no retention of older trees.

4. Retention trees should be distributed throughout the block but concentrated near the intermittent streams on the south and north boundaries of the block. Rationale: This pattern closely resembles historical disturbance patterns and will help shade and stabilize the streams.

5. A mix of shade-intolerant and shade-tolerant species be planted according to the density of green-tree retention within the local area. Rationale: More shadetolerant species will survive and grow better in localized areas of higher retention tree density.

6. Block should be harvested in three different cutting units to minimize ground disturbance. Rationale: This configuration allows for efficient use of logging systems while minimizing ground disturbance.

7. Prescribed fire should be used in conjunction with the harvest activities. Rationale: Fire will help stimulate early successional herbs and shrubs and reduce fuel loadings.

8. Low-intensity prescribed fire should be allowed to burn into areas having soils unsuited for timber harvest. Rationale: Integrating the disturbance over the entire block creates more natural environmental gradients and creates dead wood habitat.

Silvicultural activities and prescribed fire may be appropriate in the near-term in blocks scheduled for regeneration harvests in later decades. For example, precommercial and commercial thinning prescriptions can be based on the projected trajectory of conditions for the corresponding landscape block. The timing of major cutting and regeneration efforts for the block as a whole can help determine thinning prescriptions (e.g., stocking levels, spatial patterns within stands, timing of entries). Thinning prescriptions for a 30-year-old plantation, for example, would likely differ depending on whether the block were scheduled for regeneration harvest 20 to 40 years from now or 120 to 140 years from now. Prescribed fire may be most appropriate in the short term in blocks dominated by mature or older forests scheduled for regeneration harvest in later periods. This approach avoids high levels of mortality that might result if younger stands were burned and allows natural postfire processes to occur for several decades before timber harvest.

Fire, primarily through natural ignitions, was prescribed in two of the special area reserves. Followup analysis will be necessary to identify the conditions and zones where fires may safely burn. Active management efforts were called for to maintain the high-elevation meadow component in the Chucksney Unroaded Recreation Area. Succession to conifers and continued fire suppression threatens the existence of the extensive meadows in this area. Analysis of historical conditions revealed the extent and rate of meadow loss. These results indicate the need to develop projects that will either maintain existing meadows or create new meadows.

Watershed recovery and restoration projects also can be identified and focused based on the results of this analysis. Information on historical disturbance regimes affecting stream channels can be combined with stream survey data to identify the 
Discussion

Key Elements of This Approach locations and types of restoration activities likely to be effective. For example, historical aerial photographs showed areas that were chronic sources of mass failures before road development and clearcutting in the area. Other areas experienced roadside failures in more recent times. Rehabilitating the roadside failures may be more effective than placing woody debris in streams subject to periodic debris-flows. Other examples could include road decommissioning in areas with high contribution to rain-on-snow events or summer baseflows, or silvicultural activities in relatively stable riparian zones currently deficient in large wood to accelerate conifer regeneration and growth.

The level of detail in the landscape prescriptions reflects the level of accuracy and precision in the data and analysis, and provides flexibility to make project-level decisions fit the larger scale context and at the same time work well with specific onsite conditions. We purposefully left many choices for project-level planning, such as the size and level of riparian buffer for many streams. This flexibility also reflects a degree of trust that land managers have the skills and on-the-ground expertise to integrate ecological conditions and objectives into practical prescriptions. Without such flexibility, the complexity and diversity of on-the-ground conditions cannot be adequately considered, and any resulting standardized prescriptions likely will fall short of meeting ecological and social objectives. This flexibility needs to be balanced by active monitoring programs to ensure that local decisions are consistent with larger scale objectives and plans.

The approach we have described provides an example of a spatially and temporally explicit landscape plan for ecosystem management. Our objectives were to maintain native species, ecosystem processes and structures, and ecosystem productivity over the long-term in a federally managed landscape where substantial acreage was allocated to timber harvest. The landscape management approach we have described demonstrates:

- Use of historical disturbance regimes to develop future vegetation management regimes: In portions of the landscape where timber harvest was allocated, rotation lengths, harvest rates, green-tree retention levels, the spatial pattern of timber harvests, and prescriptions for fire were based on past fire frequencies, intensities, and spatial patterns.

- An integration of terrestrial and aquatic management objectives and prescriptions: Landscape objectives and prescriptions were established based on aquatic and terrestrial habitat information. Aquatic reserves were designed to complement upslope management patterns given both the larger landscape prescriptions and local conditions. An intent of this approach was to provide many habitats (e.g., spotted owl dispersal habitat) across the entire landscape.

- A linkage of objectives across scales: The management approach was set in a regional- and National Forest-scale context, and it links to project-level activities by establishing temporally and spatially specific objectives and prescriptions. The projected trajectory of conditions for individual landscape blocks provides guidance for the type and timing of appropriate management activities at individual sites. 
At this time, we can make only a conjecture about the value of this approach. It appears, however, to offer several advantages when compared to the Interim Plan (table 12). Larger patch sizes with greater interior habitat, less edge between open and closed canopy forests, greater diversity of stand structures, and better distribution of habitats across the landscape provide numerous advantages to many species. Species having both aquatic and terrestrial life history stages (e.g., Pacific giant salamanders) would benefit from the more integrated and connected landscape in this approach. Other species (e.g., American marten), whose habitat would be found predominantly in high-edge Riparian Reserve stringers in the Interim Plan, would benefit from having habitat more broadly distributed across the landscape as a result of longer timber harvest rotations, higher levels of green-tree retention, and larger patches.

Our evaluation of this approach found no significant disadvantages of this approach as compared to the Interim Plan. We felt that the differences in disturbance processes, stream flows, and potential long-term timber yields were minor relative to the benefits described above, but we recognize that others will evaluate the advantages and disadvantages differently.

Much of the benefits of this approach derive from the explicit use of historical disturbance regimes as a management template. Our use of long rotations and relatively high levels of green-tree retention provided greater flexibility than the Interim Plan to design aquatic reserves in keeping with past patterns. Riparian Reserves in the Northwest Forest Plan protect existing resources and ecological processes and are a critical part of the plan. This level of protection was necessary given the short rotations and low levels of green-tree retention built into the Matrix lands prescriptions in the Northwest Forest Plan. The level of Riparian Reserves in the Interim Plan run the risk of creating patterns inconsistent with legacies of historical forest ecosystems, successional trends in forests, and patterns of historical disturbances.

Our ability to interpret potential consequences of these two scenarios was limited by incomplete existing knowledge. We assumed, however, that managed landscape patterns incorporating key features of historical patterns are more likely to incorporate natural processes or species that are incompletely understood. Because the approach we have described was based on an understanding of historical disturbance regimes, we feel this approach provides a better hedge against unknowns and maintains more options for the future than does the Interim Plan.

The considerable uncertainties associated with predicting the consequences of this management plan, or of other management plans, point out the value of comparing alternative future management scenarios (phase 4). We evaluated two approaches by using the Northwest Forest Plan as a benchmark and reference point for the disturbance-based approach. Many other approaches are possible, and a comparison of their relative merits likely would yield insights and opportunities for blending the best aspects of each. A logical step to follow a comparison of alternative scenarios would be to refine a disturbance-based approach, such as we have described. For example, results from a scenario designed around a high level of protection for the spotted owl might be blended into a disturbance-based approach by altering the landscape block mapping and scheduling rules to further protect the owl in the short term. 


\section{Limitations of Analysis}

\section{Application to Other Landscapes}

Numerous factors limited our ability to determine historical fire patterns. The age of the oldest early seral tree species in the area (generally 500 years in the Augusta area) limited the temporal length of the record available to read. The relatively small spatial scale (approximately 7600 hectares [19,000 acres]) also may have limited our ability to accurately interpret fire patterns. Confounding factors (e.g., accuracy of ring counts, interpretation of scars as fire caused, age to stump or core height) reduced the accuracy and precision of fire dates and extents. In addition, past climatic patterns may not match current or near-future climatic patterns. We therefore limited our interpretations of historical patterns to a relatively general level. We described general fire regimes and did not attempt to recreate the exact stand history of each site.

Research is currently underway on the west side of the Oregon Cascades to extend both the temporal record, through paleological work (Sea and Whitlock 1995), and the spatial scale, through compilation and integration of numerous databases. ${ }^{23}$

The apparent relation of fire occurrence and resulting stand structures with landforms has been observed elsewhere (Barrett and Arno 1991) and may provide some degree of long-term stability to landscape projections based on analysis of disturbance regimes. Large-scale landforms do not vary significantly on the time scale of interest but do exert a persistence influence on vegetation, fuel, microclimate, and wind patterns that all influence fire behavior, severity, and frequency (Swanson and others 1993). Given the relatively short period of record available to read the fire history (approximately 400 to 500 years), and the likelihood that climate will change, linking landscape objectives and prescriptions to a persistent and ecologically significant feature, such as landforms, may be useful.

Our analyses of historical disturbance regimes and landscape patterns revealed a high level of temporal variability. Our projections of future landscape patterns are based only on projected levels of management activities and depict a relatively deterministic and uniform landscape pattern. Unplanned disturbance processes (e.g., windthrow, wildfire, landslides) cannot be completely suppressed, however, and will interact with this pattern to create some difficult-to-predict hybrid of management design and other disturbance processes. Hence, this disturbance overlay likely will create much of the variability native to the ecosystem. More sophisticated planning approaches integrating human-engineered disturbances with natural disturbances are conceptually feasible, although the data and experience to do so are currently limiting.

The general approach to landscape management described in this paper should be generally applicable in other landscapes and watersheds, but the mix of specific elements and resulting consequences likely will differ considerably; for example, fire and other types of disturbance patterns, and the conditions of stream networks and flood plains, differ markedly across the region. Areas of highly fragmented or manipulated forest may require more reserves. Areas near wilderness or other undeveloped lands may do well without an extensive aquatic reserve system. The presence of threatened or endangered species, or of mixed ownership patterns, will likely impose additional constraints.

\footnotetext{
${ }^{23}$ Weisberg, P.J. 1996. Blue River fire regime analysis and description: spatial variation in pre-settlement fire frequency, Blue River watershed, central western Oregon Cascades. Corvallis, OR: Oregon State University. 17 p. Administrative report. On file with: Blue River Ranger District, Willamette National Forest, P.O. Box 199, Blue River, OR 97413.
} 


\section{Policy Implications}

In this study, conditions across the larger surrounding river basins provided important context for our interpretations and landscape prescriptions. Past practices, such as clearcutting down to the stream, stream debris removal, and road building along stream courses, have reduced the rate of woody debris delivery to channels, reduced shade, altered riparian habitat, and had other ecological effects. In the Northwest Forest Plan, the South Fork McKenzie is identified as a "Tier 1 Key Watershed" because of the presence of bull trout. Because of these conditions, we provided a relatively conservative aquatic reserve system. We used an understanding of disturbance processes to design an aquatic reserve system that, in our judgment, would minimize chances of further decline in stream and fish values and promote riparian recovery and is integrated with upslope management regimes.

An important implication of our analysis is that the approach we followed may not make more timber available for harvest. Our results showed a small decrease (6 to 16 percent) in long-term timber yields with this approach. Variation in starting conditions or prescriptions could significantly change this number in either direction.

Fire-Much of the work reported in this paper emphasizes management prescriptions that recreate landscape patterns through timber harvest that are similar to landscape patterns created in the past through fire. However, our approach to sustaining ecosystems also includes maintaining important ecological processes, such as fire. Although ranging greatly in frequency, severity, and extent, fire obviously has been a major process in this area during the period when existing plant assemblages have occurred (Agee 1993, Sea and Whitlock 1995). Accordingly, our prescriptions included the use of fire where feasible. It is not known, however, whether the restricted range of fire behaviors allowed under a management scenario can adequately replace historical fire regimes.

The consequences of fire exclusion are not well understood. In the 20th century, fire suppression has been widely implemented, reducing the role of fire in the ecosystem. Some changes in short fire-return-interval ecosystems, such as ponderosa pine forests, are obvious, but changes along most of the west side of the Cascades, where fire-return intervals are generally much longer, are less obvious. Nevertheless, there is good reason to believe that some habitats and ecological processes in the Augusta area depend on fire to some degree; for example, certain plant species produce prolific amounts of seed when stimulated by heat from a fire. Other species germinate from the soil seed bank after a fire and can dominate a site for decades. In the case of the nitrogen-fixing snowbrush (Ceanothus velutinus) fire can serve an important role in replenishing the nutrient capital of the site. Low-intensity fires may have played an important role in the past in maintaining suitable habitat for the spotted owl by reducing understories and generating snags (Morrison and Swanson 1990). Clearly, much work is needed to understand the implications of fire exclusion.

The integrated use of fire and timber harvests are one key to sustaining a managed forest ecosystem containing a full array of habitats and ecological processes. This will be difficult to achieve, however. Timber sales are generally well funded and have a strong, politically vocal constituency. Because of concerns with smoke, escaped fires, intermingled ownerships, and long-standing antifire campaigns, prescribed fires are not well funded and have active political opposition. A high probability exists that the timber harvest portion of these prescriptions can move forward while the fire components languish. Ultimately, a focus on maintaining ecosystem performance requires a hard evaluation of fire suppression, prescribed fire, and air quality policies. 
Relation to the Northwest Forest Plan-Considerable effort is currently going into completion of watershed analyses for the National Forests and BLM districts covered under the Northwest Forest Plan. The study described in this paper is both similar to and different from these analyses. Phase 1 in this study was roughly analogous to steps 1 to 4 (Characterization, Key Questions and Issues, Current Conditions, Reference Conditions) in "Ecosystem Analysis at the Watershed Scale: Federal Guide for Watershed Analysis" (REO 1995); however, analyses in our study were strongly keyed to understanding disturbance regimes. Disturbance regimes were described as an interpretation of both landscape history and potential controls on the disturbance process (e.g., topography and potential vegetation). In our view, disturbance regimes provide a stronger and more generalized basis for design of management approaches than does an understanding of past conditions alone.

Steps 5 and 6 (Synthesis and Interpretation, Recommendations) in REO (1995) are somewhat similar to phase 2 in our study. Expected products from steps 5 and 6 in REO appear to be focused on identifying potential discrepancies among current conditions and management objectives in the Northwest Forest Plan, capability to achieve management objectives in the future, and recommendations for specific projects in the watershed to achieve those objectives. The interpretations and recommendations in our study were integrated into general management prescriptions for the planning area. The resulting landscape plan (phase 3 ) and evaluation of the consequences (phase 4) are a significant departure from the way watershed analysis generally is conducted but appear to be consistent with REO (1995).

A watershed analysis of existing conditions, historical trends, and disturbance regimes provides a framework for creating forest management approaches that retain much of the historical patterns, processes, and composition in a future landscape. The variability of landscapes, communities, and physical processes in time and space can be reflected in future landscape and watershed objectives and in a landscape management approach. The example shown here illustrates one process to integrate this knowledge into landscape and watershed objectives that translate to spatially and temporally explicit management prescriptions. Watershed analysis can provide the context and information to select a management approach tuned to the watershed or landscape under consideration.

Potential modification of the interim Riparian Reserves established in the Northwest Forest Plan was one outcome expected by many to result from watershed analysis. The interim reserves were meant to ensure that aquatic and riparian species and functions are protected in watersheds where timber harvest occurs. Additionally, many terrestrial species were assumed to benefit from the Riparian Reserve network. This study provides an example of the type of analyses and landscape plan that we feel results in an improved ability to meet the objectives expected of the interim Riparian Reserve network, as well as better meet the overall objectives of the Northwest Forest Plan while improving operational flexibility.

Implementation of this approach faces hurdles, however. The regional design established in the Northwest Forest Plan (the Interim Plan) was evaluated in a formal Environmental Impact Statement found to be legally sufficient. The landscape plan developed in this case study has not been formally evaluated in a National Environmental Policy Act (NEPA) document. A NEPA document could be developed that adopts this landscape plan by amending the Northwest Forest Plan for this particular 
Adaptive Management

Human Values watershed. The NEPA procedures for such an amendment are relatively straightforward. The chief difficulty seems to be in reconciling a landscape-specific plan with the species viability assessments conducted for the Northwest Forest Plan. To implement our landscape management approach, a mechanism needs to be developed whereby a landscape-specific plan can be evaluated to ensure that the viability of all species covered under the Northwest Forest Plan are maintained at similar levels of risk. Criteria need to be developed that link the assumptions underpinning the viability assessments with landscape features. For example, a criterion could state that a landscape plan providing at least the same amount of spotted owl dispersal habitat (average stand diameter of 28 centimeters (11 in) and •40-percent crown closure) as the Interim Plan would be sufficient to maintain the viability of the owl at the same level as the Interim Plan. Criteria similar to this could be constructed for each of the species or species groups evaluated in the NEPA documents for the Northwest Forest Plan. Criteria could be interpreted directly from the assumptions used by the viability panels in FEMAT (1993).

Even though all management is an experiment in a certain sense, we are entering a period where forest management plans in the Pacific Northwest have never been tested. The plan described here has no precedent. The need for monitoring and adaptive management is just as high for this alternative landscape plan as it is for the Interim Plan. Both are experimental and based on state-of-the-art professional analysis. Both contain uncertainty and risks for the future of resources and ecosystems. The approach we have described rests on the untested assumption that managing within an interpreted range of historical variability can mimic natural ecosystems and provide a full array of habitats and ecological processes.

This assumption needs an adaptive management program to evaluate its validity. The adaptive management toolbox likely will contain:

- Modeling as a tool for capturing implicit assumptions of how forests function and how they are anticipated to respond to management strategies.

- Experimentation on key questions and assumptions.

- Trend assessment of selected species, social factors, landscape conditions, and ecological processes to identify important trajectories in ecological and social system structure and function.

Each approach will generate new information. The management approach we have described should be viewed as a concept based on current understandings of ecosystem and social processes. When the unforeseen occurs or new information becomes available, potential modifications to the approach, or substitution of a new approach, should be considered; for example, changes in the Landscape Plan may be called for by changes in the surrounding watersheds or other changes such as new listings of threatened or endangered species.

An understanding of historical patterns and ecosystem processes may be necessary to manage for sustainable landscapes, but it is clearly not sufficient. Managing for harmonious human interactions with the ecosystem is as essential as it is elusive. Humans have long used the forest and continue to influence its composition and function in myriad ways. We pursued a strategy placing human objectives within a context of the local historical pattern; for example, many of the areas where human 


\section{Future Work}

\section{Conclusion}

uses have been concentrated (the river bottoms and main ridgelines) were placed in reserve status. Finding acceptable balance points among perceived ecosystem needs and perceived human needs remains fundamentally a social question.

In some respects this approach to landscape management offers a radically different view of how humans can interact with the ecosystem. Past approaches have generally imposed an externally derived design on the local ecosystem, characteristic of what Botkin (1990) termed the "machine-age view" of nature. Desired outputs were determined and inputs applied to optimize production. The resulting prescriptions were broadly implemented across the Northwest, with relatively little variation as compared to historical disturbance regimes. The approach outlined here generated management prescriptions based on characteristics and disturbance regimes intrinsic to the local landscape. The resulting landscape plan is internally derived and rooted in the natural and cultural history of the place. This perspective may now be appropriate for Federal forests and needs further discussion.

An advantage of this approach is that it forces people to recognize and deal with the dynamics of the system and the inevitability of disturbance. An advantage of the landscape or watershed scale is that it is small enough to deal with the specific choices that need to be made and large enough to see broad patterns. Thus, we feel that this kind of exercise can be a valuable medium to foster urgently needed collaborative learning. Lasting progress on these issues will require mutual education and discussion among public interests, scientists, policy makers, and managers.

The ability of ecologists and land managers to incorporate the new spatial and temporal perspectives of ecosystem management is limited by several factors, including the lack of analytical and modeling approaches to landscape-scale problems. Although the methodology employed in this study is a first step, there is a significant need to further develop and use spatially explicit simulators of land-use alternatives under both human and natural disturbances. Specific functional requirements include, in part, the integration of analytical and simulation methods for the prediction and evaluation of potential disturbances, vegetative dynamics modeling, hydrologic modeling, and habitat-association modeling for both plant and animal species (Garman and others, in press). Many of these components are currently available or are the subject of ongoing research efforts. But future research must focus on synthesizing and integrating current understanding and predictive abilities into a form for projecting and evaluating effects of land-use actions on the sustainability of ecosystem properties.

We view this management approach as a potential postwatershed analysis implementation of the Northwest Forest Plan. Although the exact mechanisms for adjusting the Northwest Forest Plan remain unclear, it is clear that changes in the plan were anticipated to follow from watershed analysis. We hope this analysis can help identify useful ways to improve implementation of the Northwest Forest Plan and better link results of watershed analysis with planning. The landscape plan we developed in phases 2 and 3 provides a direct link to project-scale planning. Explicit development of landscape objectives and prescriptions and integration of these into a spatially and temporally specific landscape plan lay the groundwork for a focused, efficient projectlevel planning process. Larger landscape- and watershed-scale issues have been addressed and reconciled as best our collective judgment allows. The context and landscape plan provided by this analysis can focus project-level planning for timber sales, prescribed fire, silvicultural activities, and restoration or recovery projects. 


\section{Acknowledgments}

\section{Literature Cited}

The Augusta Creek project has been a collaborative management-research venture initiated and coordinated by the Cascade Center for Ecosystem Management, a three-way partnership among Oregon State University, the Willamette National Forest, and the Pacific Northwest Research Station. The mission of the center is to develop information about how ecosystems function, integrate that information into management strategies that meet social goals, and to communicate results with the natural resource community.

We would like to particularly acknowledge two individuals who made significant contributions to this project: we thank Tere Turner for the countless maps and database queries she delivered to us with amazing dedication and quality; and we thank Miles Hemstrom, who helped initiate this project in 1991.

The following individuals also contributed to this project: Lynn Burditt, Kathy Pendergrass, Karen Geary, George Lienkaemper, Jon Martin, Jeff McAllister, Cindy McCain, Allison Reger, and Pam Skeels. Thank you for your support and review.

We thank the following reviewers: Tom Atzet, Ray Bosch, Neal Forrester, Richard Hardt, Dave Hohler, Mark Huff, Gary Marsh, and Art McKee.

Adler, P.B. 1994. "New forestry" in practice: a survey of mortality in green tree retention harvest units, western Cascades, Oregon. Cambridge, MA: Harvard College. 46 p. Honors thesis.

Agee, J.K. 1993. Fire ecology of Pacific Northwest forests. Washington, DC: Island Press. 495 p.

Aho, R.S. 1976. A population study of the cutthroat in an unshaded and shaded section of a stream. Corvallis, OR: Oregon State University. 98 p. M.S. thesis.

Baker, William L. 1992. The landscape ecology of large disturbances in the design and management of nature reserves. Landscape Ecology. 7(3): 181-194.

Barrett, S.W.; Arno, S.F. 1991. Classifying fire regimes and defining their topographic controls in the Selway-Bitterroot Wilderness. In: Andrews, P.L.; Potts, D.F., eds. Proceedings of the 11th conference on fire and forest meteorology; 1991 April 16-19; Missoula, MT. Bethesda, MD: Society of American Foresters: 299-307.

Beckman, S.D.; Minor, R.; Topel, K.A. 1981. Cultural resource overview of the Eugene BLM District, west-central Oregon. Rep. 4. Eugene, OR: Heritage Research Associates.

Berris, S.N.; Harr, R.D. 1987. Comparative snow accumulation and melt during rainfall in forested and clear-cut plots in the western Cascades of Oregon. Water Resources Research. 23(1): 135-142.

Blaustein, A.R.; Beatty, J.H.; Olson, D.H.; Storm, R.M. 1995. The biology of amphibians and reptiles in old-growth forests in the Pacific Northwest. Gen. Tech. Rep. PNW-GTR-337. Portland, OR: U.S. Department of Agriculture, Forest Service, Pacific Northwest Research Station. 98 p.

Botkin, D. 1990. Discordant harmonies: a new ecology for the twenty-first century. [Place of publication unknown]: Oxford University Press. $241 \mathrm{p}$. 
Burke, C.J. 1979. Historic fires in the central western Cascades, Oregon. Corvallis, OR: Oregon State University. 130 p. M.S. thesis.

Chen, J.; Franklin, J.F.; Spies, T.A. 1995a. Growing-season microclimatic gradients from clearcut edges into old-growth Douglas-fir forests. Ecological Applications. 5(1): 74-86.

Chen, J.; Naiman, R.J.; Franklin, J.F. 1995b. Microclimatic patterns and forest structure across riparian ecosystems. [Place of publication unknown]: [Publisher unknown]; final project report; contract USDA FS-PNW-378409. Unpaged.

Cissel, J.H.; Swanson, F.J.; McKee, W.A.; Burditt, A.L. 1994. Using the past to plan the future in the Pacific Northwest. Journal of Forestry. 92(8): 30-31, 46.

Coffin, B.A.; Harr, R.D. 1992. Effects of forest cover on volume of water delivery to soil during rain-on-snow. Olympia, WA: Timber, fish, wildlife program; Sediment, hydrology, and mass wasting steering committee, University of Washington; final report; project $\mathrm{SH}-1.118 \mathrm{p}$.

Coville, Frederick V. 1898. Forest growth and sheep grazing in the Cascade mountains of Oregon. USDA Dir. For. Bull. 15. Washington, DC: U.S. Government Printing Office. $54 \mathrm{p}$.

D’Angelo, D.J.; Howard, L.M.; Meyer, J.L. [and others]. 1995. Ecological uses for genetic algorithms predicting fish distributions in complex physical habitats. Canadian Journal of Fisheries and Aquatic Sciences. 52: 1893-1908.

Dodge, K.L. 1993. Patterns of temporal and spatial habitat used by sympatric speckled dace (Rhinichthys occulus) and longnose dace (R. cataractae) in an Oregon Cascades stream. Corvallis, OR: Oregon State University. 101 p. M.S. thesis.

Doyle, A.T. 1990. Use of riparian and upland habitats by small mammals. Journal of Mammalogy. 71(1): 14-23.

Faber, M.; Manstetten, R.; Proops, J. 1992. Toward an open future: ignorance, novelty, and evolution. In: Constanza, R.; Norton, B.; Haskell, B., eds. Ecosystem health: new goals for environmental health. Covelo, CA: Island Press: 72-96.

Forest Ecosystem Management Assessment Team [FEMAT]. 1993. Forest ecosystem management: an ecological, economic, and social assessment. Portland, OR: U.S. Department of Agriculture; U.S. Department of the Interior [and others]. [Irregular pagination].

Garman, S.L.; Hansen, A.J.; Urban, D.L.; Lee, P.F. 1992. Alternative silvicultural practices and diversity of animal habitat in western Oregon: a computer simulation approach. In: Luker, P., ed. Proceedings of the 1992 summer simulation conference; 1992 July 27-30; Reno, NV. San Diego, CA: The Society for Computer Simulation: 777-781.

Garman, S.L.; Spies, T.A.; Cohen, W.B. [and others]. [In press]. Modeling, monitoring, and displaying ecological change at watershed to landscape scales: tools for ecosystem management. Spec. Publ. 2. Corvallis, OR: U.S. Department of the Interior, National Biological Service, Forest and Rangeland Ecosystem Science Center. 
Goetz, F.A. 1994. Distribution and juvenile ecology of bull trout (Salvelinus confluentus) in the Cascade mountains. Corvallis, OR: Oregon State University. 173 p. M.S. thesis.

Grant, G. 1988. The RAPID technique: a new method for evaluating downstream effects of forest practices on riparian zones. Gen. Tech. Rep. PNW-GTR-220. Portland, OR: U.S. Department of Agriculture, Forest Service, Pacific Northwest Research Station. $36 \mathrm{p}$.

Gratkowski, H.J. 1956. Windthrow around staggered-settings in old-growth Douglasfir. Forest Science. 2(1): 60-74.

Gregory, S.V.; Swanson, F.J.; McKee, W.A.; Cummins, K.W. 1991. An ecosystem perspective of riparian zones. Bioscience. 41(8): 540-551.

Grumbine, R.E. 1994. What is ecosystem management? Conservation Biology. 8: 27-38.

Hardy, C.C.; Arno, S.F. 1996. The use of fire in forest restoration. Gen. Tech. Rep. INT-GTR-341. Ogden, UT: U.S. Department of Agriculture, Forest Service, Intermountain Research Station. $86 \mathrm{p}$.

Harmon, M.E.; Franklin, J.F.; Swanson, F.J. [and others]. 1986. Ecology of coarse woody debris in temperate ecosystems. Advances in Ecological Research. 15: 133-302.

Harr, R.D. 1981. Some characteristics and consequences of snowmelt during rainfall in western Oregon. Journal of Hydrology. 53: 277-304.

Harr, R.D. 1986. Effects of clearcutting on rain-on-snow runoff in western Oregon-a new look at old studies. Water Resources Research. 22(7): 1095-1100.

Hawkins, C.P.; Murphy, M.L.; Anderson, N.H. 1982. Effects of canopy, substrate composition, and gradient on the structure of macroinvertebrate communities in Cascade Range streams of Oregon. Ecology. 63(6): 1840-1856.

Hawkins, C.P.; Murphy, M.L.; Anderson, N.H.; Wilzbach, M.A. 1983. Density of fish and salamanders in relation to riparian canopy and physical habitat in streams of the northwestern United States. Canadian Journal of Fisheries and Aquatic Sciences. 40(8): 1173-1185.

Hicks, B.J.; Beschta, R.L.; Harr, R.D. 1991. Long-term changes in streamflow following logging in western Oregon and associated fisheries implications. Water Resources Bulletin. 27(2): 217-226.

Hunter, M.L., Jr. 1993. Natural fire regimes as spatial models for managing boreal forests. Biological Conservation. 65: 115-120.

Johnson, D.H. 1992. Spotted owls, great horned owls, and forest fragmentation in the central Oregon Cascades. Corvallis, OR: Oregon State University. 125 p. M.S. thesis.

Jones, J.A.; Grant, G.E. 1996. Peak flow responses to clear-cutting and roads in small and large basins, western Cascades, Oregon. Water Resources Research. 32(4): 959-974. 
Lamberti, G.A.; Gregory, S.V. 1989. Influence of channel geomorphology and riparian zones on nutrient retention in stream ecosystems. In: Abell, D.L., tech. coord. Proceedings of the California riparian systems conference: protection, management and restoration for the 1990s; 1988 September 22-24; Davis, CA. Gen. Tech. Rep. PSW-110. Berkeley, CA: U.S. Department of Agriculture, Forest Service, Pacific Southwest Forest and Range Experiment Station: 33-39.

Lamberti, G.A.; Gregory, S.V.; Ashkenas, L.R. [and others]. 1991. Stream ecosystem recovery following a catastrophic debris flow. Canadian Journal of Fisheries and Aquatic Sciences. 48(2): 196-208.

Leonard, W.P.; Brown, H.A.; Jones, L.L.C. [and others]. 1993. Amphibians of Washington and Oregon. Seattle, WA: Seattle Audubon Society. 168 p.

Lienkaemper, G.W.; Swanson, F.J. 1987. Dynamics of large woody debris in streams in old-growth Douglas-fir forests. Canadian Journal of Forest Research. 17: 150-156.

Marion, D.A. 1981. Landslide occurrence in the Blue River drainage, Oregon. Corvallis, OR: Oregon State University. 114 p. M.S. thesis.

McGarigal, K.; Marks, B.J. 1995. FRAGSTATS: spatial pattern analysis program for quantifying landscape structure. Gen. Tech. Rep. PNW-GTR-351. Portland, OR: U.S. Department of Agriculture, Forest Service, Pacific Northwest Research Station. $122 \mathrm{p}$.

McGarigal, K.; McComb, W.C. 1993. Research problem analysis on biodiversity conservation in western Oregon forests. Spec. Res. Rep. Corvallis, OR: Bureau of Land Management, The Pacific Forest and Basin Rangeland Systems Cooperative Research and Technology Unit. 174 p.

Mladenoff, D.J.; White, M.A.; Pastor, J.; Crow, T.R. 1993. Comparing spatial pattern in unaltered old-growth and disturbed forest landscapes. Ecological Applications. 3(2): 294-306.

Moore, K.M.S.; Gregory, S.V. 1988a. Response of young-of-the year cutthroat trout to manipulation of habitat structure in a small stream. Transactions of the American Fisheries Society. 117: 162-170.

Moore, K.M.S.; Gregory, S.V. 1988b. Summer habitat utilization and ecology of cutthroat trout fry (Salmo clarki) in Cascade mountain streams. Canadian Journal of Fisheries and Aquatic Sciences. 45(11): 1921-1930.

Moore, K.M.S.; Gregory S.V. 1989. Geomorphic and riparian influences on the distribution and abundance of salmonids in a Cascade mountain stream. In: Abell, D.L., tech. coord. Proceedings of the California riparian systems conference: protection, management and restoration for the 1990s; 1988 September 22-24; Davis, CA. Gen. Tech. Rep. PSW-110. Berkeley, CA: U.S. Department of Agriculture, Forest Service, Pacific Southwest Forest and Range Experiment Station: 256-261.

Morgan, P.; Aplet, G.H.; Haufler, J.B. [and others]. 1994. Historical range of variability: a useful tool for evaluating ecosystem change. Journal of Sustainable Forestry. 2(1/2): 87-111. 
Morrison, P.H. 1975. Ecological and geomorphological consequences of mass movements in the Alder Creek watershed and implications for forest land management. Eugene, OR: University of Oregon. 102 p. B.A. thesis.

Morrison, P.H.; Swanson, F.J. 1990. Fire history and pattern in a Cascade Range landscape. Gen. Tech. Rep. PNW-GTR-254. Portland, OR: U.S. Department of Agriculture, Forest Service, Pacific Northwest Research Station. 77 p.

Murphy, M.L. 1979. Predator assemblages in old-growth and logged sections of small Cascade streams. Corvallis, OR: Oregon State University. 72 p. M.S. thesis.

Murphy, M.L.; Hawkins, C.P.; Anderson, N.H. 1981. Effects of canopy modification and accumulated sediment on stream communities. Transactions of the American Fisheries Society. 110: 469-478.

Noss, R.F.; Cooperrider, A.Y. 1994. Saving nature's legacy. Washington, DC: Island Press. $416 \mathrm{p}$.

Perry, D.A. 1994. Forest ecosystems. Baltimore; London: The Johns Hopkins University Press. 649 p.

Regional Ecosystem Office [REO]. 1995. Ecosystem analysis at the watershed scale: Federal guide for watershed analysis. Portland, OR: U.S. Department of Agriculture, Forest Service. 26 p.

Ripple, W.J.; Johnson, D.H.; Hershey, K.T.; Meslow, E.C. 1991. Old-growth and mature forests near spotted owl nests in western Oregon. Journal of Wildlife Management. 55(2): 316-318.

Rothacher, J.; Dyrness, C.T.; Fredriksen, R.L. 1967. Hydrologic and related characteristics of three small watersheds in the Oregon Cascades. Portland, OR: U.S. Department of Agriculture, Forest Service, Pacific Northwest Forest and Range Experiment Station. $54 \mathrm{p}$.

Schowalter, T.D. 1995a. Canopy arthropod communities in relation to forest age and alternative harvest practices in western Oregon. Forest Ecology and Management. 78: 115-125.

Schowalter, T.D. 1995b. Canopy invertebrate community response to disturbance and consequences of herbivory in temperate and tropical forests. Selbyana. 16(1): 41-48.

Sea, D.S.; Whitlock, C. 1995. Postglacial vegetation and climate of the Cascade Range, central Oregon. Quaternary Research. 43: 370-381.

Sedell, J.R.; Reeves, G.H.; Hauer, F.R. [and others]. 1990. Role of refugia in recovery from disturbances: modern fragmented and disconnected river systems. Environmental Management. 14(5): 711-724.

Sherwood, K. 1993. Buffer strip dynamics in the western Oregon Cascades. Corvallis, OR: Oregon State University. 185 p. M.S. thesis.

Sidle, R.C.; Pearce, A.J.; O’Loughlin, C.L. 1985. Hillslope stability and land use: Water Resour. Monogr. Ser. 11. [Place of publication unknown]: American Geophysical Union. 140 p. 
Sinton, D.S. 1996. Spatial and temporal patterns of windthrow in the Bull Run watershed, Oregon. Corvallis, OR: Oregon State University. 230 p. Ph.D. dissertation.

Steinblums, I.J.; Froehlich, H.A.; Lyons, J.K. 1984. Designing stable buffer strips for stream protection. Journal of Forestry. 85(1): 49-52.

Stuart-Smith, K.; Hebert, D. 1996. Putting sustainable forestry into practice at Alberta-Pacific. Canadian Forest Industries. April/May: 57-60.

Swanson, F.J.; Dyrness, C.T. 1975. Impact of clear-cutting and road construction on soil erosion by landslides in the western Cascade Range, Oregon. Geology. 3(7): 393-396.

Swanson, F.J.; Jones, J.A.; Wallin, D.O.; Cissel, J.H. 1993. Natural variabilityimplications for ecosystem management. In: Jensen, M.E.; Bourgeron, P.S., tech. eds. Volume II: Ecosystem management: principles and applications. Gen. Tech. Rep. GTR-PNW-318. Portland, OR: U.S. Department of Agriculture, Forest Service, Pacific Northwest Research Station: 80-94. (Everett, Richard L., assessment team leader; Eastside forest ecosystem health assessment).

Swanson, F.J.; Lienkaemper, G.W. 1978. Physical consequences of large organic debris in Pacific Northwest streams. Gen. Tech. Rep. PNW-69. Portland, OR: U.S. Department of Agriculture, Forest Service, Pacific Northwest Forest and Range Experiment Station. $12 \mathrm{p}$.

Teensma, P.D.A. 1987. Fire history and fire regimes of the central western Cascades of Oregon. Eugene, OR: University of Oregon. 188 p. Ph.D. dissertation.

Thomas, J.W.; Forsman, E.D.; Lint, J.B. [and others]. 1990. A conservation strategy for the northern spotted owl: a report of the Interagency Scientific Committee to address the conservation of the northern spotted owl. Portland, OR: U.S. Department of Agriculture, Forest Service; U.S. Department of the Interior, Bureau of Land Management, U.S. Fish and Wildlife Service, and National Park Service. $427 \mathrm{p}$.

Urban, D.L. 1993. A user's guide to ZELIG version 2. Fort Collins, CO: Department of Forest Sciences, Colorado State University. 77 p.

U.S. Department of Agriculture, Forest Service. 1990. Land and resource management plan, Willamette National Forest. Eugene, OR: Willamette National Forest. 327 p. with appendices.

U.S. Department of Agriculture, Forest Service; U.S. Department of the Interior, Bureau of Land Management. 1994. Record of decision for amendments to Forest Service and Bureau of Land Management planning documents within the range of the northern spotted owl. [Place of publication unknown]. $74 \mathrm{p}$. [plus attachment A: standards and guidelines].

U.S. Department of the Interior. 1992. Draft recovery plan for the northern spotted owl. Portland, OR. $662 \mathrm{p}$.

Wallin, D.O.; Swanson, F.S.; Marks, B. [and others]. 1996. Comparison of managed and pre-settlement landscape dynamics in forests of the Pacific Northwest, USA. Forest Ecology and Management. 85: 291-309. 
Wemple, B.C. 1994. Hydrologic integration of forest roads with stream networks in two basins, western Cascades, Oregon. Corvallis, OR: Oregon State University. 88 p. M.S. thesis.

Wemple, B.C.; Jones, J.A.; Grant, G.E. 1996. Channel network extension by logging roads in two basins, western Cascades, Oregon. Water Resources Bulletin. 32(6): 1195-1207.

Wilzbach, M.A. 1985. Relative roles of food abundance and cover in determining the habitat distribution of stream-dwelling cutthroat trout (Salmo clarki). Canadian Journal of Fisheries and Aquatic Sciences. 42(10): 1668-1672.

Wilzbach, M.A.; Cummins, K.W.; Hall, J.D. 1986. Influence of habitat manipulations on interactions between cutthroat trout and invertebrate drift. Ecology. 67(4): 898-911.

Wood, C.A. 1994. Ecosystem management: achieving the new land ethic. Renewable Resources Journal. 12: 6-12.

Wustenberg, D.A. 1954. A preliminary survey of the influences of controlled logging on a trout stream in the H.J. Andrews Experimental Forest, Oregon. Corvallis, OR: Oregon State College. 51 p. M.S. thesis.

Wyatt, B. 1959. Observations on the movements and reproduction of the Cascade form of cutthroat trout. Corvallis, OR: Oregon State College. 60 p. M.S. thesis. 
Cissel, John H.; Swanson, Frederick J.; Grant, Gordon E.; Olson, Deanna H.; Stanley, Gregory V.; Garman, Steven L.; Ashkenas, Linda R.; Hunter, Matthew G.; Kertis, Jane A.; Mayo, James H.; McSwain, Michelle D.; Swetland, Sam G.; Swindle, Keith A.; Wallin, David O. 1998. A landscape plan based on historical fire regimes for a managed forest ecosystem: the Augusta Creek study. Gen. Tech. Rep. PNW-GTR-422. Portland, OR: U.S. Department of Agriculture, Forest Service, Pacific Northwest Research Station. $82 \mathrm{p}$.

Vegetation management regimes governing the frequency, intensity, and spatial pattern of future timber harvest activities were derived from historic fire regimes for a 7600-hectare study area in western Oregon. Results showed a greater amount of late-successional habitat, large patches, and better habitat connectivity across the landscape than would result from literal application of standards and guidelines in the Northwest Forest Plan.

Keywords: Landscape ecology, landscape management, landscape planning, fire history, range of historical variability, watershed analysis, fire ecology.

The Forest Service of the U.S. Department of Agriculture is dedicated to the principle of multiple use management of the Nation's forest resources for sustained yields of wood, water, forage, wildlife, and recreation. Through forestry research, cooperation with the States and private forest owners, and management of the National Forests and National Grasslands, it strives-as directed by Congress-to provide increasingly greater service to a growing Nation.

The United States Department of Agriculture (USDA) prohibits discrimination in its programs on the basis of race, color, national origin, sex, religion, age, disability, political beliefs, and marital or familial status. (Not all prohibited bases apply to all programs.) Persons with disabilities who require alternative means of communication of program information (Braille, large print, audiotape, etc.) should contact the USDA's TARGET Center at (202) 720-2600 (voice and TDD).

To file a complaint, write the Secretary of Agriculture, U.S. Department of Agriculture, Washington, DC 20250, or call (800) 245-6340 (voice), or (202) 720-1127 (TDD). USDA is an equal employment opportunity employer.

Pacific Northwest Research Station

333 S.W. First Avenue

P.O. Box 3890

Portland, Oregon 97208-3890 
U.S. Department of Agriculture

Pacific Northwest Research Station

333 S.W. First Avenue

P.O. Box 3890

Portland, OR 97208

Official Business

Penalty for Private Use, $\$ 300$ 